\title{
2009 Release of the Evaluated Nuclear Data Library \\ (ENDL2009)
}

B. Beck, D. A. Brown, M. A. Descalle, C. Hagmann, R. Hoffman, E. Ormand, P. Navratil, T. Luu, N. C. Summers, I. J. Summers, I. J. Thompson, R. Vogt, R. Barnowski

September 1, 2010 
This document was prepared as an account of work sponsored by an agency of the United States government. Neither the United States government nor Lawrence Livermore National Security, LLC, nor any of their employees makes any warranty, expressed or implied, or assumes any legal liability or responsibility for the accuracy, completeness, or usefulness of any information, apparatus, product, or process disclosed, or represents that its use would not infringe privately owned rights. Reference herein to any specific commercial product, process, or service by trade name, trademark, manufacturer, or otherwise does not necessarily constitute or imply its endorsement, recommendation, or favoring by the United States government or Lawrence Livermore National Security, LLC. The views and opinions of authors expressed herein do not necessarily state or reflect those of the United States government or Lawrence Livermore National Security, LLC, and shall not be used for advertising or product endorsement purposes.

This work performed under the auspices of the U.S. Department of Energy by Lawrence Livermore National Laboratory under Contract DE-AC52-07NA27344. 


\title{
2009 Release of the Evaluated Nuclear Data Library (ENDL2009)
}

\author{
B. Beck, D. A. Brown, M.-A. Descalle, C. Hagmann, R. Hoffman, E.
}

Ormand, P. Navratil, T. Luu, N. C. Summers, I. J. Thompson, and R. Vogt

Lawrence Livermore National Laboratory, Livermore California 94551

\author{
R. Barnowski \\ University of Michigan, Ann Arbor Michigan
}

(Dated: September 1, 2010)

\begin{abstract}
LLNL's Computational Nuclear Physics Group and Nuclear Theory and Modeling Group have collaborated to produce the next iteration of LLNL's evaluated nuclear database ENDL2009. ENDL2009 is the second in a series of major ENDL library releases designed to support LLNL's current and future nuclear data needs. This library contains many new evaluations for radiochemical diagnostics, structural materials, and thermonuclear reactions. We have striven to keep ENDL2009 at the leading edge of nuclear data library development by reviewing and incorporating new evaluations as they are made available to the nuclear data community. In addition, ENDL2009 support new features such as energy dependent $Q$ values from fission and unresolved resonances. Furthermore, this is the first ENDL library release to be released in the TDF format. Finally, this release is our most highly tested release as we have strengthened our already rigorous testing regime by adding tests against LANL Activation Ratio Measurements and many more new critical assemblies. Our testing is now being incorporated into our development process and is serving to guide library improvements.
\end{abstract}

\section{Contents}

\section{Introduction}

II. Library release procedures
A. Quality control
B. Release review
C. Sourceforge

III. Release Formats

A. ASCII

1. ENDL

2. ENDF

3. Unresolved resonances

4. Uncertainties and covariances

B. Monte-Carlo data (mcf)

C. Deterministic data (ndf)

D. Thermonuclear data (tdf)

IV. Unclassified Data Testing

A. Critical assemblies

B. Activation foils

C. LLNL Pulsed spheres

D. Oktavian spheres

E. Basic Checks

F. Integral tests in development

V. Reviews of new evaluations

A. ENDF/A

1. ${ }^{22} \mathrm{Na}$

2. ${ }^{35,37} \mathrm{Cl}$

3. ${ }^{39-41} \mathrm{~K}$

4. ${ }^{46-50} \mathrm{Ti}$

5. ${ }^{55} \mathrm{Mn}$

6. ${ }^{89} \mathrm{Y}$

4

4

5

5

6

6

7

7

8

9
7. ${ }^{113} \mathrm{Cd}$

8. ${ }^{174-180} \mathrm{Hf}$

9. ${ }^{236} \mathrm{U}$

10. ${ }^{240} \mathrm{Pu}$

11. ${ }^{241} \mathrm{Am}$

B. TENDL-2008

C. JEFF-3.1.1

D. IAEA Tungsten evaluation

E. Nuclear Research and Consultancy Group (NRG) evaluations

11

11

11

11

12

4

4

5

5

8

9

10

10

10

10

10

10

11

VI. New neutron sublibrary evaluations

A. Methods for building evaluations

B. Radiochemical diagnostics

1. Basic considerations

2. Calculational details

3. ${ }^{195-197} \mathrm{Au}$

4. ${ }^{76-78} \mathrm{Kr}$

5. ${ }^{73-75} \mathrm{As}$

6. ${ }^{122-124}$ Xe and ${ }^{34-36} \mathrm{Ar}$

C. Structural materials

1. ${ }^{25-29} \mathrm{Al}$

2. ${ }^{57-61} \mathrm{Co}$

3. ${ }^{178-183} \mathrm{Ta}$

4. ${ }^{178-188} \mathrm{~W}$

5. ${ }^{183-189} \mathrm{Re}$

6. ${ }^{202-210} \mathrm{~Pb}$

12

12

13

13

13

14

14

15

16

17

17

17

18

19

20

20

D. Actinides

1. ${ }^{239} \mathrm{U}$

2. ${ }^{240} \mathrm{Am}$

21

21

23

VII. Charge-particle incident reaction data

A. Inverse kinematics

23

B. $p+\mathrm{t}$

24

C. $\mathrm{d}+\mathrm{d}$ 

D. $d+t$
E. $\mathrm{d}+{ }^{3} \mathrm{He}$
F. $\mathrm{t}+\mathrm{t}$
G. $p+{ }^{7} \mathrm{Li}$
H. $\mathrm{d}+{ }^{6} \mathrm{Li}$
I. Large-Angle Coulomb Scattering (LACS)

\section{Outlook}

\section{Acknowledgements}

\section{A. Evaluation sources}

B. Detailed Test Results

1. ndf File Tests
a. ZA Loop
b. Criticality Benchmarks
c. Activation Ratios

2. mcf File Tests
a. ZA Loop
b. Criticality Benchmarks
c. Reaction Ratios
d. LLNL Pulsed Spheres
e. Oktavian Spheres
f. $d(n, 2 n)$
g. $(n, \gamma)$ production

C. Release Checklist

D. The README file
E. Cross section uncertainty formats in ENDL2009

F. Known Issues

References

\section{INTRODUCTION}

LLNL's Computational Nuclear Physics Group and Nuclear Theory and Modeling Group have collaborated to create the 2009 release of the Evaluated Nuclear Data Library (ENDL2009). ENDL2009 is designed to support LLNL's current and future nuclear data needs and will be employed in nuclear reactor, nuclear security and stockpile stewardship simulations with ASC codes. This database is currently the most complete nuclear database for Monte Carlo and deterministic transport of neutrons and charged particles. This library was assembled with strong support from the ASC program, leveraged with support from NNSA science campaigns and the DOE/Office of Science's US Nuclear Data Program.

ENDL2009 includes 585 distinct transport-ready evaluations in the neutron sub-library and another 35 evaluations in the charged-particle sub-libraries. ENDL2009 contains many physics improvements for calculating weapon performance, output effects, attribution signatures, key radiochemical diagnostics and performance of conventional and hybrid fission/fusion reactors. In building this library, the best output from the world's nuclear data efforts were adopted: $46 \%$ of the library is from the ENDF/B-VII.0 library, $10 \%$ is from the JENDL libraries and $8 \%$ from other libraries. The remaining $36 \%$ of the neutron sub-library and most of the charged-particle sub-libraries consist of new evaluations developed at LLNL for the ENDL2009 library. Figure 1 summarizes the ENDL2009 evaluation sources graphically. In addition, ENDL2009 supports new features such as energydependent fission $Q$ values, average momentum deposition, large-angle Coulomb scattering for all charged particles, support for unresolved resonances and cross-section covariance data. Finally, this library is LLNL's most highly tested nuclear data release as LLNL's already rigorous testing regime has been strengthened by adding tests against activation ratio measurements and many more new critical assemblies.

The new library can be found on LLNL's Open \& Secure Computing facilities. In addition, the data may be viewed in the Nuclear and Atomic Data System (NADS) data viewer at http://nuclear.1lnl.gov/NADS.

\section{LIBRARY RELEASE PROCEDURES}

In response to quality control concerns raised by our programmatic users over the last year, we have implemented a series of release procedures. Here we list these procedures and subsequently describe the steps in detail:

1. Generate the data library in a variety of formats (see Section III for details on the formats and data preparation);

2. Perform basic quality control checks (see Section II A);

3. Perform detailed simulations of experimental system in client codes (see Section IV);

4. Present a release review to the Computational Nuclear Physics group (see Section II B);

5. Tag the release in the project subversion repository and post on LLNL's computer cluster;

6. Open our sourceforge project for bug reports/etc. (see Section II C).

\section{A. Quality control}

Since ENDL2009 contains a great deal of information, we have implemented a number of tests to check the quality of the data. These tests can be divided into two categories: basic tests operating directly on ascii or processed forms of the data and integrated tests conducted on a 


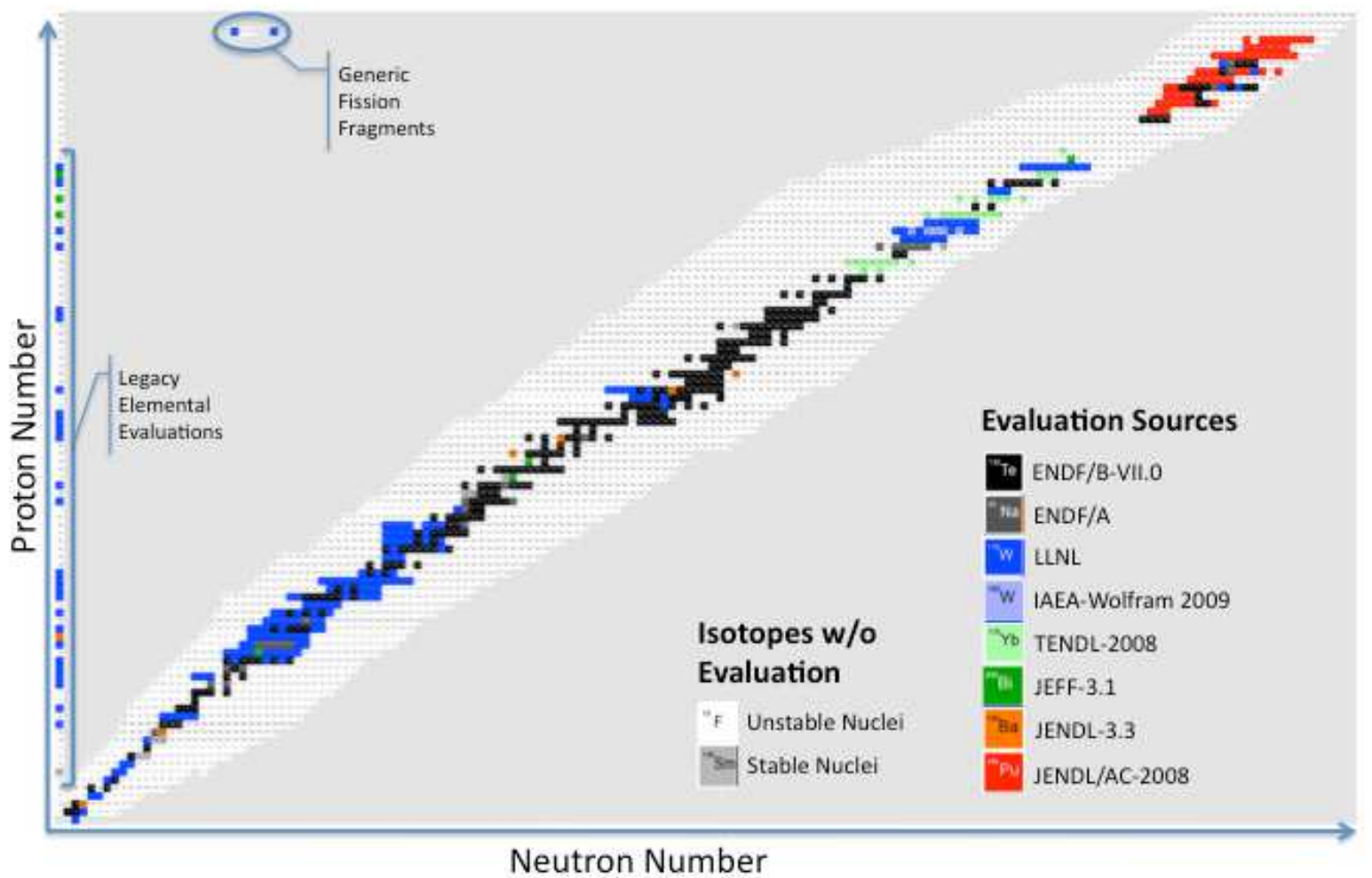

FIG. 1: Table of isotopes highlighting the 585 evaluations for neutron-induced reaction targets in ENDL2009. Each target isotope is color coded according to the evaluation source library. Isotopes in white are unstable nuclei for which no evaluation exists. There are nine stable isotopes in light grey which presently have not been evaluated. The generic fission fragment (upper left) and elemental evaluations (along $y$-axis) are maintained for compatibility with archival calculations.

problem with a known solution. While the basic tests tend to focus on reasonableness, such as searching for negative cross sections, and negative outgoing energies of reaction products, they also include checks run during processing. These basic tests are advantageous because they are closely related to the raw data so that failures or problems here tend to be more easily isolated. They are:

- $\operatorname{check}()$ functions built into all Python classes in FUDGE. These checks operate directly on the raw ENDL (ascii) formatted data. Specifically they check: 1) the consistency of $Q$ values, thresholds and particle masses; 2) whether all cross sections, probabilities and multiplicities are positive definite; 3 ) if all probabilities are normalized, and 4) that all data are single-valued.

- During processing of deterministic and MonteCarlo data, we investigate all processing code errors and warning messages.
- simpleNDFCrayChecker.py checks the ndf files used in deterministic transport. Specifically it reports the temperatures and maximum Legendre orders supported by each isotope and checks all reactions to determine: 1 ) the presence and positivity of energy depositions; 2) whether the transfer matrix obeys the required sum rules; and 3 ) if the transfer matrix and cross section for the isotope are consistent with each other.

- simpleMCFPDBChecker. py checks the mcf files used in Monte-Carlo transport. Specifically it reports the creation date, superlibrary version, number of isotopes, supported group structures and temperatures and, on a per isotope basis it checks for the presence of unresolved resonances, momentum and energy depositions, and bad kinTypes as well as for energy dependent fission $Q$ values.

- MCAPM (MCAPM) is the software library that provides routines handling particle-nucleus collision 
physics, x-ray fluorescense, and thermal neutron scattering $\left(S_{\alpha \beta}\right)$ treatment of some compounds. The MCAPM-level checking codes all are simple drivers on top of the MCAPM library. The drivers used for data testing read the data in mcf format, perform calls to the collision routines and check for negative reaction cross sections and negative outgoing product energies.

Integrated testing stresses the entire system, from the evaluations that make up ENDL2009 to processing and delivery. Such testing also more closely matches the ways in which the data will actually be used. While these tests focus on the more relevent regions of problem space, causes of failure can be more difficult to pin down. Our integral testing is described in Section IV and detailed in appendix B.

\section{B. Release review}

Before a library can be officially released to users, it is now subjected to a release review. The library release manager presents evidence to the full Computational $\mathrm{Nu}$ clear Physics (CNP) group that the version under consideration is ready for release to lab customers. The CNP group ensures that all mandatory criteria in the release checklist are met and all optional items are either met or that there are acceptable explanations for why they are not met. This simple addition to our release procedure has already identified issues important to certain users that the library developers would otherwise have missed.

\section{Sourceforge}

Even though our release procedures are quite rigourous, problems do arise. Therefore, we now employ LLNL's sourceforge installation to manage the ENDL project. Sourceforge provides not only a source code repository but also bug and issue tracking facilities. This capability allows us to communicate any shortcomings that arise in our databases with users as well as provide updates on the resolution of these problems. The ENDL sourceforge site is https://sourceforge.llnl.gov/sf / projects/endl.

\section{RELEASE FORMATS}

ENDL2009 is being released in several formats:

- ASCII, the raw, unprocessed, nuclear data in both ENDL and ENDF formats;

- mcf, supporting Monte-Carlo transport;

- ndf, supporting deterministic transport;

- tdf, providing thermonuclear data to simulations;
We describe any particular facets of note in the remainder of this section.

\section{A. ASCII}

The ENDF and ENDL library formats are the native ASCII formats for raw, unprocessed, nuclear data evaluations. Here we detail how these formats are used in the ENDL2009 library.

\section{ENDL}

The ENDL format is the native format of the ENDL2009 data library. We closely follow the standards laid out in Ref. $\left[\mathrm{BHH}^{+} 06 \mathrm{a}\right]$. However, since releasing this specification, we have made several (mostly minor) format modifications. These include:

- Documentation in the documentation.txt file;

- Resonance data from ENDF-formatted evaluations, the source of many of the ENDL evaluations, in the resonances. $\mathrm{xml}$ file;

- Uncertainty and covariance files (see Section III A 4 and Appendix E);

- Energy dependent $Q(E)$ values for fission in $\mathrm{I}=12$, as detailed in Refs. [BBD $\left.{ }^{+} 07, \operatorname{Vog} 08\right]$;

- Unresolved resonance region (URR) data in $\mathrm{I}=20$ (see Section III A 3);

- Average forward momentum deposition, $\left\langle p_{z}\right\rangle$, in $I=13$.

While the documentation file and the $\mathrm{xml}$ files are all ignored in processing, they may be viewed by users.

\section{2. $E N D F$}

As part of our evaluation methodology (see Section VIA), we now produce ENDF-formatted files for all our new evaluations. All of these, as well as ENDF-formatted files for evaluations adopted elsewhere, are collected in the endf/ directory of the ENDL2009 project. This is valuable addition enables our LANL users to generate ACE files for most of the evaluations in ENDL2009, simplifying inter-lab code comparisons.

\section{Unresolved resonances}

ENDL2009 includes unresolved resonance probability tables for 236 target isotopes. These tables were generated using the PURR module of NJOY-99.296 and converted into ENDL I=20 files. Probability tables for temperatures of $2.586 \mathrm{e}-05$, 1.e-04, 3.1e-04, 1.e-03, 3.1e-03, 
1.e-02, 3.1e-02, 1.e-01 and 3.1e-01 MeV are included for all 236 isotopes.

\section{Uncertainties and covariances}

In response to frequent user requests, we have added a trial feature in the first release of ENDL2009: cross section covariances and their corresponding uncertainties. The covariance files in ENDL2009.0 are derived from ENDF/B-VII.0 covariance data $\left[\mathrm{COH}^{+} 06\right]$, from the ENDF/A library and from the LoFi covariance project $\left[\mathrm{LKH}^{+} 08\right]$. While the ENDF.B-VII.0 and ENDF/A derived files represent the best source of uncertainties, they are only available for a few isotopes, including all the major actinides: ${ }^{232} \mathrm{Th},{ }^{233} \mathrm{U},{ }^{235} \mathrm{U},{ }^{238} \mathrm{U},{ }^{239} \mathrm{Pu}$. The remaining isotopes contain uncertainties derived from the LoFi covariance project. These crude uncertainties should function as a reasonable stop gap until better uncertainty evaluations can be made. In Appendix E, we explain the cross section uncertainty format. The indevelopment code called kiwi [BPL10] can use both the uncertainty and covariance data to generate realizations of the nuclear data for use in uncertainty quantification studies.

\section{B. Monte-Carlo data (mcf)}

All ENDL2009 files with projectile neutrons, except for ${ }^{242} \mathrm{Am}$ and ${ }^{244 m} \mathrm{Am}$, have been produced in a format suitable for LLNL deterministic transport codes. The processing was done using mcfgen with group ID $=7$ which includes 230 groups. There are data sets for 22 temperatures ranging from room temperature to $65.5 \mathrm{keV}$.

\section{Deterministic data (ndf)}

All ENDL2009 files with projectile neutrons, except for ${ }^{242} \mathrm{Am}$ and ${ }^{244 m} \mathrm{Am}$, have been produced in a format suitable for LLNL deterministic transport codes. The processing was done using ndfgen with group ID $=7$ which includes 230 groups. The neutron transfer matrices are stored as Legendre polynomials up to order 3 inclusive. A dataset exists for room temperature $\left(2.58522 \times 10^{-8}\right.$ $\mathrm{MeV}$ ) targets with no elastic scattering correction for target motion. In addition, data sets at 22 temperatures, ranging from room temperature to $65.5 \mathrm{keV}$, which include elastic scattering corrections for target motion will be produced.

\section{Thermonuclear data (tdf)}

The original Thermonuclear Data File (TDF) system, and the codes that supported it, were developed by
TABLE I: Original five supported TDF reactions

\begin{tabular}{c|c}
\hline \hline Reaction & $Q(\mathrm{MeV})$ \\
\hline${ }^{2} \mathrm{H}\left({ }^{2} \mathrm{H}, n\right){ }^{3} \mathrm{He}$ & 3.26861 \\
${ }^{2} \mathrm{H}\left({ }^{2} \mathrm{H}, p\right){ }^{3} \mathrm{H}$ & 4.03244 \\
${ }^{3} \mathrm{H}\left({ }^{2} \mathrm{H}, n\right){ }^{4} \mathrm{He}$ & 17.5903 \\
${ }^{3} \mathrm{H}\left({ }^{3} \mathrm{H}, 2 n\right){ }^{4} \mathrm{He}$ & 11.3335 \\
${ }^{3} \mathrm{He}\left({ }^{2} \mathrm{H}, p\right){ }^{4} \mathrm{He}$ & 18.3542 \\
\hline \hline
\end{tabular}

S. Warshaw [War01] in the late 90s and early 00s. Algorithms were developed to calculate plasma reactivities, mean kinetic energies and two-body final-state distributions (as well as inverse cumulative distributions) of five light-ion reactions [66] at tabulated intervals. These results were subsequently stored in one tdf file. This data file can be read in by other codes to obtain interpolated values of the physical quantities from the data file using access routines from the TDF system.

The original five reactions and their $Q$ values are listed in Table I. The original TDF system performed calculations assuming that all reacting ions could be described by Maxwellian distributions with the same temperature. It was developed using a nonrelativistic framework, adequate for the reactions of Table I under typical plasma conditions with temperatures $k T<100 \mathrm{keV}$.

Recently the TDF system has been revamped. In versions TDF-V2.0 and higher, the final-state neutron distributions from the reaction ${ }^{3} \mathrm{H}\left({ }^{3} \mathrm{H}, 2 n\right){ }^{4} \mathrm{He}$ have been correctly implemented. An example of the probability distribution is shown for several temperatures in Fig. 2. Furthermore, the mean kinetic energies of the reaction products are calculated using these distributions rather than those in Ref. [War01].

The types of quantities calculated in the TDF system has also been expanded. In addition to reactivities, exit particle distributions, cumulative probability distributions (and an inverse lookup routine for the cumulative probability), and mean kinetic energies, TDF-V2.0 and higher also calculates absorption spectra for the reacting species; energy-exchange rates for both the incoming and outgoing species; and non-thermal reactivities (i.e. reactivities calculated from non-Maxwell-Boltzmann-type distributions).

In addition, TDF-V2.0 and higher are now 'hooked' into FUDGE via an executable called tdfgen [67]. This link to FUDGE gives the user a wide range of tools to manipulate light-ion data that could be incorporated into TDF. As part of the ENDL build system, fete is used to produce light-ion data files in the tdf format. Thus the number of supported reactions has been expanded. The new reactions include Lithium as a reactant. The list of new supported reactions is presented in Table II. The list of new features incorporated into TDFv2.0 is given in Table III. The reaction ${ }^{6} \mathrm{Li}+{ }^{2} \mathrm{H} \rightarrow p+{ }^{3} \mathrm{H}+{ }^{4} \mathrm{He}$ is treated as a direct three-body breakup reaction. The 

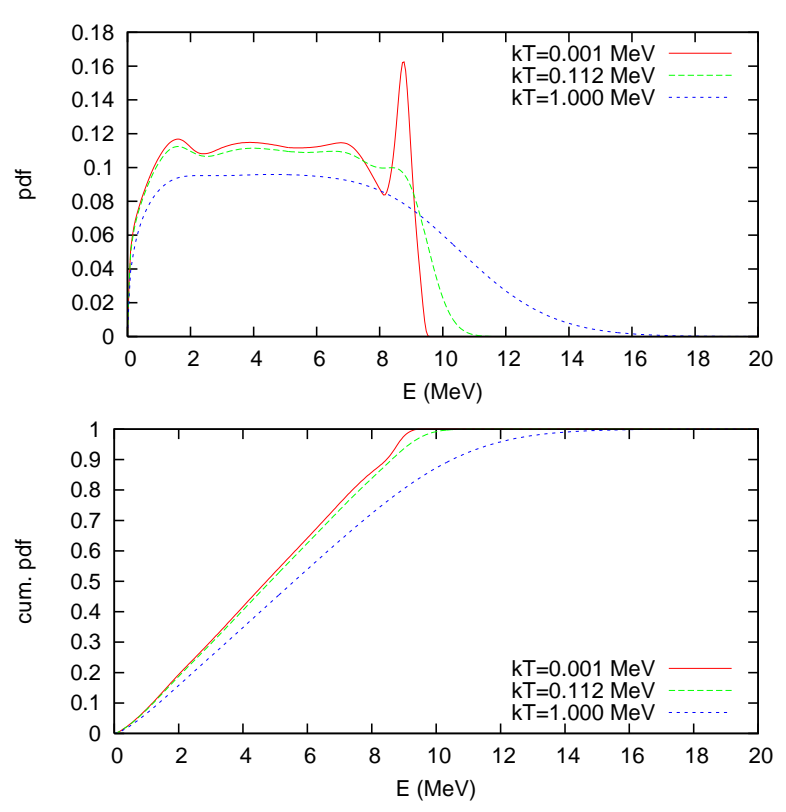

FIG. 2: Sample outgoing neutron probability distributions (top) and cumulative probabilities (bottom) from ${ }^{3} \mathrm{H}\left({ }^{3} \mathrm{H}, 2 n\right){ }^{4} \mathrm{He}$ at several plasma temperatures.

TABLE II: New TDF reactions

\begin{tabular}{c|c}
\hline \hline Reaction & $Q(\mathrm{MeV})$ \\
\hline${ }^{6} \mathrm{Li}\left(p,{ }^{3} \mathrm{He}\right){ }^{4} \mathrm{He}$ & 4.02033 \\
${ }^{7} \mathrm{Li}\left(p,{ }^{4} \mathrm{He}\right){ }^{4} \mathrm{He}$ & 17.34814 \\
${ }^{6} \mathrm{Li}\left({ }^{2} \mathrm{H}, n\right){ }^{7} \mathrm{Be}$ & 3.38225 \\
${ }^{6} \mathrm{Li}\left({ }^{2} \mathrm{H}, p\right){ }^{7} \mathrm{Li}$ & 5.02634 \\
${ }^{6} \mathrm{Li}\left({ }^{2} \mathrm{H},{ }^{4} \mathrm{He}\right){ }^{4} \mathrm{He}$ & 2.23745 \\
${ }^{6} \mathrm{Li}+{ }^{2} \mathrm{H} \rightarrow p+{ }^{3} \mathrm{H}+{ }^{4} \mathrm{He}$ & 2.55974 \\
\hline \hline
\end{tabular}

reactivities involving Lithium, assuming thermal plasma temperatures, are shown in Fig. 3.

\section{UNCLASSIFIED DATA TESTING}

Several models of tests using the Mercury (Monte Carlo) and AMTRAN (deterministic) codes have been developed over the last three years to test the ndf and mcf cross section library files. Tests fall within five general categories: criticality safety benchmark experiments; activation foils; LLNL pulsed spheres; Oktavian spheres; and basic checks. New tests are currently under development.

\section{A. Critical assemblies}

ENDL2009 was tested using $k_{\text {eff }}$ benchmark simulations taken from the criticality safety benchmark hand-
TABLE III: New features in TDF-V2.0

\begin{tabular}{c}
\hline \hline Relativistic formalism \\
Lithium reactions \\
Absorption spectrum calculation \\
Energy-exchange rate calculation \\
Reactivities calculable for non-thermal distributions \\
Reacting ions can be at different temperatures \\
${ }^{3} \mathrm{H}\left({ }^{3} \mathrm{H}, 2 n\right){ }^{4} \mathrm{He}$ correctly implemented \\
Simple interface to FUDGE \\
Included in ENDL build \\
\hline \hline
\end{tabular}

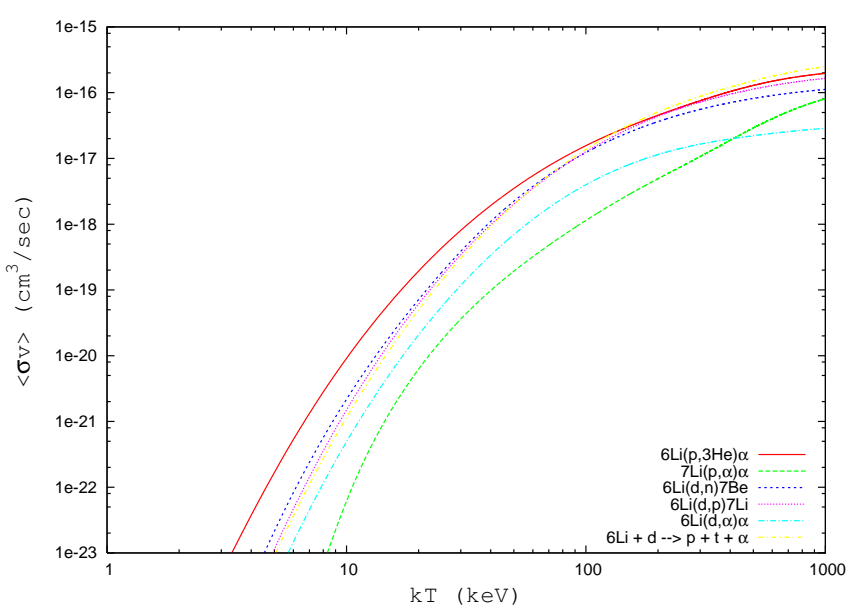

FIG. 3: Reactivities of the new Lithium reactions included in TDF-V2.0.

book [Bri06]. The mcf and ndf libraries were tested using an automated suite of 27 Mercury and 15 AMTRAN benchmark calculations. The $k_{\text {eff }}$ values for ${ }^{235} \mathrm{U},{ }^{239} \mathrm{Pu}$, ${ }^{233} \mathrm{U}$ and some mixed-metal assemblies are compiled in Table XVI in Appendix B. Mercury and AMTRAN benchmark simulations are compared to benchmark values and MCNP4C3 calculations using ENDF/B-VII.0. ENDL2009 performs well in most assemblies and the deviations are under control. Most discrepancies are understood and can be traced back to three main factors:

- Poor performance for thermal assemblies (PST11) and thermalizing-reflector assemblies (HMF19, PMF11, PMF23, PMF24) due to poor thermal neutron support in ENDL2009;

- The unresolved resonance region is not yet treated in either the production code or the data library;

- The Ni and Be evaluations are poor in all libraries.

The $k_{\text {eff }}$ for ENDL2009 calculated for two well-known bare assemblies, Godiva and Jezebel, are in excellent agreement with ENDF/B-VII.0. The complete set of results are given in appendix B. 
Big ten: central fission ratios and activation ratios

Amtran Simulations/ Endl2009.b1

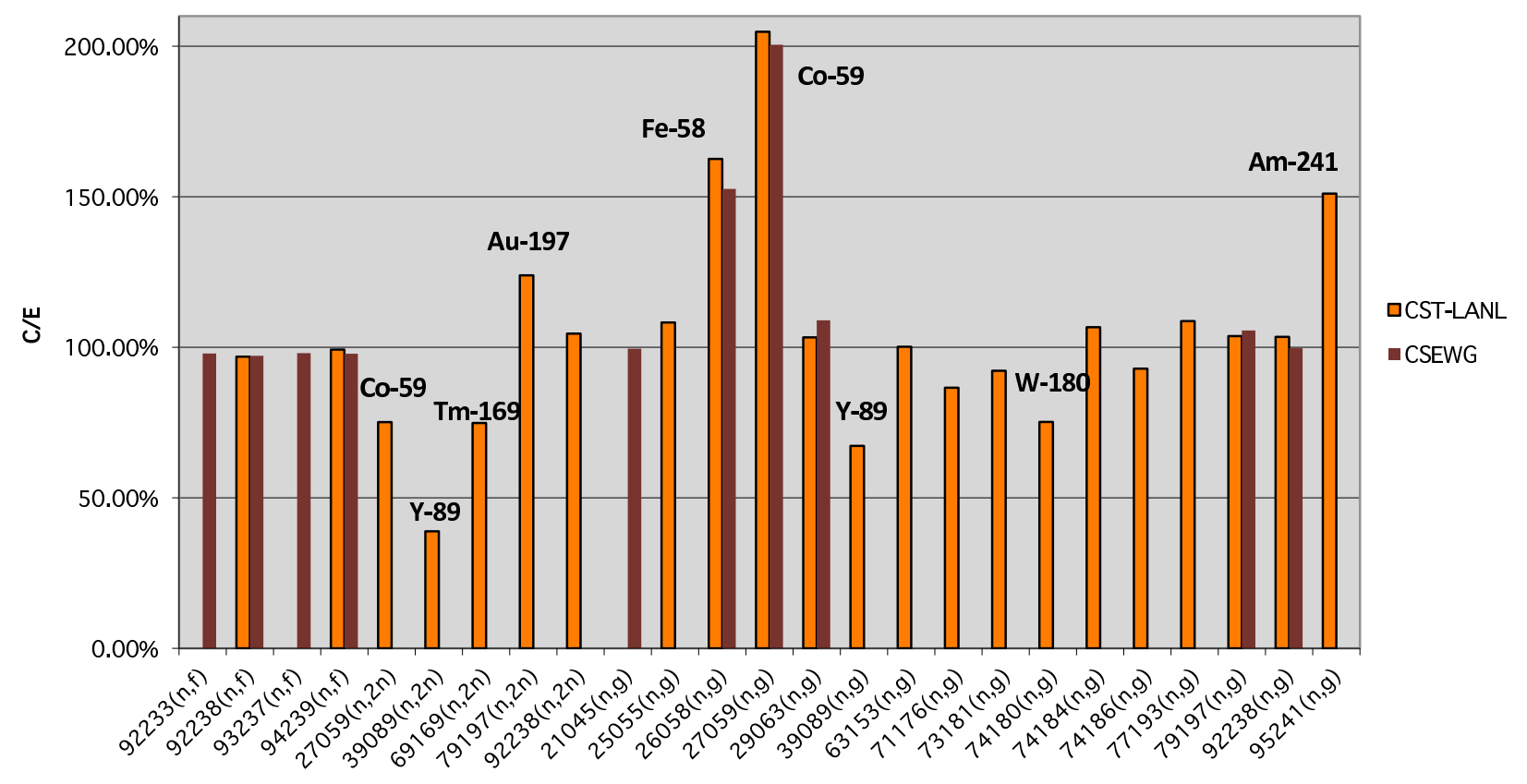

FIG. 4: Activation ratios from the Big Ten assembly.

\section{B. Activation foils}

"Classic" fast criticality safety benchmark assemblies such as Godiva, Jezebel, Big Ten, Flattop-25 and Flattop-Pu were used to measure not only $k_{\text {eff }}$ but also reaction rates for a variety of isotopes. In the latter experiments, foils of material were introduced in various known locations in an assembly and submitted to the characteristic neutron spectrum within that assembly. Reaction rates varied with location since the neutron spectrum become softer away from the core or center of the assembly. Results are presented as central fission ratios and activation for several neutron reactions. Almost ten years ago, Frankle and Briemeister published extensive comparisons between these central-fission and activation ratio measurements and MCNP simulations run with several cross section libraries [FB99]. Recently, MCNP5 simulations performed with ENDF.B-VII.0 were compared to previously unpublished LANL measurements $\left[\mathrm{WIB}^{+} 07\right]$.
The two main data sets are found in the Cross Section Evaluation Working Group (CSEWG) specifications as well as from the Chemical Science and Technology Division at Los Alamos National Laboratory (CST-LANL). A third, smaller, set was published by Byers.

AMTRAN simulations were set up to model fission, neutron capture and $(n, 2 n)$ reaction rates for a diverse set of isotopes in the Godiva, Jezebel, and Big Ten criticality benchmarks. The results are normalized by the fission rate for ${ }^{235} \mathrm{U}$ in the same assembly to obtain the central fission ratio for $(n, f)$ and the activation ratios for $(n, \gamma)$, and $(n, 2 n)$. These results are compared to a compilation of experimental data [FB99, WIB $\left.^{+} 07\right]$. A model of ${ }^{238} \mathrm{U}(n, f),(n, \gamma)$ and $(n, 2 n)$ in Big Ten using Mercury [DCP09].

The comparison between our simulations and the data is shown in Figs. IV B, IV B, and IV B for the Big Ten, Godiva, Jezebel and Flattop-25 critical assemblies. Individual results, organized by isotopes, are also given.

\section{LLNL Pulsed spheres}

ENDL2009 was tested against LLNL pulsed-sphere experiments, a set of fusion-shielding benchmarks [DP08].
The pulsed-sphere program, which ran from the 70's to 


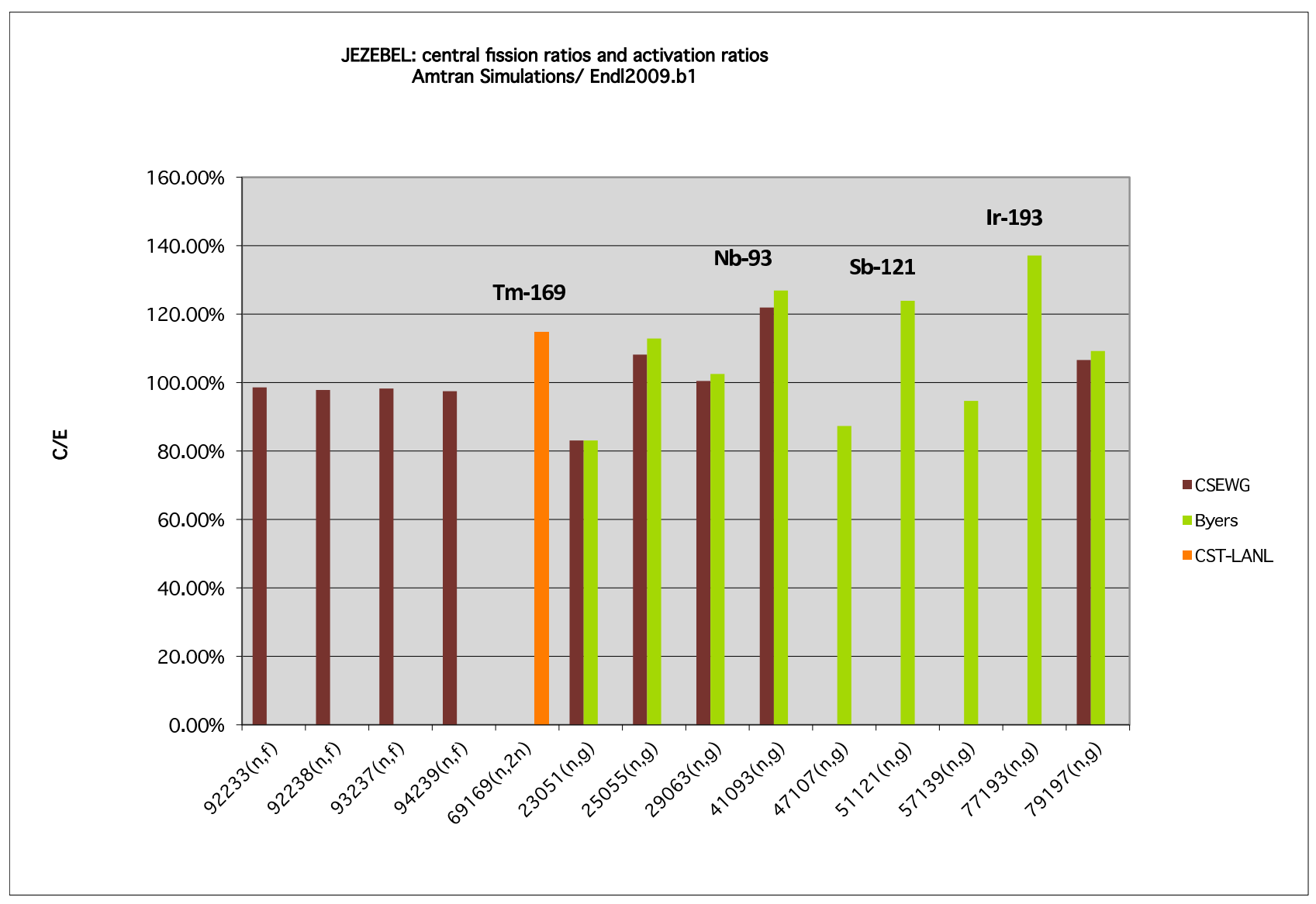

FIG. 5: Activation ratios from the Jezebel assembly.

the early 90's, measured neutron time-of-flight (TOF) and gamma spectra resulting from emission of a $14 \mathrm{MeV}$ neutron pulse produced by $\mathrm{d}+\mathrm{t}$ reactions occuring inside spheres composed of a variety of materials $\left[\mathrm{WAB}^{+} 72\right]$. Models of the LLNL pulsed-sphere experiments using the Mercury Monte Carlo were developed for the materials reported in Goldberg et al. [GHK ${ }^{+}$90, MH98]. Comparisons of the measured and simulated TOF spectra are shown in Figs. 9 and 18 . These results highlight the improved tungsten, and tantalum evaluations relative to ENDL2008. Overall, ENDL2009 matches the data quite well.

Since electron transport is not yet implemented in Mercury, we did not simulate electron recoil spectra. Instead, we used published average leaked gamma energies $\left[\mathrm{GHK}^{+} 90\right]$, based on simulations, in our comparisons.

\section{Oktavian spheres}

The Oktavian sphere experiments are essentially pulsed-sphere experiments conducted in at the OKTAVIAN facility in Osaka, Japan in the 80's. We modeled oktavian sphere benchmark experiments using 1dimensional Mercury simulations of spheres composed of nickel, tungsten, and silicon. The resulting neutron leakage currents were compared to experimental neutron TOF spectra and to MCNP4C simulations published in the SINBAD Handbook [OEC09]. The tungsten simulations are shown in figure 9 and the nickel and silicon results in appendix B.

\section{E. Basic Checks}

Once the data were processed, the ENDL2009 library went through several simple tests to ensure that each isotope or element ran normally and did not lead to a core dump of the application code. These tests were first described in the ENDL2008 release documentation $\left[\mathrm{BDH}^{+} 09\right]$. The mcf file was tested using Mercury to dynamically simulate the response of a $40 \mathrm{~cm}$ sphere composed of a single isotopic material with a $14 \mathrm{MeV}$ neutron source at the center. Gamma production from the same sphere was studied using a similar test that tallied the average gamma energy leaking from the material. The ndf file was tested using AMTRAN, a deterministic code. A fast $k_{\text {eff }}$ simulation was run for a ${ }^{239} \mathrm{Pu}$ core inside a reflector made of the isotopic material under study.

A simple broomstick model was developed to test the $\mathrm{d}(n, 2 n)$ reaction cross sections. A monoenergetic pencil beam of neutrons hits the center of a thin cylinder 


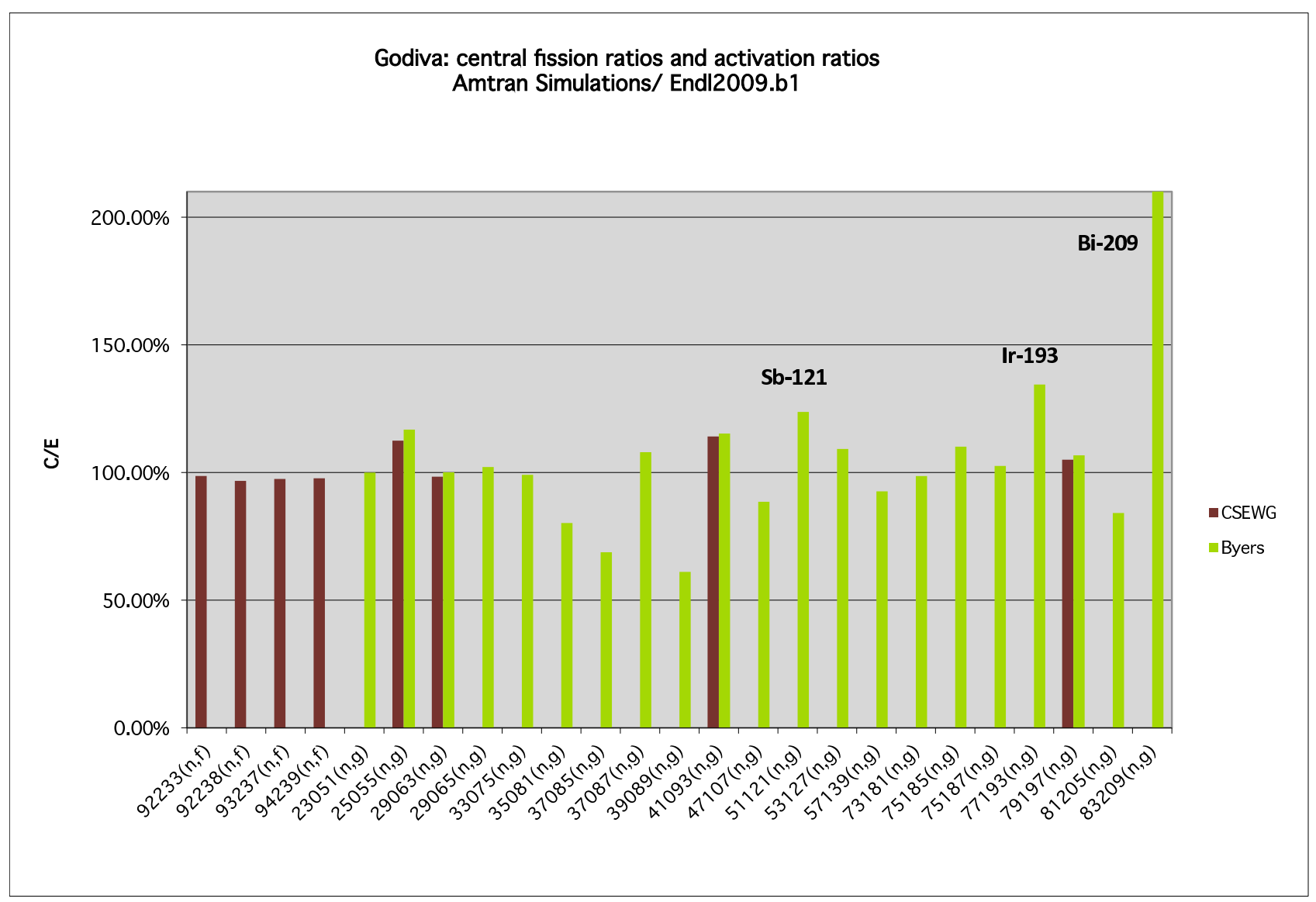

FIG. 6: Activation ratios from the Godiva assembly.

of material. The beam direction is aligned with the axis of the cylinder. The radius of the cylinder is small enough for neutron to escape after a collision. Results of Mercury simulations in combination with the ENDL2009 library matched the MCNP5 and ENDF-B.VII.0 results. The model can be easily modified to simulate other isotopes and reactions.

\section{F. Integral tests in development}

There is an ongoing effort to increase our AMTRAN and Mercury benchmark criticality suite by translating the existing TART suite containing more than 1000 input decks. We focused on fast assemblies since most thermal and medium spectrum assemblies are surrounded by water or polyethylene moderators which require thermal neutron scattering data, not included in ENDL2009, to obtain a reasonable result for $k_{\text {eff. }}$.

Recent versions of Mercury have been modified to run activation foil simulations similar to those of AMTRAN, discussed in Section IV B.

Mercury simulations of aluminum Oktavian spheres and the Fusion Neutronics Source vanadium experiment are also in development. When applicable, we will also model photon leakage results [OEC09].
A number of other tests are in development. We will model replacement coefficient tests in Godiva and Jezebel. These simulations study the change in $k_{\text {eff }}$ when a test material is inserted into a hole in the assembly. We will test aluminum cross sections by modeling MIT reactor data from the aluminum collimator around the beamline. Finally, we are developing Mercury models of ${ }^{6} \mathrm{LiD}$ Wyman spheres and ${ }^{7} \mathrm{LiD}-\mathrm{U}$ Bethe spheres to simulate tritium production and isotopic reaction rates.

\section{REVIEWS OF NEW EVALUATIONS}

Every year, new evaluations are released to the larger nuclear data community to be considered for inclusion in various libraries. As these evaluations become available, we review them for possible inclusion in forthcoming ENDL releases. Here, we present the reviews of these evaluations, organized by source library. We have adopted these evaluations for inclusion in ENDL2009 unless otherwise stated.

Our process for review is simple: we plot the major reaction cross sections for a particular target/projectile combination, along with any data available from the EXFOR library. In addition, we compute the $\chi^{2}$ of the data 


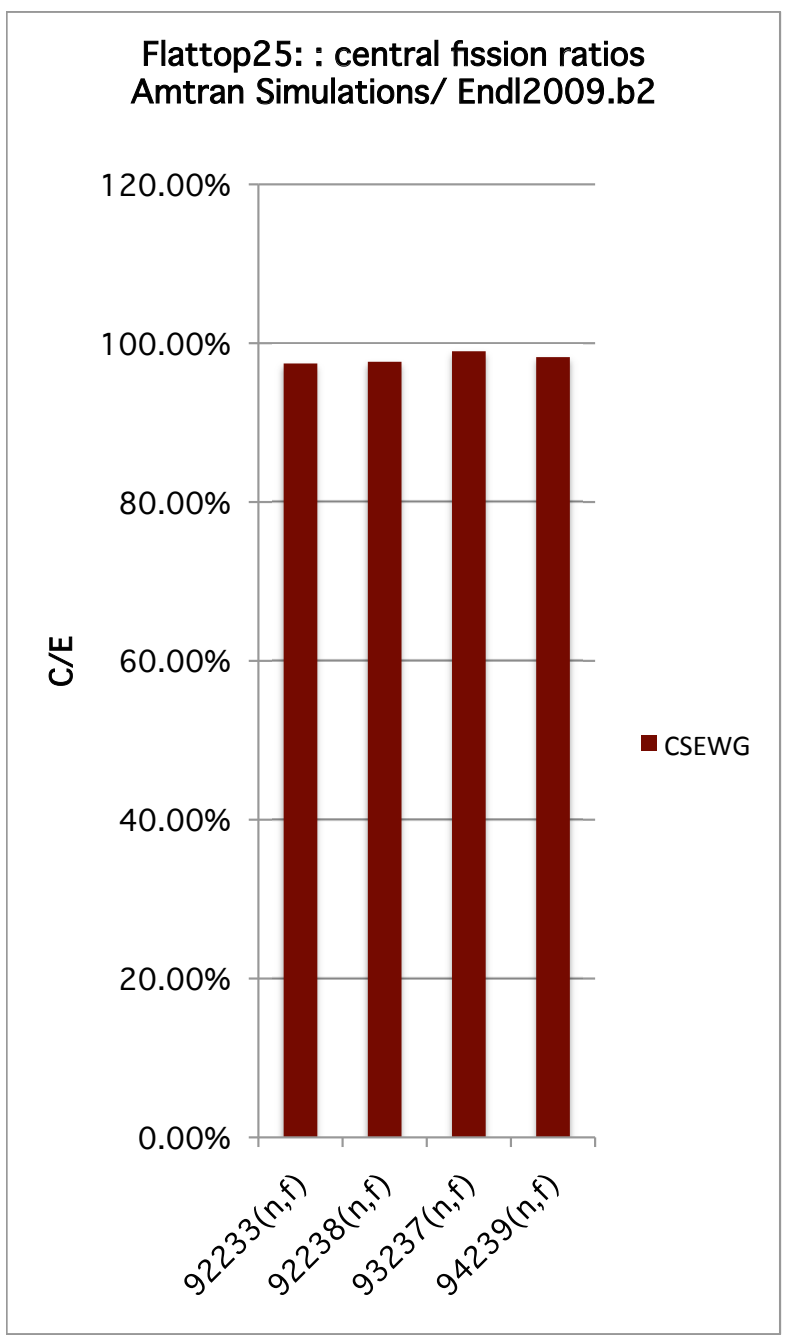

FIG. 7: Activation ratios from the Flattop-25 assembly.

relative to the evaluations,

$$
\chi^{2}=\sum_{i} \frac{\left(\sigma_{i}-\sigma_{\text {eval }}\left(E_{i}\right)\right)^{2}}{\left(\Delta \sigma_{i}\right)^{2}}
$$

The sum runs over the data points in all the data sets available for a given reaction cross section. We use the $\chi^{2}$ as a crude measure of evaluation quality when we cannot determine the best evaluation by eye.

\section{A. ENDF/A}

ENDF/A is the "beta" library for ENDF/B; all new evaluations to be considered for inclusion in ENDF/BVII.1 are stored here. Several isotopes were taken from ENDF/A simply because they are minor bug-fixes of ENDF/B-VII.0 evaluations we have already reviewed and selected. These isotopes are: ${ }^{87} \mathrm{Rb},{ }^{96} \mathrm{Zr}$ and ${ }^{97} \mathrm{Mo}$. The evaluation documentation contains the details of these bug fixes. Below we detail the review of the other isotopes.

$$
\text { 1. }{ }^{22} \mathrm{Na}
$$

This is a new evaluation added to the ENDF/A library for possible inclusion in ENDF/B-VII.1. Since there is no other evaluation for ${ }^{22} \mathrm{Na}$, we have adopted it.

$$
\text { 2. }{ }^{35,37} \mathrm{Cl}
$$

These two evaluations are updates of those in ENDF/B-VII.0, utilizing the full generality of the ReichMoore theory, including charged-particle exit channels, as described in the most recent ENDF/B format documentation. The Reich-Moore format with $L R F=3$ and LCOMP $=1$ was used for ${ }^{37} \mathrm{Cl}$ while the Reich-Moore Limited $(L R F=7, L C O M P=2)$ format was used for ${ }^{35} \mathrm{Cl}$ because the proton exit channel is open $(Q=0.61522 \mathrm{MeV})$. Above $1.2 \mathrm{MeV}$, cross sections from ENDF/B-VII.0 are used.

$$
\text { 3. }{ }^{39-41} \mathrm{~K}
$$

ENDF/A and other major data libraries have adopted the JENDL-3.3 evaluations. In addition, ORNL replaced the resolved resonance region with a new evaluation using the multi-level Reich-Moore $R$-matrix formalism. The resonance analyses themselves were performed with the SAMMY code [Lar98] which uses a generalized least-squares fitting technique. These evaluations also incorporate recent capture and transmission measurements from the Oak Ridge Electron Linear Accelerator (ORELA), allowing the evaluators to extend the resolved resonance energy range to $1.0 \mathrm{MeV}$.

$$
\text { 4. }{ }^{46-50} \mathrm{Ti}
$$

These evaluations are taken from the ENDF/B-VII.1 development library, ENDF/A, since the ENDF/B-VII.0 and JENDL-3.3 evaluations had severe energy balance problems caused by unphysical outgoing photon distributions. These evaluations are still based on the ENDF/BVII.0 evaluation but with the photon production data removed. In addition, the evaluators have two important improvements: the cross section data was replaced with results of GNASH calculations tuned to repoduce recent GEANIE experimental data [Das07] and the and resonance parameters were updated [Oh08] based on Mughabghab's systematics [Mug06].

$$
\text { 5. }{ }^{55} \mathrm{Mn}
$$

While the high-energy portion of this ENDF/A evaluation is unchanged from ENDF/B-VII.0, the resonance region underwent substantial revision. In particular, $\mathrm{H}$. 
Derrien, L.C. Leal, N.M.Larson, D. Wiarda, K. Guber, and G. Arbanas generated new resonance parameters and their covariances in the range from $1.0 \times 10^{-5} \mathrm{eV}$ to 125 $\mathrm{keV}$ using SAMMY. The new fit includes the most recent experimental neutron transmission and capture cross sections in the resolved energy range: Harvey et al. transmission measured at ORELA (1980), Aerts et al. capture cross sections measured at GELINA (2006), and Guber et al. capture cross section measured at ORELA (2007). The cross section data used in the thermal energy range are the Widder et al. capture cross section (1975), the Cote et al. total cross sections (1964), and the Rainwater et al. data (1964).

$$
\text { 6. }{ }^{89} \mathrm{Y}
$$

This evaluation is basically that of ENDF/B-VII.0 with one bug fix that still needs further investigation. The original file's $\left(n, n^{\prime}\right)$ continuum cross section was negative from its initial threshold of $0.99 \mathrm{MeV}$ to 4.06844 $\mathrm{MeV}$ to ensure both energy balance and that all of the $\left(n, n^{\prime}\right)$ channels would sum to the total $\left(n, n^{\prime}\right)$ result stored in the ENDF MT=4 section. The excursion below zero was not small: the cross section reaches roughly -0.1 b. The fixed file zeros out the cross section in the region where it is negative, introducing an energy balance problem. The fix does not affect any radiochemically-relavent channels.

$$
\text { 7. } \quad{ }^{113} \mathrm{Cd}
$$

The resonance region was slightly modified to match the new Mughabghab thermal value [Mug06].

$$
\text { 8. }{ }^{174-180} \mathrm{Hf}
$$

The resolved and unresolved resonance parameters in the JEFF-3.1 evaluations were revised by R. Q. Wright.

$$
\text { 9. }{ }^{236} \mathrm{U}
$$

T. Kawano, M. B. Chadwick, A. Kahler and P. G. Young slightly modified the fission cross sections near $100 \mathrm{keV}$ to better match the URR boundary. They also reevaluated the capture cross section with the Hauser-Feshbach code GNASH, finding a $10 \%$ increase above $100 \mathrm{keV}$.

$$
\text { 10. }{ }^{240} \mathrm{Pu}
$$

P. G. Young, P. Talou, M. B. Chadwick, A. Kahler, and T. Kawano substantially reworked the ENDF/B-VII.0 evaluation:
- They incorperated the new covariance evaluations of $\bar{\nu}$ and the total, $(n, \gamma)$, and $(n, f)$ cross sections using the ENDF/B-VII standards data.

- They used the resolved resonance parameters from the JENDL Actinoid 2008 library.

- They recalcuated the $(n, x n)$ cross sections and angular distributions based on the theory used in the ENDF/B-VII.0 ${ }^{238} \mathrm{U}$ evaluation.

$$
\text { 11. }{ }^{241} \mathrm{Am}
$$

The fission cross section below $1 \mathrm{MeV}$ was reevaluated using a least-squares fit to the data by T. Kawano, M. B. Chadwick, A. Kahler and P. G. Young. They also reevaluated the capture cross using Hauser-Feshbach calculations with GNASH to reproduce the DANCE data as well as an integral measurement.

\section{B. TENDL-2008}

TENDL-2008 is a library of evaluations created using the reaction code talys in "default mode" [KR08]. Some tuning beyond the default parameters was done. Although this library has the greatest number of projectile/target combinations of any library, the evaluations it produces by its automated procedures are often not as good as those achieved by individual tuning of a given reaction. As a result, we only adopted evaluations for isotopes with no other available evaluation. These include:

$$
\begin{aligned}
& \text { - }{ }^{169,171} \mathrm{Tm} \\
& \text { • }{ }^{168-174} \mathrm{Yb},{ }^{176} \mathrm{Yb} \\
& \text { - }{ }^{184,186-193} \mathrm{Os} \\
& \text { - }{ }^{190,192,194-196,198} \mathrm{Pt} \\
& \text { - }{ }^{203-205} \mathrm{Tl} \\
& \text { - }{ }^{209} \mathrm{Po}
\end{aligned}
$$

\section{JEFF-3.1.1}

The maintainers of the JEFF library released an update to the JEFF-3.1 library. This update contained no new isotopes and a few modest fixes to existing ones.

The only new evaluation included in JEFF-3.1.1 is ${ }^{99}$ Tc. All other evaluations are corrections to JEFF3.1. This release is an iterative improvement over the existing evaluations in JEFF-3.1 since it uses the same resonances as JEFF-3.1 with improved high-energy data derived from talys fits to data. The $\chi^{2}$ for $(n, \gamma),(n$, tot $)$ for JEFF-3.1.1 is better than ENDF/B-VII.0, the $\chi^{2}$ for 
$(n, 2 n)$ is the same as ENDF/B-VII.0, and the $\chi^{2}$ in ENDF/B-VII.0 for $(n, p)$ is better. However, the $(n, p)$ cross section is only $1 \%$ of $(n, 2 n)$ magnitude.

\section{IAEA Tungsten evaluation}

In 2008, the IAEA Coordinated Research Project entitled "Evaluation of Tungsten Nuclear Reaction Data with Covariances" concluded, producing evaluations for all stable tungsten isotopes [TCKL08]: ${ }^{180,182-184,186} \mathrm{~W}$. We review these evaluations and compare them to other available evaluations below.

The experimental data for these five stable tungsten isotopes was compared with existing evaluations: ENDF/B-VII, JEFF-3.1.1, JENDL-3.3, and ENDL2008. We also compared these to two newly-produced evaluations. We first studied TENDL-2008 [KR08], the collection of default talys stable isotope calculations. We also studied the recent set of stable tungsten isotope evaluations from the IAEA [TCKL08]. These evaluations by Capote and Trkov consisted of empire $\left[\mathrm{HCC}^{+} 07\right]$ calculations with discrete levels from the RIPL-2 database, and an isospin-dependent dispersive optical potential [CSQC07]. They used exciton model calculations with code PCROSS, shell corrections according to Myers and Swiatecki, cluster emission in terms of the IwamotoHarada model, and Kalbach systematic angular distributions. Some mean-free path parameters and particle emission widths were fit to the data. ECIS total cross sections were scaled as necessary, and GDR parameters were taken from RIPL-2.

We find that the IAEA stable tungsten evaluations are uniformly superior to the alternatives. Therefore we have included them in the ENDL2009 collection.

Figures 8 and 9 demonstrate our testing of these evaluations with Oktavian Sphere and LLNL pulsed-sphere simulations.

\section{E. Nuclear Research and Consultancy Group (NRG) evaluations}

In 2004, the creators of talys performed evaluations of ${ }^{204,206-208} \mathrm{~Pb}$, and ${ }^{209} \mathrm{Bi}$. While these evaluations are uniformly of high quality, they are not superior to those in ENDF/B-VII.0 in the resolved and unresolved resonance regions. Importing resonances from ENDF/BVII.0 and combining them with fitted talys results at higher energies gives more accurate evaluations.

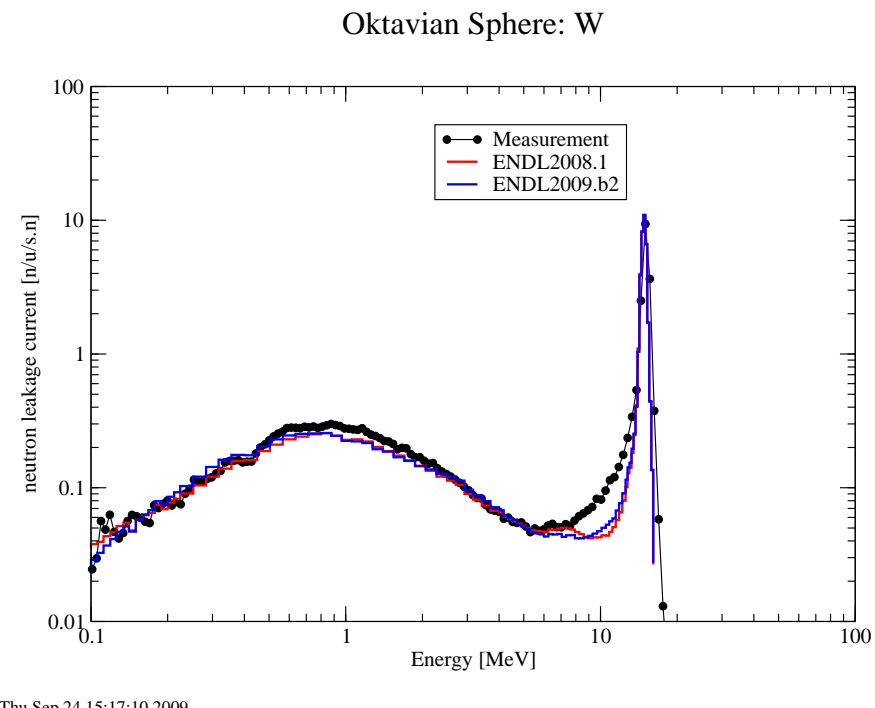

Thu Sep 24 15:17:10 2009

FIG. 8: Oktavian sphere tungsten comparison.

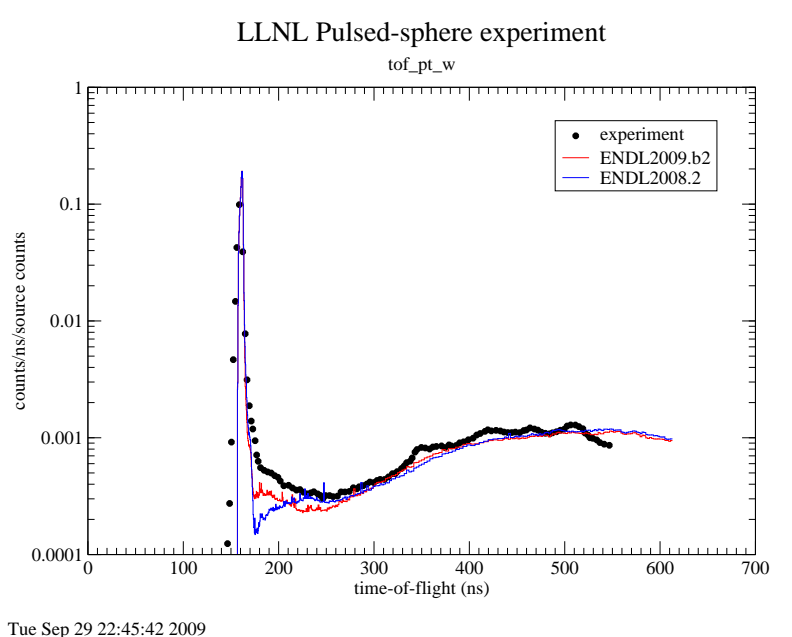

FIG. 9: LLNL pulsed sphere tungsten comparison.

\section{NEW NEUTRON SUBLIBRARY EVALUATIONS}

\section{A. Methods for building evaluations}

All of the new evaluations in the neutron sub-library of ENDL2009 were created using Hauser-Feshbach calculations employing the talys code [KHD07]. In general we tuned our calculations to all available EXFOR cross section data. In the case of structural materials, this involved only simple tuning by hand. However, for the radiochemical evaluations, we sampled the talys inputs by Monte-Carlo to estimate the theoretical uncertainties as well as to match the EXFOR data.

Although the talys calculations mainly model the fast neutron region, they can be extrapolated to thermal energies to obtain average cross sections. Since resonance data are available for stable nuclei, we reviewed and 
adopted the best resonance region evaluations available. In other cases, we used the talys average cross sections. Because the ENDL format is a purely point-wise, the resonances are most efficiently stored in the ENDF format. We used the codes endl2endf [Bro08] and geft [Sum08] to first build the evaluations in ENDF format and merge them with selected resonance regions. Then we use the code fete [BHH06b] to convert the ENDF-formatted evaluation into ENDL format. This method allows us to keep the unresolved resonance region intact and store the discrete gammas in parameterized form until the final translation step. In addition, we are able to employ Kalbach systematics along with the pre-equilibrium fraction modeled by talys.

\section{B. Radiochemical diagnostics}

\section{Basic considerations}

Evaluated partial cross sections were required for a recent radiochemistry L2-milestone addressing neutroninduced reactions on the lightest stable isotope of Ar, As, Kr, Xe, Tm, and Au. Networks of $(n, 2 n)$ reactions were of particular interest. Thus the evaluations required a complete set of partial reaction cross sections for isotopes with as many as two fewer neutrons than the stable isotope, e.g., ${ }^{73} \mathrm{As},{ }^{74} \mathrm{As}$, and ${ }^{75} \mathrm{As}$. The available data for nuclei of interest are generally rather limited with only sparse data typically available for the stable isotope alone. The prospects for obtaining the required partial cross sections from experiment are low since the lifetimes of unstable lighter isotopes are too short to make practical targets.

In principle, surrogate methods, such as a transfer reaction on a stable target producing an appropriate compound nucleus, could provide a means for inferring the necessary partial cross sections. For example, the transfer reaction ${ }^{75} \mathrm{As}\left({ }^{3} \mathrm{He}, \alpha\right)$ produces the same compound nucleus as ${ }^{73} \mathrm{As}(n, X)$. Unfortunately, even surrogate measurements must rely on calculations to infer the $(n, X)$ reaction cross sections. An accurate optical potential is needed to obtain the total reaction cross section. In addition, surrogate reactions can only produce the desired compound nucleus and cannot estimate contributions from pre-equilibrium emission which could be important for many target nuclei. One such case is ${ }^{77} \mathrm{Kr}$, where current models in reaction codes predict a large knockout component for the $(n, \alpha)$ channel. Unfortunately, this system, which is inaccessible experimentally, is a primary source of uncertainty in the modeled cross sections.

Given the current state of experiment, models are necessary to evaluate the nuclear reaction data. Here, estimates of neutron-induced reaction cross sections were obtained employing talys [KHD07]. Estimates of the model uncertainties for each channel were calculated by varying input parameters and comparing with existing

\begin{tabular}{|l|c|}
\hline Program Option & Value \\
\hline relativistic & $\mathrm{y}$ \\
bins & 50 \\
channels & $\mathrm{y}$ \\
filechannels & $\mathrm{y}$ \\
spherical & $\mathrm{y}$ \\
localomp & $\mathrm{n}$ \\
preequilibrium & $\mathrm{y}$ \\
twocomponent & $\mathrm{n}$ \\
preeqmode & 1 \\
multipreeq & $\mathrm{n}$ \\
preeqsurface & $\mathrm{n}$ \\
preeqcomplex & $\mathrm{y}$ \\
ENDF & $\mathrm{y}$ \\
\hline
\end{tabular}

TABLE IV: List of input options used in the talys calculations.

experimental data. The discussion of radiochemical diagnostics is divided into two parts. The details of the talys calculations are described first, followed by the results obtained for selected nuclei.

\section{Calculational details}

Here the procedure used to compute the reaction cross sections and to estimate their uncertainties is outlined. The partial cross sections for all channels available in neutron-induced reactions on ${ }^{34,35,36} \mathrm{Ar},{ }^{73,74,75} \mathrm{As}$, $76,77,78 \mathrm{Kr}, \quad{ }^{122,124,124} \mathrm{Xe},{ }^{167,168} \mathrm{Tm}$, and ${ }^{195,196,197} \mathrm{Au}$ were calculated using talys. The list of program options used for the calculations is given in Table IV.

The calculations were typically performed using the default settings for input parameters such as the optical potential, level densities, and gamma strength functions. The sensitivity of the calculations to the input parameters was estimated by a Monte Carlo variation of the default parameters within a specified range. The evaluated cross sections were assigned the average value, while the standard deviation is the theoretical uncertainty. One hundred separate talys calculations were performed for each isotope assuming that the mean and spread of the input parameters obeyed a Gaussian distribution.

The default multipliers on the input parameters and their Gaussian widths are given in Table V. The parameters M2constant, Cknock, and Cstrip govern the pre-equilibrium contribution. All "adjust" parameters specify the optical potentials. In Table V, the factor in the 'Spread' column is added to the default multiplier given in the 'Value' column to obtain the Gaussian spread on the default multiplier. The Gaussian spread was chosen to reproduce the expected variation in the reaction cross sections, roughly $5 \%$ for incident neutron energies greater than $10 \mathrm{MeV}$ and $\sim 8-10 \%$ for energies less than $10 \mathrm{MeV}$. Finally, alimit, pair, and deltaW 


\begin{tabular}{|l|c|l|l||l|l|l|l|}
\hline Parameter & Part & Value & Spread & Parameter & Part & Value & Spread \\
\hline M2constant & & 1.00 & 0.250 & w1adjust & $\mathrm{p}$ & 1.000 & 0.300 \\
Cknock & $\mathrm{a}$ & 0.75 & 0.200 & w2adjust & $\mathrm{p}$ & 1.000 & 0.300 \\
Cstrip & $\mathrm{a}$ & 1.00 & 0.250 & d1adjust & $\mathrm{p}$ & 1.00 & 0.0500 \\
v1adjust & $\mathrm{n}$ & 1.00 & 0.005 & d2adjust & $\mathrm{p}$ & 1.00 & 0.050 \\
v2adjust & $\mathrm{n}$ & 1.00 & 0.025 & d2adjust & $\mathrm{p}$ & 1.00 & 0.050 \\
v3adjust & $\mathrm{n}$ & 1.00 & 0.050 & rvadjust & $\mathrm{p}$ & 1.00 & 0.002 \\
v4adjust & $\mathrm{n}$ & 1.00 & 0.050 & v1adjust & $\mathrm{a}$ & 1.00 & 0.0075 \\
w1adjust & $\mathrm{n}$ & 1.00 & 0.300 & v2adjust & $\mathrm{a}$ & 1.00 & 0.050 \\
w2adjust & $\mathrm{n}$ & 1.00 & 0.300 & v3adjust & $\mathrm{a}$ & 1.00 & 0.075 \\
d1adjust & $\mathrm{n}$ & 1.00 & 0.050 & v4adjust & $\mathrm{a}$ & 1.00 & 0.075 \\
d2adjust & $\mathrm{n}$ & 1.00 & 0.050 & w1adjust & $\mathrm{a}$ & 1.00 & 0.300 \\
d3adjust & $\mathrm{n}$ & 1.00 & 0.050 & w2adjust & $\mathrm{a}$ & 1.00 & 0.300 \\
rvadjust & $\mathrm{n}$ & 1.00 & 0.002 & d1adjust & $\mathrm{a}$ & 1.00 & 0.075 \\
v1adjust & $\mathrm{p}$ & 1.00 & 0.005 & d2adjust & $\mathrm{a}$ & 1.00 & 0.075 \\
v2adjust & $\mathrm{p}$ & 1.00 & 0.025 & d3adjust & $\mathrm{a}$ & 1.00 & 0.075 \\
v3adjust & $\mathrm{p}$ & 1.00 & 0.050 & rvadjust & $\mathrm{a}$ & 1.00 & 0.003 \\
v4adjust & $\mathrm{p}$ & 1.00 & 0.050 & & & & \\
\hline
\end{tabular}

TABLE V: The talys input parameters for each particle (Part) type. Here 'a', 'n', and 'p' denote alpha, neutron, and proton, respectively. The quantity in the 'Value' column is a multiplicative factor applied to the talys default value. The column labeled 'Spread' indicates the maximum amount added randomly to the multiplicative factor in the 'Value' column.

determine the nuclear level densities. The level density parameters were varied for each isotope in the reaction chain. The central values were the default talys values, with an explicit Gaussian spread of 0.02, 0.02, and 0.05 on alimit, pair, and deltaW, respectively. A full description of the talys options and input parameters are given in the talys manual [KHD07].

$$
\text { 3. }{ }^{195-197} A u
$$

Figure 10 shows the results, including the estimated uncertainties for the three $\mathrm{Au}$ isotopes as well as a comparison with $(n, 2 n)$ data (magenta points) for ${ }^{197} \mathrm{Au}$. The data represent a composite of the EXFOR/CSISRS data compilation [Net08]. The partial cross sections are obtained from an average of 100 talys runs. The error bars show how the results change with variations of the talys input parameters as described previously. The calculation exhibits excellent agreement with the compiled $(n, 2 n)$ data.

Models of heavier isotopes are generally better under control because the charged-particle channels are more suppressed due to their substantially larger Coulomb barrier. Consequently, at the higher incident neutron energies, the $(n, 2 n)$ channel dominates, taking up most of the total reaction cross section (black points), in stark contrast to the $\mathrm{Kr}$ isotopes discussed next.

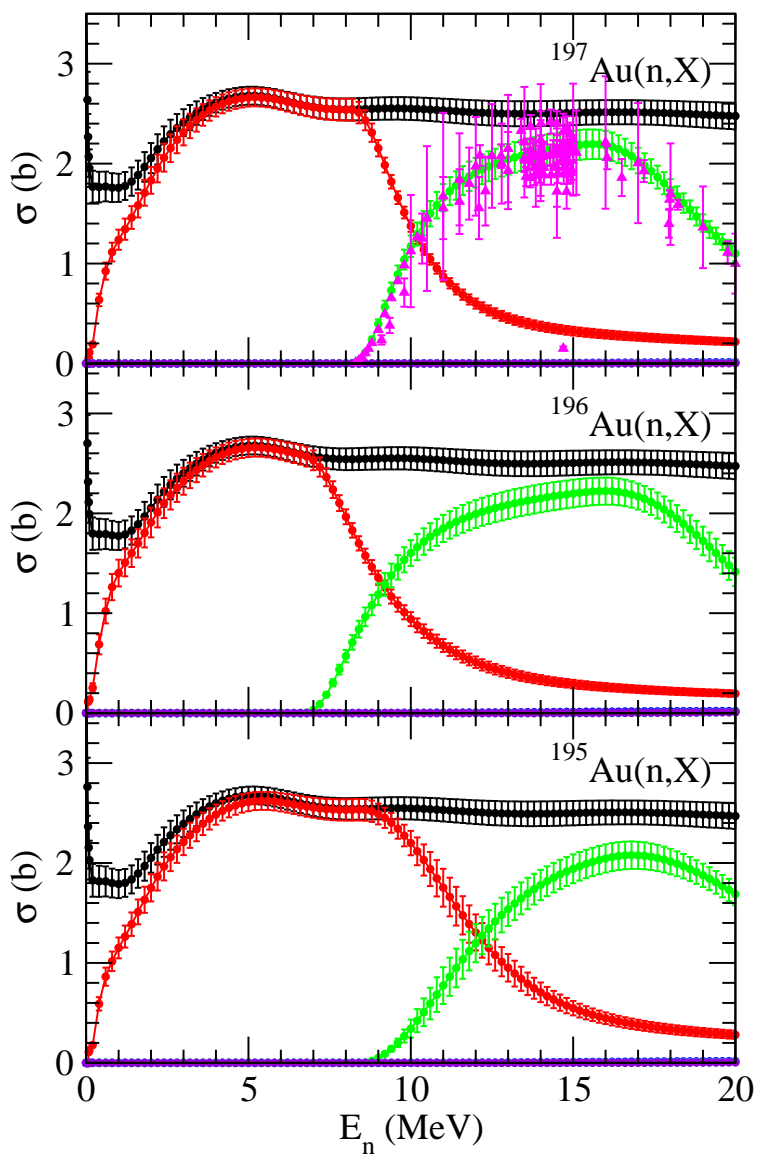

FIG. 10: Partial $(n, X)$ reaction cross sections for $\mathrm{Au}$ targets as a function of incident neutron energy $E_{n}$. The total (black), $\left(n, n^{\prime}\right)$ (red) and $(n, 2 n)$ (green) cross sections are shown. The EXFOR/CSISRS data (magenta points) are compared to the $(n, 2 n)$ calculation for ${ }^{197} \mathrm{Au}$.

$$
\text { 4. }{ }^{76-78} \mathrm{Kr}
$$

In Fig. 11, the talys results are shown for the $\mathrm{Kr}$ isotopes. The $(n, 2 n)$ data for ${ }^{78} \mathrm{Kr}$ (magenta points) from the EXFOR/CSISRS compilation are compared to the calculations (green). Although the data are limited, the models agrees reasonably well with experiment, within the theoretical uncertainty.

The Kr isotopes are significantly different from the other isotopes investigated in this study, where the $(n, 2 n)$ reaction typically accounts for $\sim 70-80 \%)$ of the cross section. However, these isotopes are substantially neutron deficient and consequently have very low proton and alpha thresholds. This is apparent from Fig. 11 where both the proton and alpha emission channels are sub-threshold for ${ }^{77} \mathrm{Kr}$. As a consequence, these probabilities are quite large.

To further complicate the situation, the $(n, \alpha)$ knockout models predict a factor of $5-10$ larger $(n, \alpha)$ cross section than for many other systems. This is also evident in ${ }^{77} \mathrm{Kr}$ where the $(n, \alpha)$ cross section (violet) is on the or- 


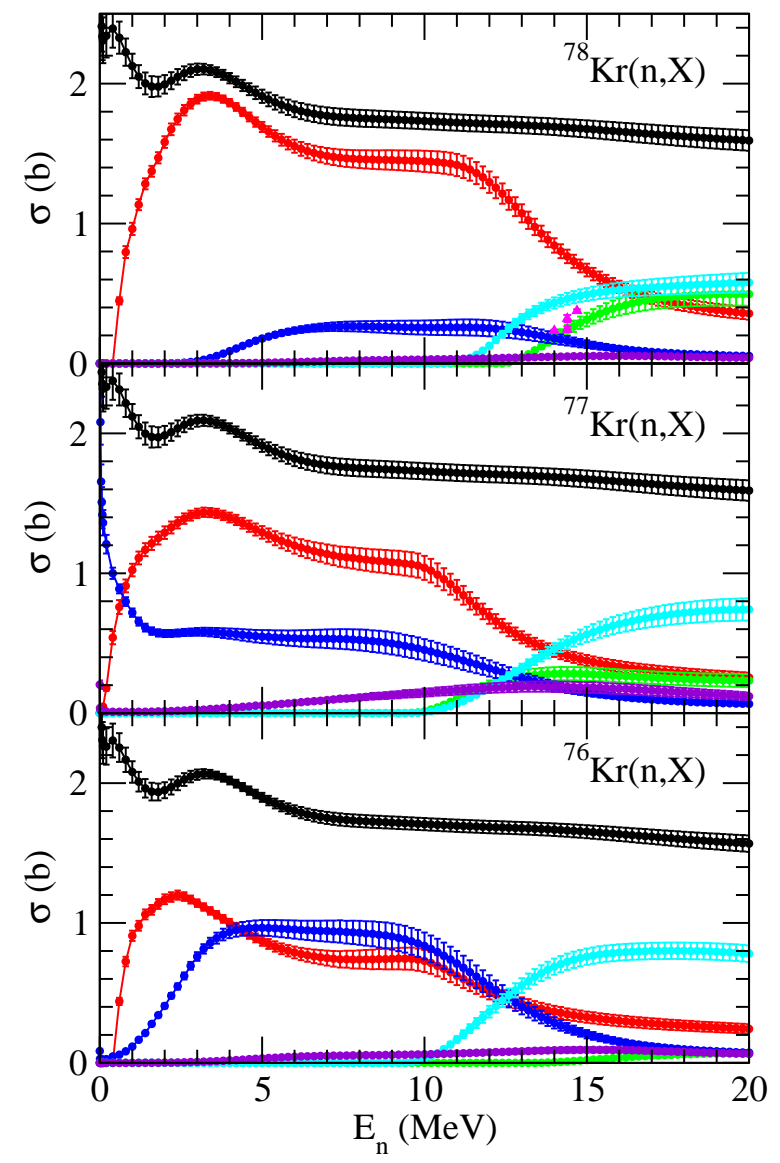

FIG. 11: Partial $(n, X)$ reaction cross sections for Kr targets as a function of incident neutron energy $E_{n}$. The total (black), $\left(n, n^{\prime}\right)$ (red), $(n, 2 n)$ (green), $(n, p)$ (dark blue), $(n, n p)$ (light blue) and $(n, \alpha)$ (violet) cross sections are shown. The EXFOR/CSISRS data (magenta points) are compared to the $(n, 2 n)$ calculation for ${ }^{78} \mathrm{Kr}$.

der of the $(n, 2 n)$ cross section, $\sim 200 \mathrm{mb}$. There is some concern that the knockout model gives the correct result. To check this channel, additional calculations with and without knockout were performed for several other nuclei with rather large $(n, \alpha)$ cross sections and compared to data. In most cases, better agreement with experiment was obtained when the knockout model was included. However, the normalization needed to be rescaled by a factor of 0.75 relative to the default value. We also note that, even for these systems, the $(n, \alpha)$ cross section is typically $\sim 50 \mathrm{mb}$, substantially smaller than the $\sim 200$ $\mathrm{mb}$ predicted for ${ }^{77} \mathrm{Kr}$.

Unfortunately, it is extremely difficult to experimentally test the knockout model in talys against data for unstable, proton-rich nuclei with very low alpha thresholds since this channel cannot be probed by surrogate reactions. Here, all calculations were performed with Cknock $=0.75 \pm 0.20$. Note that even an uncertainty of $100 \mathrm{mb}$ in the $(n, \alpha)$ channel would not automatically feed into the $(n, 2 n)$ channel alone. The uncertainty would be spread among all four open channels: $\left(n, n^{\prime}\right)$; $(n, p) ;(n, n p)$; and $(n, 2 n)$, according to the respective branching ratios. The $\left(n, n^{\prime}\right)$ and $(n, n p)$ branching ratios are largest for $14 \mathrm{MeV}$ incident neutron energies.

The low proton threshold also complicates matters even though the proton final states are much better understood. The larger $(n, n p){ }^{78} \mathrm{Kr}$ cross section, with ${ }^{76} \mathrm{Br}$ in the final state, can be mimiced by the $(n, 2 n)$ reaction, ${ }^{77} \mathrm{Kr}(n, 2 n){ }^{76} \mathrm{Kr} \rightarrow{ }^{76} \mathrm{Br}$ (following $\beta$ decay). Thus it is necessary to count the ${ }^{77} \mathrm{Kr} \beta$-decay products. Finally, for incident neutrons of order $10 \mathrm{MeV}$, the uncertainty in each of the $\left(n, n^{\prime}\right)$ and $(n, p)$ channels is larger than that of the reaction cross section, reflecting the branching uncertainty, governed by the level density, for each nucleus.

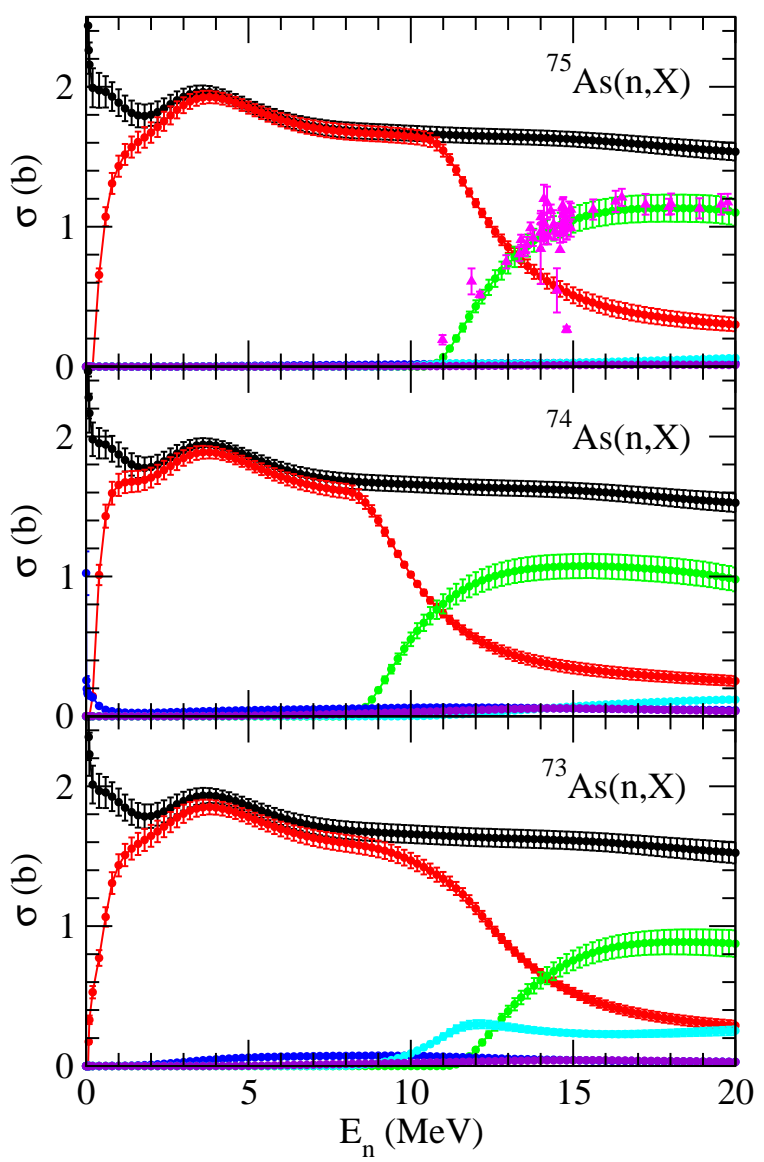

FIG. 12: Partial $(n, X)$ reaction cross sections for As targets as a function of incident neutron energy $E_{n}$. The total (black), $\left(n, n^{\prime}\right)$ (red), $(n, 2 n)$ (green), $(n, p)$ (dark blue), $(n, n p)$ (light blue) and $(n, \alpha)$ (violet) cross sections are shown. The EXFOR/CSISRS data (magenta points) are compared to the $(n, 2 n)$ calculation for ${ }^{75} \mathrm{As}$.

$$
\text { 5. }{ }^{73-75} \text { As }
$$

Figure 12 shows the talys results for the $(n, X)$ channels with three As isotopes, ${ }^{73-75}$ As. Overall, very good agreement is achieved between the $(n, 2 n)$ data and 
the calculation, especially within the model uncertainties. The charged-particle channels open for neutrondeficient isotopes, such as ${ }^{73} \mathrm{As}$, diminish the strength of the $(n, 2 n)$ channel.

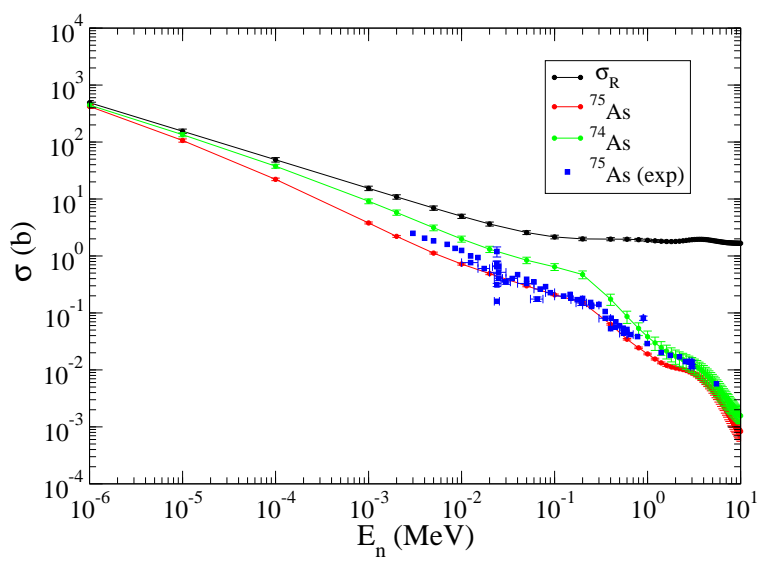

FIG. 13: Comparison of the calculated ${ }^{75} \mathrm{As}$ and ${ }^{74} \mathrm{As}(n, \gamma)$ cross sections as a function of incident neutron energy. The ${ }^{75}$ As data from the EXFOR/CRISRS compilation (blue squares) are compared to the calculations.

There are data on the $(n, \gamma)$ channel in ${ }^{75}$ As which can be used to infer information about this channel in ${ }^{74} \mathrm{As}$, important for network calculations. In general, modeling $(n, \gamma)$ reactions is more difficult than the particle channels that open at higher energies because the capture cross section is strongly dependent on the E1 gamma strength function, the level density, and the neutron separation energy of the compound nucleus. At very low incident neutron energies, below the inelastic neutron scattering threshold (i.e. when the neutron energy is equal to the energy of the first excited state), the branching probability, $B_{\gamma}$, for gamma decay relative to neutron emission is given by

$$
B_{\gamma}=\frac{I_{\gamma}\left(E_{n}\right)}{T_{n}\left(E_{n}\right)+I_{\gamma}\left(E_{n}\right)} .
$$

Hhere $T_{n}$ is the neutron transmission coefficient and $I_{\gamma}$ is given by the integral

$$
I_{\gamma}\left(E_{n}\right)=\int_{0}^{E_{x}} \sum d E_{\gamma} T_{\gamma}\left(E_{\gamma}\right) \rho\left(E_{x}-E_{\gamma}\right) .
$$

In this equation, $E_{x}=S_{n}+E_{n}$ is the excitation energy of the compound nucleus, $S_{n}$ is the neutron separation energy, $E_{\gamma}$ is the gamma energy, $T_{\gamma}$ is the transmission coefficient for gamma emission, $\rho(E)$ is the total density of final states for gamma emission from the initial compound nucleus, and $\sum$ denotes the sum over the allowed final state spins and parities. The radiative width, $\Gamma_{\gamma}$, in principle measurable is

$$
\Gamma_{\gamma}=\frac{I_{\gamma}}{2 \pi \rho\left(E_{x}\right)}
$$

For stable targets, with accurate measurements of $\Gamma_{\gamma}$ and the level spacing at the neutron separation energy, reasonable agreement between the calculated and measured $(n, \gamma)$ cross sections. The role of the neutron separation energy can easily be seen in the $E_{x}$ dependence of Eq. (3): $I_{\gamma}$ increases dramatically with increasing separation energy. Thus, the $(n, \gamma)$ cross sections should be large when the compound nucleus has a large neutron separation energy. The As calculations illustrate this effect: the ${ }^{74} \mathrm{As}(n, \gamma)$ cross section, with $S_{n}=10.244 \mathrm{MeV}$, is much larger than of ${ }^{75} \mathrm{As}(n, \gamma)$, with $S_{n}=7.328 \mathrm{MeV}$, see Fig. 13. The total reaction cross sections, identical for the two isotopes within the accuracy of the figure, are also shown, along with the ${ }^{75} \mathrm{As}$ data from the EXFOR/CRISRS database. At $E_{n} \approx 20 \mathrm{keV}$, the calculated ${ }^{74} \mathrm{As}(n, \gamma)$ cross section is 3-4 times larger than that of ${ }^{75} \mathrm{As}(n, \gamma)$. In general, there is reasonable agreement between the calculated and measured $(n, \gamma){ }^{75}$ As cross section: the calculation is $\sim 10-20 \%$ below the data.

To obtain the best overall representation of $(n, \gamma)$ reactions in talys, the code attempts to renormalize the gamma strength function to reproduce $\Gamma_{\gamma}$, Eq. (4), and will adjust the level density input parameters to reproduce the $S$-wave level spacing, $D_{0} \approx 1 / \rho\left(S_{n}\right)$. When the compound nucleus is ${ }^{76} \mathrm{As}$ ( ${ }^{75} \mathrm{As}$ target) (i.e., ${ }^{76} \mathrm{As}$ compound), we use $\Gamma_{\gamma}=300 \pm 90 \mathrm{meV}$ and $D_{0}=77 \pm 8 \mathrm{eV}$. When there is no experimental data available, such as for compound nuclei from unstable targets, talys uses an interpolation table [Kop] for $40 \leq A \leq 250$. We use $\Gamma_{\gamma}=305 \mathrm{meV}$ for ${ }^{74} \mathrm{As}$. Since the branching ratio for gamma decay is essentially proportional to the radiative width, given the uncertainty in $\Gamma_{\gamma}$ for ${ }^{75} \mathrm{As}$, we expect a $25-30 \%$ uncertainty in all the $\operatorname{As}(n, \gamma)$ cross sections.

$$
\text { 6. }{ }^{122-124} \mathrm{Xe} \text { and }{ }^{34-36} \mathrm{Ar}
$$

Finally, Figs. 14 and 15 show the calculated $(n, X)$ cross sections for $\mathrm{Ar}$ and $\mathrm{Xe}$ isotopes. The Xe isotopes are quite similar to the $\mathrm{Au}$ isotopes because there are no significant charged-particle channels so that the inelastic and $(n, 2 n)$ channels are the largest contribution to the reaction cross section.

The principal difference between the Ar isotopes and the other isotopes examined in this study is the strong suppression of the $(n, 2 n)$ channel due to its high neutron separation energy. As a consequence, proton emission channels dominate the proton-rich isotopes ${ }^{35} \mathrm{Ar}$ and ${ }^{34} \mathrm{Ar},(n, 2 p)$ in particular.

In addition, the default parameters used in Table $\mathrm{V}$ result in a discontinuity in the $(n, \gamma){ }^{35} \mathrm{Ar}$ cross section at $\sim 9 \mathrm{MeV}$ since talys may have have a problem with complex pre-equilibrium emission from light nuclei. Thus we use preeqcomplex $=\mathrm{n}$ for the Ar isotopes. 


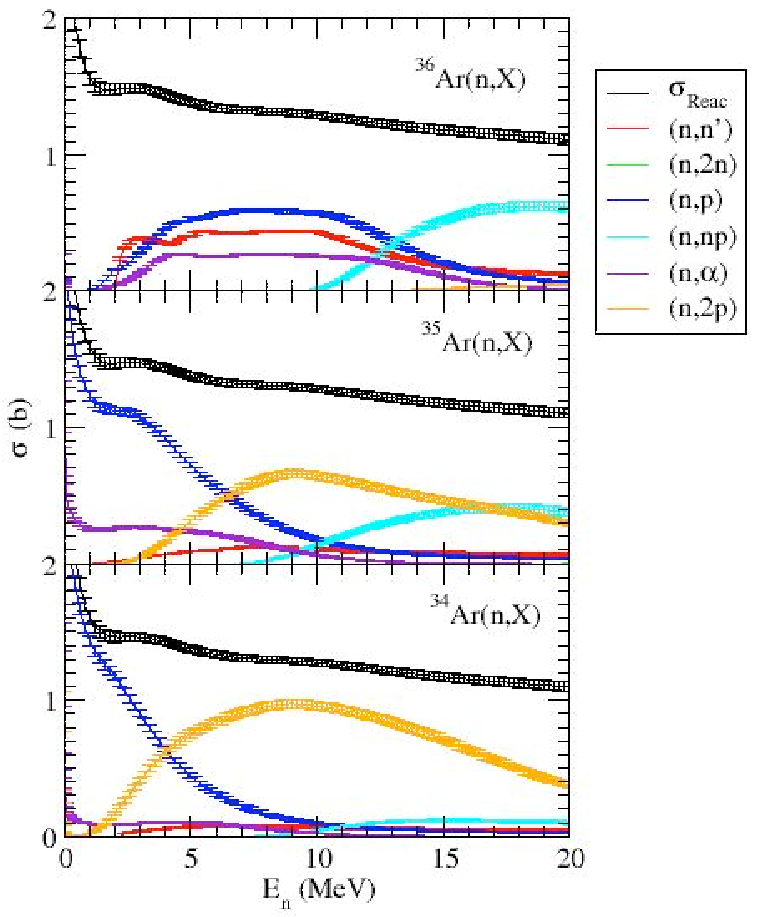

FIG. 14: Partial $(n, X)$ reaction cross sections for Ar targets as a function of incident neutron energy $E_{n}$. The total (black), ( $\left.n, n^{\prime}\right)$ (red), $(n, 2 n)$ (green), $(n, p)$ (dark blue), $(n, n p)$ (light blue), $(n, \alpha)$ (violet) and $(n, 2 p)$ (yellow) cross sections are shown. The EXFOR/CSISRS data (magenta points) are compared to the $(n, 2 n)$ calculation for ${ }^{36} \mathrm{Ar}$.

\section{Structural materials}

The method used in the evaluation of the following structural materials, developed for an L2 Attribution milestone, compares measured data with the existing evaluations, choosing the overall best agreement for ENDL2009. In order to produce evaluations for unstable nuclei, where there is no experimental data, we compare our evaluation with talys calculations employing all default parameters and also with talys calculations where some parameters have been tuned to important experimental cross sections from stable nuclei. In practice, this means that the ( $n$, tot), $(n, 2 n)$ and $(n, \gamma)$ cross sections were used to guide parameter adjustments.

We separately examine the way the evaluations of stable isotopes agree with the resonance region. The best evaluation of this region is inserted into our final result.

$$
\text { 1. }{ }^{25-29} \mathrm{Al}
$$

There are a great deal of low energy data for the only stable $\mathrm{Al}$ isotope, ${ }^{27} \mathrm{Al}$. The ( $n$, tot) data below $20 \mathrm{keV}$ are in conflict with each other, see Fig. 16. Thus we use the same parameters as in the ENDF/B.VII.0 evaluation, extracted by Derrien et al. $\left[\mathrm{GLS}^{+} 00\right]$ using the multi-

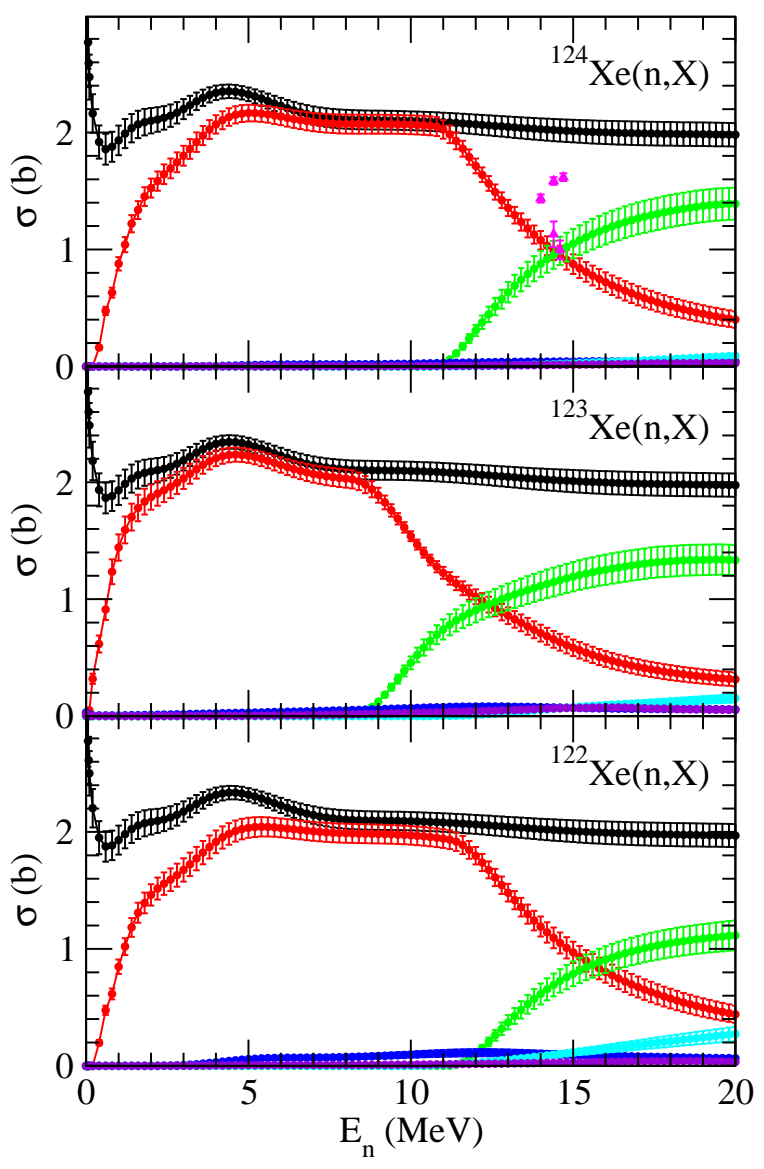

FIG. 15: Partial $(n, X)$ reaction cross sections for Xe targets as a function of incident neutron energy $E_{n}$. The total (black), ( $\left.n, n^{\prime}\right)$ (red), $(n, 2 n)$ (green), $(n, p)$ (dark blue), $(n, n p)$ (light blue) and $(n, \alpha)$ (violet) cross sections are shown. The EXFOR/CSISRS data (magenta points) are compared to the $(n, 2 n)$ calculation for ${ }^{124} \mathrm{Xe}$.

level $R$-matrix code SAMMY [Lar98].

There are complete resonance descriptions up to 850 $\mathrm{keV}$. On a light nucleus such as ${ }^{27} \mathrm{Al}$, there are resolvable resonances up to $3-5 \mathrm{MeV}$. However, these are not included in any evaluation. We therefore include only average cross sections obtained from statistical talys calculations above $850 \mathrm{keV}$. Since there are conflicting $(n, \gamma)$ data at higher energies, an average that comes close to the better-determined $14 \mathrm{MeV}$ was chosen, as shown in Fig. 16. We thus arrive at a recommended evaluation for ${ }^{27} \mathrm{Al}$. The same talys procedure is used for the unstable isotopes.

$$
\text { 2. }{ }^{57-61} \mathrm{Co}
$$

The cobalt isotopes, ${ }^{57-61} \mathrm{Co}$, were evaluated for ENDL2008, neglecting the resonance region. We have thus suplemented the previous ${ }^{58-59}$ Co evaluations with resonances from ENDF/B-VII.0 [SNJN92]. We briefly describe the evaluation method. 


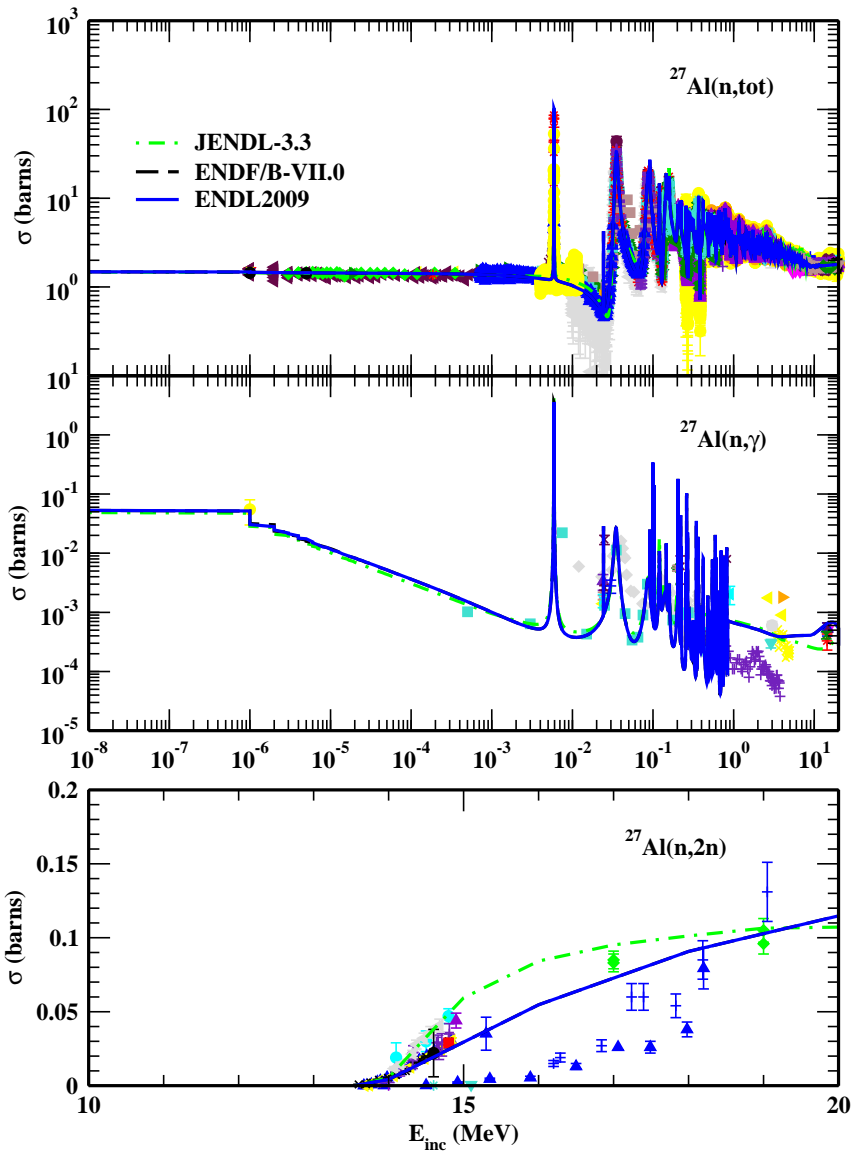

FIG. 16: Experimental data and evaluations of the total, neutron capture and $(n, 2 n)$ cross sections for $n+{ }^{27} \mathrm{Al}$. The proposed ENDL2009 evaluation is in blue.

The evaluations were generated from the talys output using geft. Cross sections were directly imported. Particle spectra were taken from the talys spectra files and assumed to be isotropic $(L=0)$ distributions. Elastic angular distributions were taken from the talys distributions. Continuum gamma multiplicities were calculated from the talys spectra files while discrete gammas were taken from the talys output list.

A version of talys was modified so that $\sigma^{2}$, the spin cut-off parameter for the level densities, could be specified separately for each nucleus by introducing a new input, $\lambda$, calculated from the Nilsson model deformation parameters assuming a zero non-axiality angle. The values of lambda are listed in Table ??. The resulting expression for $\sigma^{2}$ is

$$
\sigma^{2}=\lambda(0.1223)^{2} A^{5 / 3}(U / a)^{1 / 2}
$$

where $U=E-\Delta, E$ is the excitation energy in the nucleus and $\Delta$ is an energy shift related to the pairing energy. The value of the level density parameter $a$ for asymptotically large excitation energies, $a_{\text {lim }}$, can either be obtained from global systematics:

$$
a_{\lim }=0.181788 A-0.25384 A^{2 / 3}
$$

TABLE VI: The parameters and values of $\lambda$ entering the calculation of the spin cutoff parameters, $\sigma^{2}$, in Eq. (5) for the cobalt isotopes. The column labeled $\mathrm{x} / \mathrm{s}$ indicates whether the resonance spacing $D_{0}$ was obtained from experiment (x)

\begin{tabular}{|c|c|c|c|c|c|}
\hline$A$ & $a_{\lim }\left(\mathrm{MeV}^{-1}\right.$ & $\mathrm{x} / \mathrm{s}$ & $\Delta(\mathrm{MeV})$ & $\delta W(\mathrm{MeV})$ & $\lambda\left(\mathrm{MeV}^{-1}\right)$ \\
\hline 57 & 6.602 & $\mathrm{~s}$ & 0.165 & -0.89 & 0.948 \\
\hline 58 & 6.740 & $\mathrm{~s}$ & -0.881 & 0.11 & 0.931 \\
\hline 59 & 6.878 & $\mathrm{~s}$ & 0.198 & 0.77 & 0.931 \\
\hline 60 & 7.057 & $\mathrm{x}$ & -0.854 & 1.39 & 0.921 \\
\hline 61 & 7.156 & $\mathrm{~s}$ & 0.089 & 1.75 & 0.927 \\
\hline 62 & 7.294 & $\mathrm{~s}$ & -0.862 & 2.35 & 0.937 \\
\hline
\end{tabular}
or global systematics (s).

or by fitting to known values of $D_{0}$, the average resonance spacing for neutrons with energies close to the neutron separation energy. The energy-dependent value of $a$ is

$$
a=a_{\lim }[1+\delta W(1-\exp (-0.05188 U)) / U]
$$

where $\delta W$, the shell correction energy, is specified for each nucleus.

To fit the gamma emission cross sections, we adopted the following parameters for the Giant Dipole Resonance: $E_{\gamma}=80 / A^{1 / 3} \mathrm{MeV} ; \Gamma_{\gamma}=5 \mathrm{MeV}$; and $\sigma_{\gamma}=(13 / 5) A \mathrm{mb}$.

Pre-equilibrium particle emission was calculated using a two-component exciton model. The model transition rates are determined numerically using an energydependent matrix element (Eq. (4.102) in the talys 1.00 manual, ref. [KHD07]):

$$
M^{2}=\frac{1}{A^{3}}\left[7.48+\frac{4.62 \times 10^{5}}{\left.\left(E_{\mathrm{comp}} / n+10.7\right)^{3}\right)}\right]
$$

where $A$ is the target mass number, $E_{\text {comp }}$ is the total energy of composite system, and $n$ is the exciton number [KD04].

The gamma strength function, $\Gamma_{\gamma}=1890.14-$ $22.8076 A \mathrm{meV}$, is extracted from fits over the range $50<A<70$. We use this linear form instead of the talys default which overestimates the photoemission cross sections by factors of $2-3$.

$$
\text { 3. }{ }^{178-183} \mathrm{Ta}
$$

Resonance data are available up to $2 \mathrm{keV}$ only for ${ }^{181} \mathrm{Ta}$ since it is the only stable tantalum isotope. Because the ${ }^{180} \mathrm{Ta}$ ground state has a lifetime of 8.2 hours as well as a long-lived $9^{-}$isomeric state at $77.1 \mathrm{keV}\left(10^{15}\right.$ years), it may be possible to make a ${ }^{180} \mathrm{Ta}$ target in the future. Meanwhile, only ${ }^{181} \mathrm{Ta}$ is available to extrapolate the evaluations over the range $178<A<183$.

The current $n+{ }^{181} \mathrm{Ta}$ evaluations are sufficient for the total cross section. Since there are discrepant $(n, 2 n)$ data between $13-15 \mathrm{MeV}$, we adopt a mean which is very close to (or within) all error bars. Fitting the ${ }^{181} \mathrm{Ta}(n, \gamma)$ 


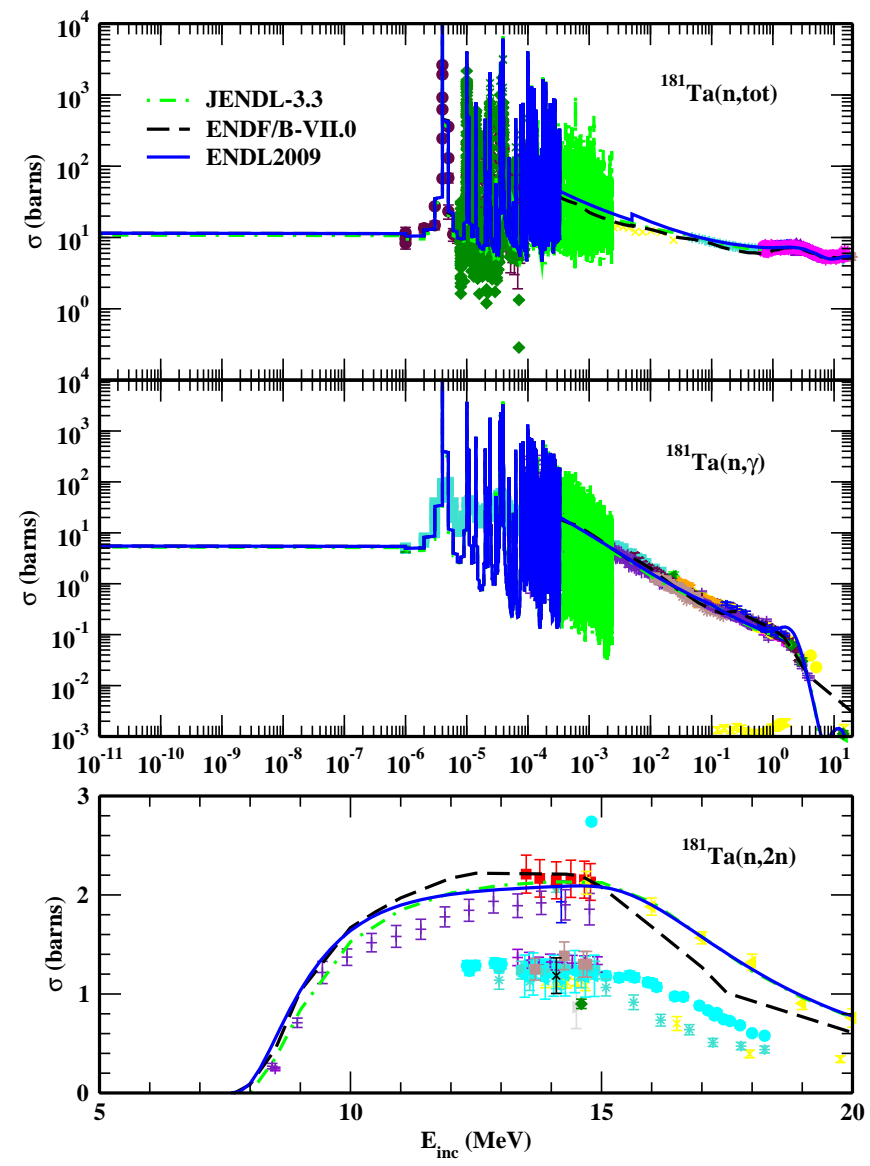

FIG. 17: Experimental data and evaluations for the total, neutron capture and $(n, 2 n)$ cross sections for $n+{ }^{181} \mathrm{Ta}$. The proposed ENDL2009 evaluation is in blue.

rate is, however, more difficult. Most evaluations agree with experiment up to $1 \mathrm{MeV}$. There is additional data up to $3 \mathrm{MeV}$ and also at $15 \mathrm{MeV}$. The talys default calculation is close to the $15 \mathrm{MeV}$ data, but overestimates it between 1.5 and $3 \mathrm{MeV}$. The talys normalization can be adjusted in this region by scaling the parameter $G_{\text {norm }}$ to adjust the input $\Gamma_{\gamma}$ in talys to better match the data. In this case, we scale $\Gamma_{\gamma}$ by a factor of 0.74 by setting $G_{\text {norm }}=1.7$. The talys calculation agrees with the data in all other respects. Therefore, we make it into a provisional evaluation. There are no resonances in the evaluations except for ${ }^{181} \mathrm{Ta}$.

In figure 18 we show the LLNL Pulsed Sphere test of our new tantalum evaluations.

$$
\text { 4. }{ }^{178-188} \mathrm{~W}
$$

We have already adopted IAEA evaluations $\left[\mathrm{CTK}^{+} 07\right]$ for the stable tungsten isotopes: ${ }^{180} \mathrm{~W} ;{ }^{182-184} \mathrm{~W}$; and ${ }^{186} \mathrm{~W}$. A basis for extrapolation over the full isotopic range, $178<A<188$, is now required. We therefore examine the quality of the default talys calculations

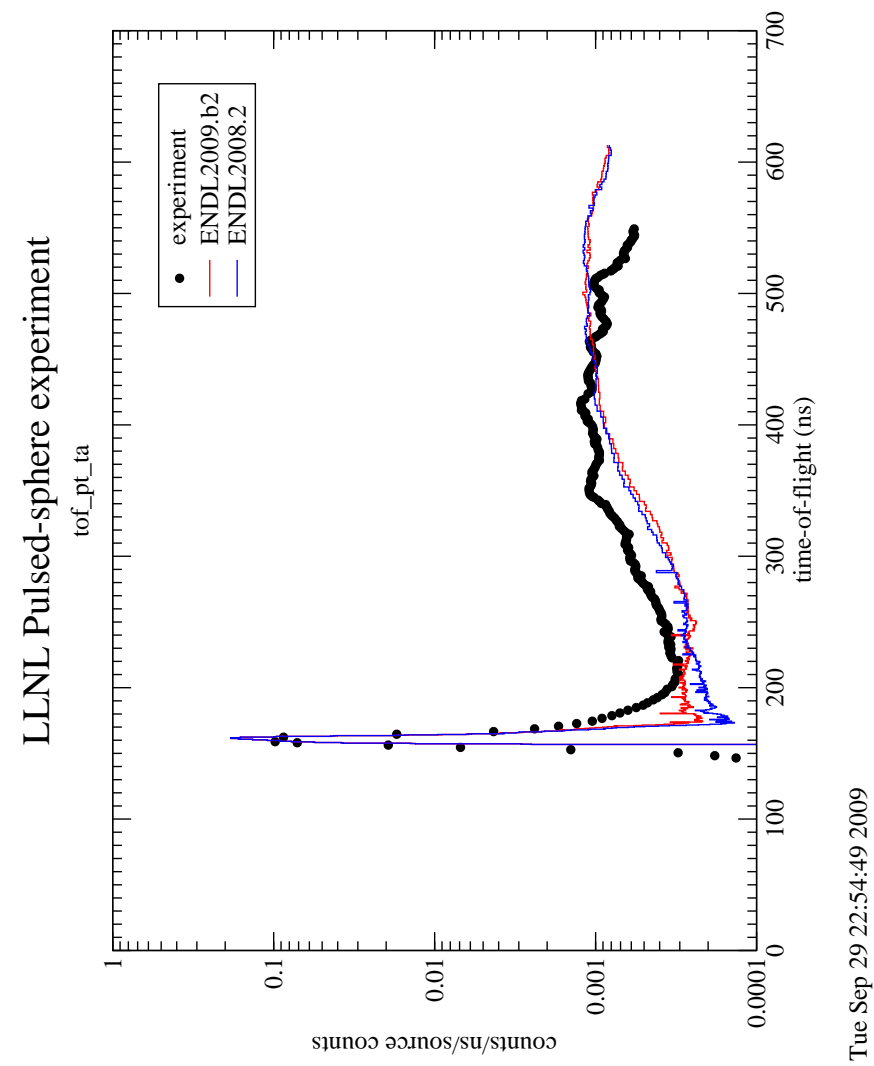

F

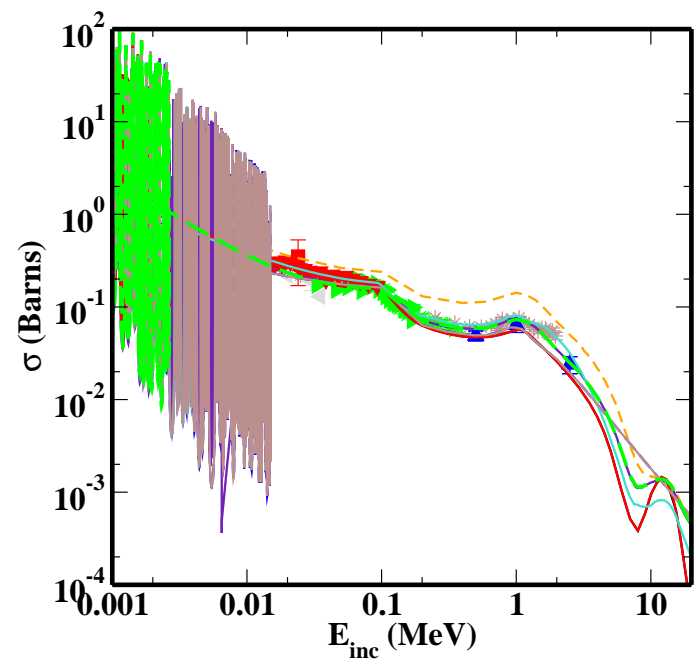

FIG. 19: Experimental cross sections and evaluations for neutron capture in $n+{ }^{184} \mathrm{~W}$ reactions. The orange dashed line is the default talys calculation. The proposed ENDL2009 evaluation is in green.

for ${ }^{180,182-184,186} \mathrm{~W}$, adjusting the parameters to improve the quality of these comparisons. It is necessary to adjust the gamma strength function, $\Gamma_{\gamma}$, by factor of 0.69 to fit the data by fixing $G_{\text {norm }}=2.5$, see Fig. 19. Similarly, we require $G_{\text {norm }}=2$ for ${ }^{182} \mathrm{~W}$ and $G_{\text {norm }}=3$ for ${ }^{186} \mathrm{~W}$. Thus we adopt an $A$-dependent systematic 


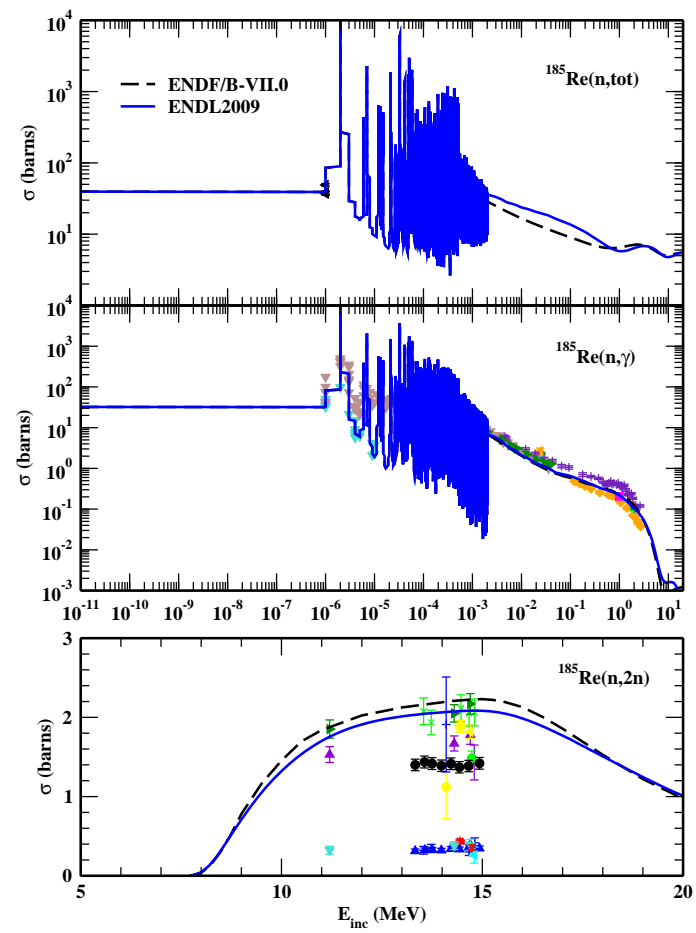

FIG. 20: Measurements and evaluations of the total, neutron capture, and $(n, 2 n)$ cross sections for $n+{ }^{185}$ Re. The solid blue line is the default talys calculation, which we adopt for ENDL2009.

for $G_{\text {norm }}$ with $G_{\text {norm }}=2$ for $178<A<183,2.5$ for $A=184,185$ and 3 for $186<A<188$. Using these scale factors for the photon width near zero energy, we calculate talys cross sections for the unstable tungsten isotopes and adopt them for our new evaluation.

$$
\text { 5. }{ }^{183-189} \operatorname{Re}
$$

Our procedure for the rhenium isotopes is similar to that for the tungsten isotopes since ${ }^{185,187}$ Re are the only stable isotopes of rhenium. While there is very little $(n$, tot) data on any of the isotopes, there are useful $(n, \gamma)$ cross sections for ${ }^{185,187}$ Re. These cross sections are well reproduced by a calculation with the default talys parameters, as shown in Figs. 20 and 21. Thus the default talys parameters are used to produce evaluations of the unstable rhenium isotopes.

$$
\text { 6. }{ }^{202-210} \mathrm{~Pb}
$$

The stable isotopes of lead are ${ }^{204,207-208} \mathrm{~Pb}$. These isotpes were used to obtain fits which could be used as the basis for extrapolation to the unstable isotopes. As detailed previously, we find that the default talys calculation of the $(n, \gamma)$ cross sections needs some tuning to fit the measured stable isotope rates. For example, the

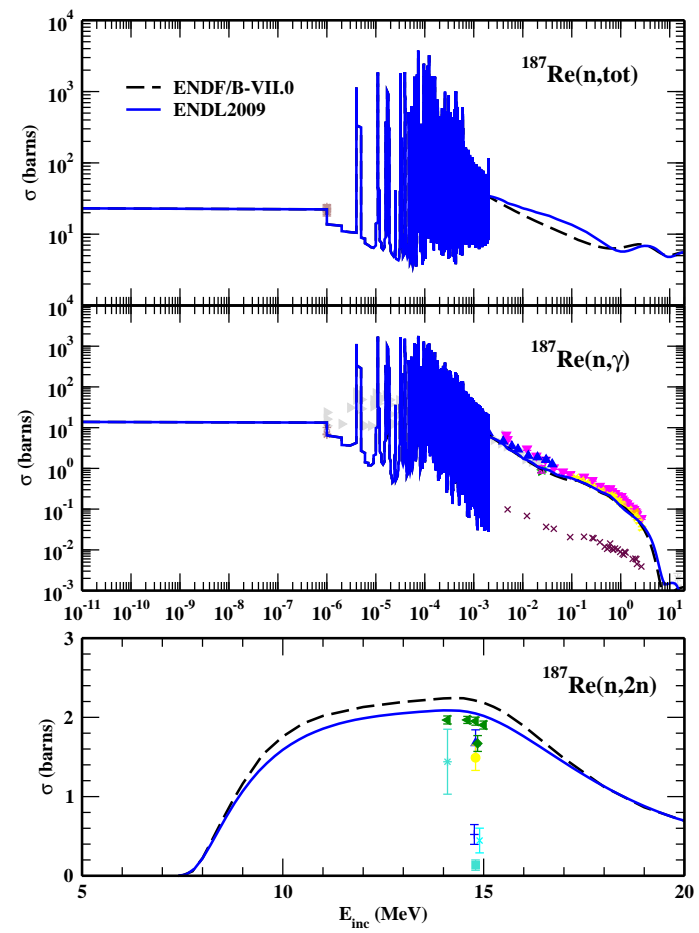

FIG. 21: Measurements and evaluations of the total, neutron capture, and $(n, 2 n)$ cross sections for $n+{ }^{187}$ Re. The solid blue line is the default talys calculation, which we adopt for ENDL2009.

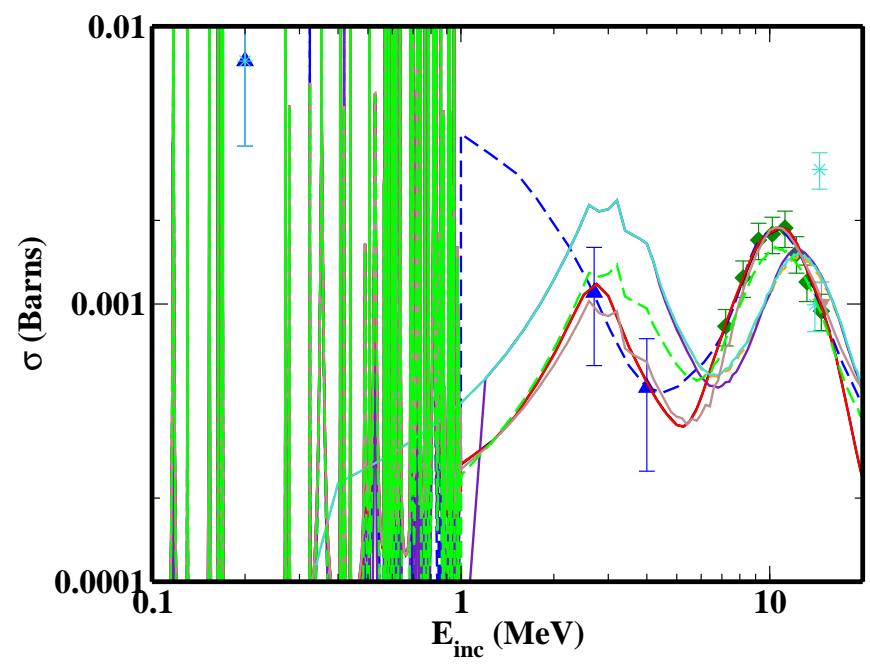

FIG. 22: Measurements and evaluations of the neutron capture cross sections for $n+{ }^{208} \mathrm{~Pb}$. The orange dashed line is the default talys calculation. The proposed ENDL2009 evaluation is in green.

GDR energy was reduced to $12 \mathrm{MeV}$ and $G_{\text {norm }}$ was set to 0.45 for the ${ }^{208} \mathrm{~Pb}(n, \gamma)$ cross section in Fig. 22 .

We have decided that one of the ${ }^{208} \mathrm{~Pb}(n$, tot $)$ measurements is lower than the others for energies below 200 $\mathrm{keV}$. Since it is inconsistent with other measurements, we thus exclude it from our evaluation. We use the tuned 


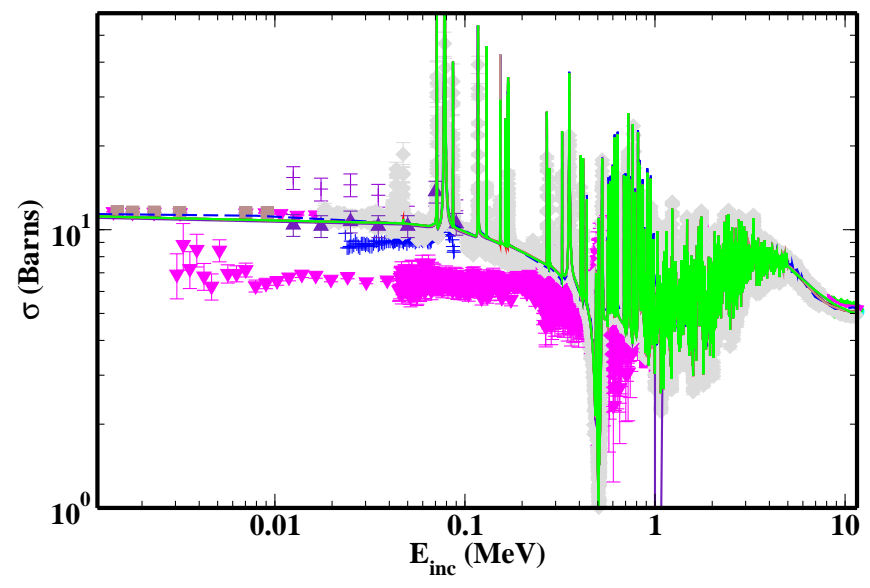

FIG. 23: Experimental data and evaluations for the total cross sections of neutrons incident on ${ }^{208} \mathrm{~Pb}$. The orange dashed line is the default Talys calculation, whereas the proposed ENDL2009 is shown as the green curve.
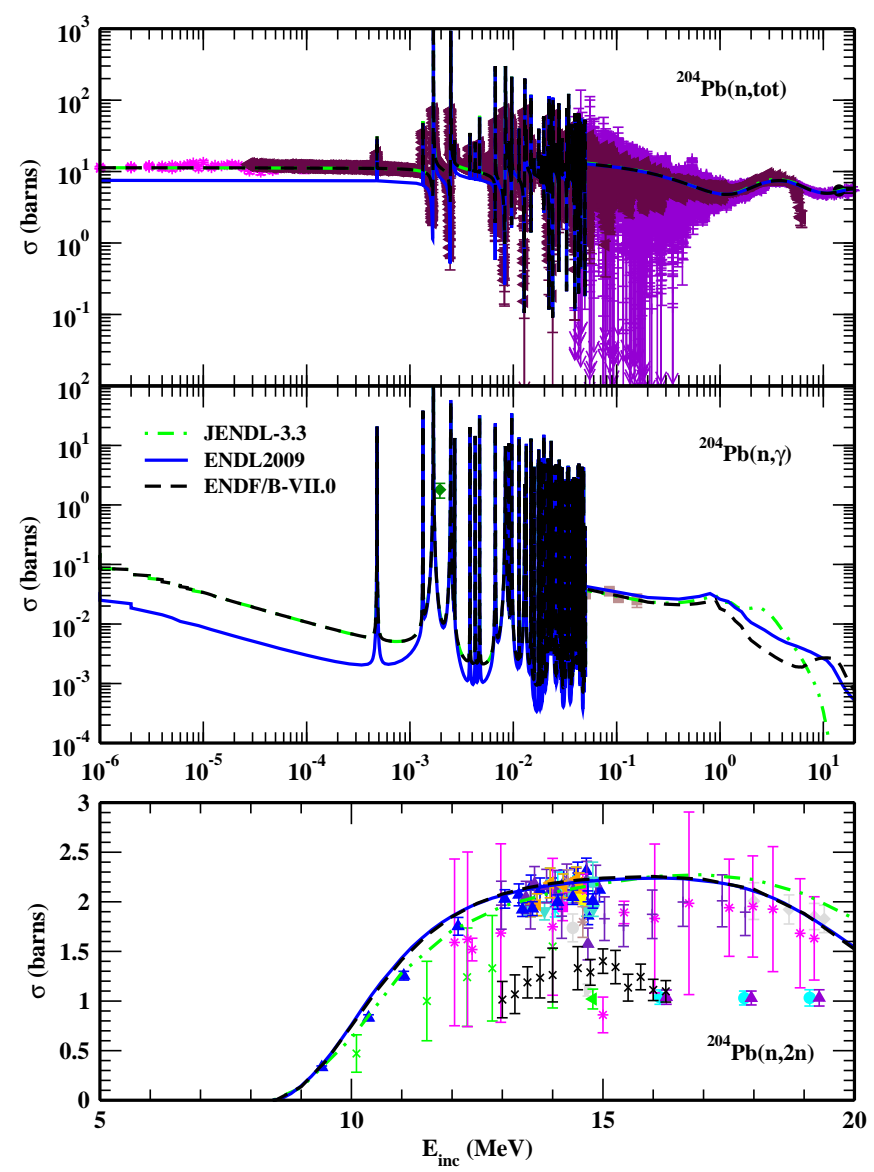

FIG. 24: $n+{ }^{204} \mathrm{~Pb}$. The solid blue is our ENDL2009.0 evaluation, dashed black is ENDF/B-VII.0 and the dot-dashed green line is JENDL-3.3.

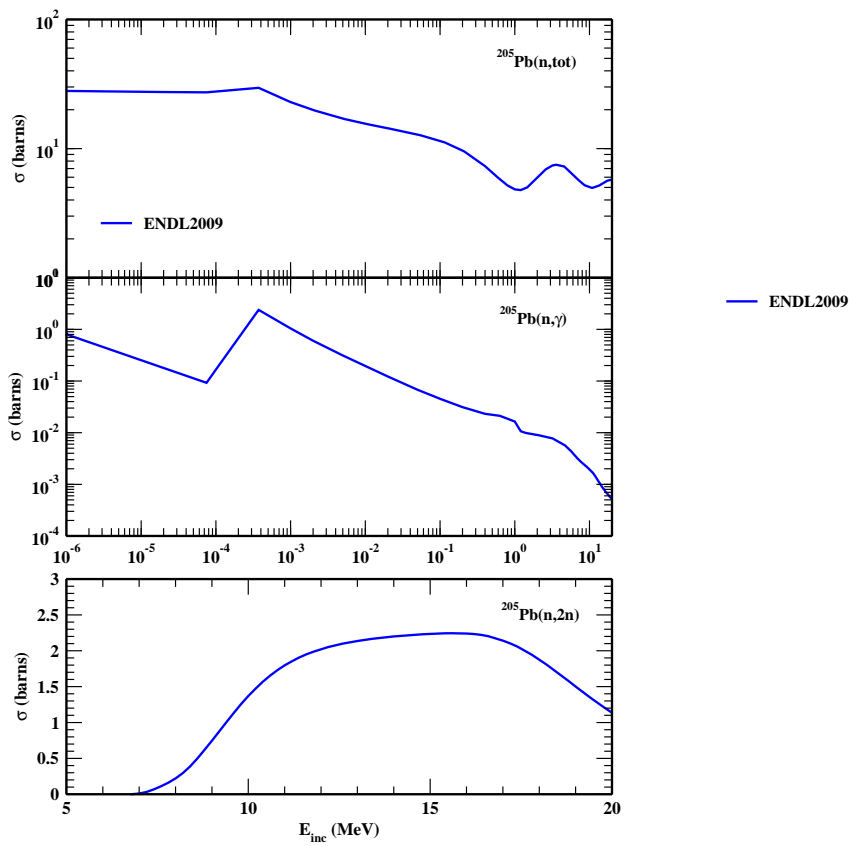

FIG. 25: $n+{ }^{205} \mathrm{~Pb}$. The solid blue is our ENDL2009.0 evaluation, dashed black is ENDF/B-VII.0 and the dot-dashed green line is JENDL-3.3.

values of $G_{\text {norm }}$ to modify the default talys calculations for our evaluations. Note that the ENDF/B.VII.0 evaluations, similar to the TENDL2008 evaluations, have fluctuating cross sections above the formal resonance region. These cross sections were imported from ENDF/B.VII.0 to ENDL2009 above the resonance region, up to $5 \mathrm{MeV}$ for $206<A<208$, and up to $0.85 \mathrm{MeV}$ for $A=204$.

\section{Actinides}

Two new actinide evaluations were generated for ENDL2009: ${ }^{239} \mathrm{U}$ and ${ }^{240} \mathrm{Am}$. They are described in this subsection.

$$
\text { 1. }{ }^{239} \mathrm{U}
$$

Recently Burke et al. measured the ${ }^{239} \mathrm{U}\left({ }^{18} \mathrm{O},{ }^{17} \mathrm{O} f\right)$ cross section to extract the ${ }^{239} \mathrm{U}(n, f)$ cross section using the surrogate technique [BO09]. In support of the Attribution L2 milestone, we folded this measurement into the existing ENDF/B-VII.0 ${ }^{239} \mathrm{U}$ evaluation. Figure 29 shows the surrogate data on ${ }^{239} \mathrm{U}$, the ENDF/B-VII.0 evaluation and the new fit. This work corrected several problems with the previous evaluation. The new evaluation will be submitted for possible inclusion in ENDF/BVII.1.

The ENDF/B-VII.0 ${ }^{239} \mathrm{U}$ evaluation uses GNASH calculations from LANL $\left[\mathrm{YCM}^{+} 07\right]$ for the high energy region and also takes liberally from the ${ }^{237} \mathrm{U}$ evaluation. 

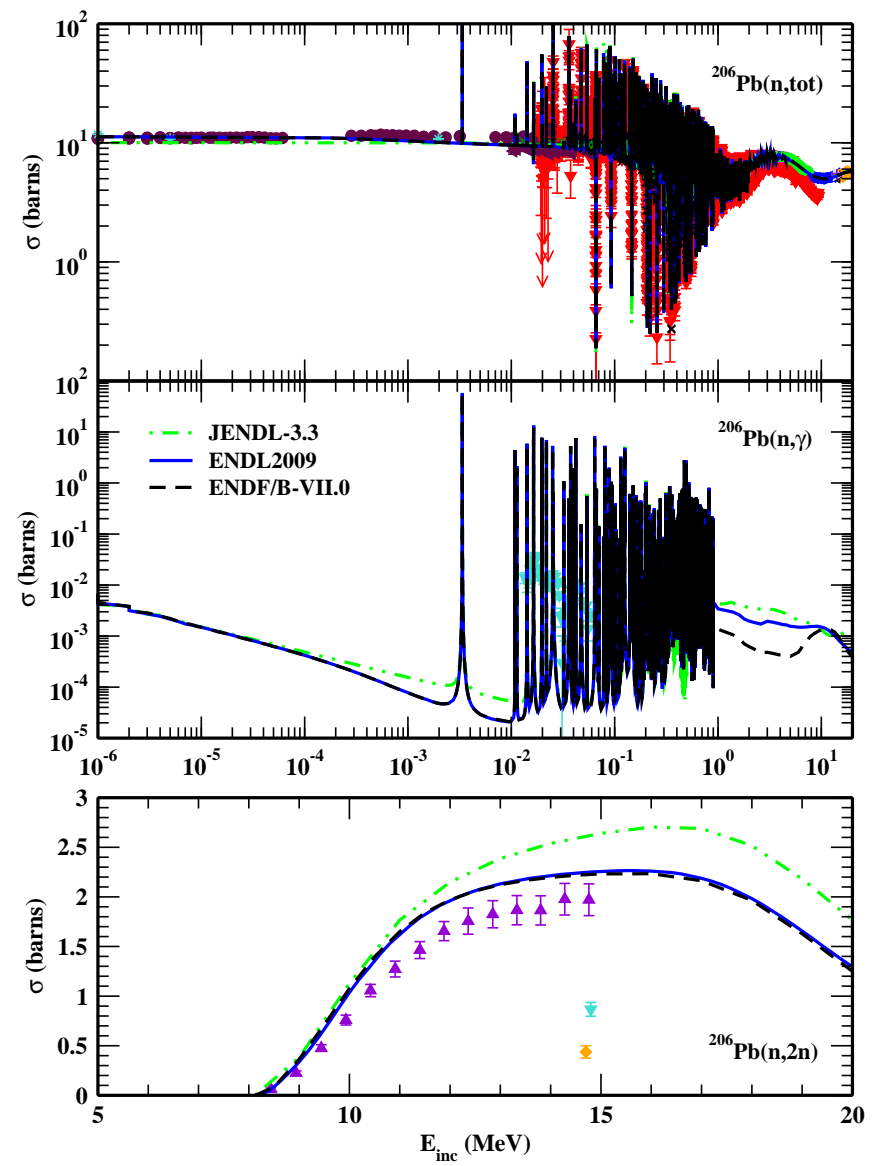

FIG. 26: $n+{ }^{206} \mathrm{~Pb}$. The solid blue is our ENDL2009.0 evaluation, dashed black is ENDF/B-VII.0 and the dot-dashed green line is JENDL-3.3.

In particular, the fission neutron and gamma distributions and the resonance regions were taken directly from the ${ }^{237} \mathrm{U}$ evaluation. The radiative capture width in the resolved and unresolved resonance regions were changed from $34.56 \mathrm{meV}$ to $23 \mathrm{meV}$ to match the ${ }^{237} \mathrm{U}$ evaluation. The fission neutron spectrum is assumed to be Watt shaped while $\bar{\nu}$ is based on the systematics of Manero and Konshin [MK72]. We adopt both the ENDF/B-VII.0 fission spectra and $\bar{\nu}$ for our evaluation.

We incorporate the Burke et al. and Younes and Britt data sets into a new estimate of the ${ }^{239} \mathrm{U}(n, f)$ cross section. Combining GNASH calculations with measurements of $(\mathrm{t}, p f)$ and $\left({ }^{3} \mathrm{He}, X f\right)$, Younes and Britt modeled the ${ }^{239} \mathrm{U}$ fission probabilities and extracted the ${ }^{235,237,239} \mathrm{U}(n, f)$ cross sections [YB05] but did not estimate the uncertainty. Figure 11 of Ref. [YB05] shows how the linear extrapolation of $1^{\text {st }}$ chance fission underpins the $2^{\text {nd }}$ and $3^{\text {rd }}$ chance fission. This extrapolation is used to obtain an estimate of the fission cross section uncertainty. First chance fission is expected to have an uncertainty of less than 10\% [YB05]. The uncertainty in second chance fission due to the linear extrapolation is less than $20 \%$ while the uncertainty for third chance fis-
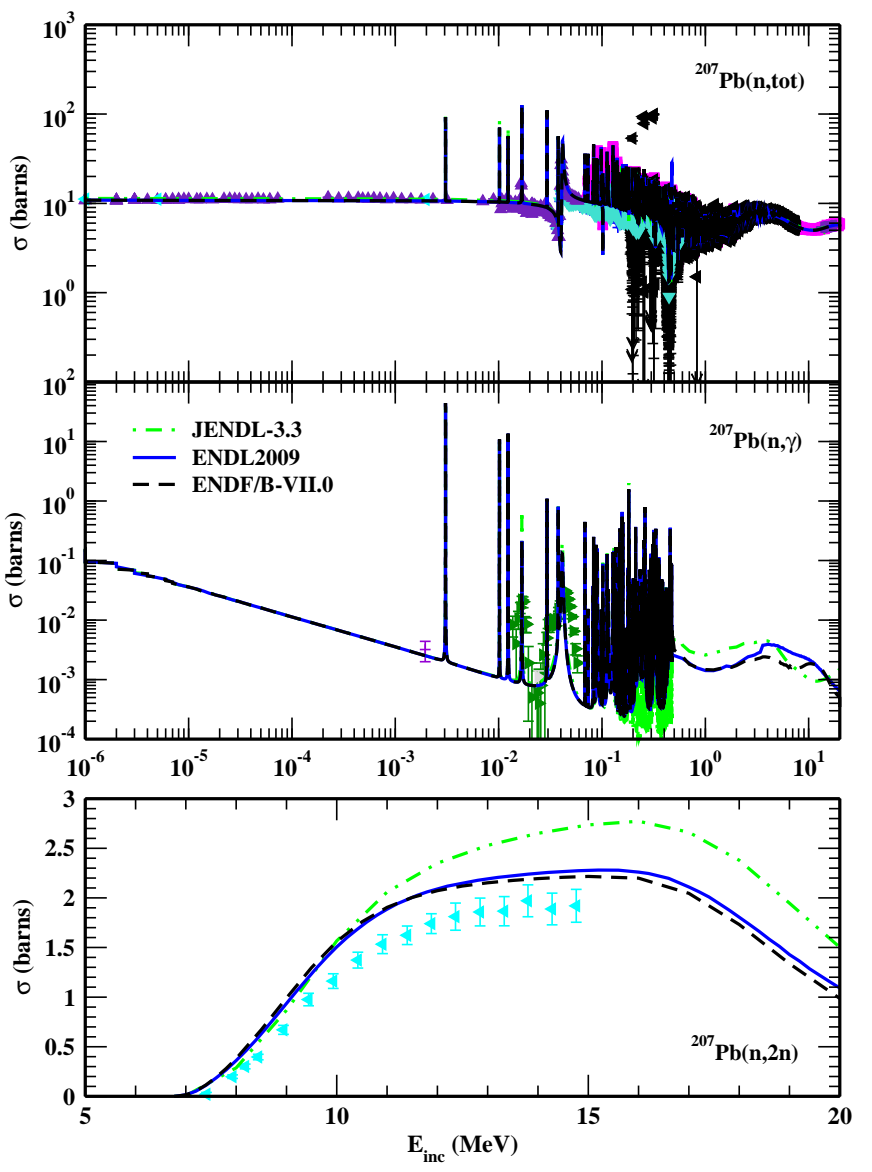

FIG. 27: $n+{ }^{207} \mathrm{~Pb}$. The solid blue is our ENDL2009.0 evaluation, dashed black is ENDF/B-VII.0 and the dot-dashed green line is JENDL-3.3.

\begin{tabular}{ccc}
\hline \hline Energy range $(\mathrm{MeV})$ & Chance & Uncertainty \\
\hline $0-5.2$ & $1^{\text {st }}$ & $10 \%$ \\
$5.2-10.2$ & $2^{\text {nd }}$ & $20 \%$ \\
$10.2-20$ & $3^{\text {rd }}$ & $25 \%$ \\
\hline \hline
\end{tabular}

TABLE VII: Estimates of the ${ }^{239} \mathrm{U}$ multichance fission cross section uncertainties [YB05].

sion is much smaller than that of second chance fission. These estimates, summarized in Table VII, are used to make a least-squares fit to Burke et al. data [BO09] as well as the Younes and Britt evaluation.

The other ENDF/B-VII.0 neutron-induced ${ }^{239} \mathrm{U}$ cross sections need to be corrected for the improved fission cross section developed here. Working in the WeisskopfEwing limit and assuming that the compound elastic contribution is negligible, the high energy cross sections can be corrected by a simple rescaling:

$$
\sigma_{\text {old }(n, X)}=\frac{\sigma_{\text {reac }}-\sigma_{\text {new }(n, f)}}{\sigma_{\text {reac }}-\sigma_{\text {old }(n, f)}} .
$$

The results are shown in Fig. 30. 

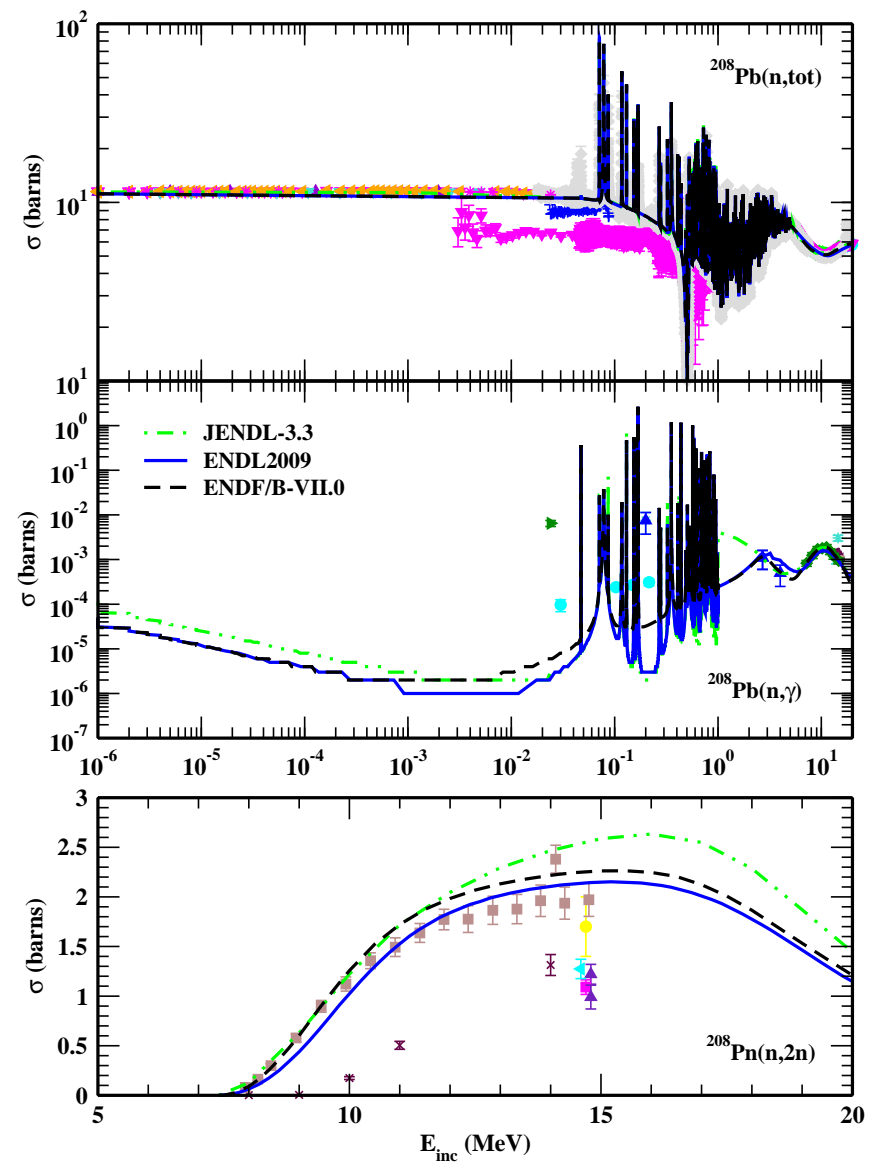

FIG. 28: $n+{ }^{208} \mathrm{~Pb}$. The solid blue is our ENDL2009.0 evaluation, dashed black is ENDF/B-VII.0 and the dot-dashed green line is JENDL-3.3.

\begin{tabular}{|c|c|c|c|}
\hline Channel & Resonance (b) & Thermal (b) & Mughabghab (b) \\
\hline$(n, \mathrm{el})$ & 199.9 & 21.32 & - \\
\hline$(n, \gamma)$ & 50.5 & 22.16 & $22 \pm 5$ \\
\hline$(n, f)$ & 19.0 & 13.97 & $14 \pm 3$ \\
\hline
\end{tabular}

TABLE VIII: Comparison of the resonance integral and thermal cross section from our evaluation and Mughabghab's evaluation [Mug06].

The previous ${ }^{239} \mathrm{U}$ resonance regions required several fixes since they were copied from the ${ }^{237} \mathrm{U}$ resonances. In particular, the resolved resonances were in the form of a "picket fence": a set of fake resonances with constant energy spacings and widths. The unresolved resonances were based on the average parameters used in the "picket fence". Since the resonance $J^{\Pi}$ was set to the ${ }^{237} \mathrm{U}$ ground state value of $1 / 2^{+}$, changing the $J^{\Pi}$ assignment to $5 / 2^{+}$for ${ }^{239} \mathrm{U}$ broke the matching onto the high energy $(n, f)$ cross section. Thus we replaced the current resonance regions with a single unresolved resonance region with parameters tuned to match the Mughabghab high energy and thermal cross sections [Mug06], see Table VIII.

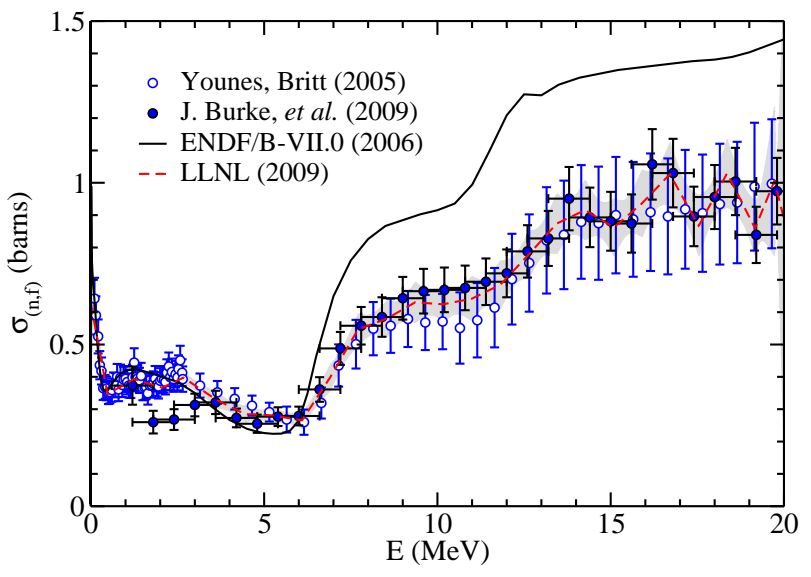

FIG. 29: The ${ }^{239} \mathrm{U}(n, f)$ cross section extracted by Burke et al. [BO09] and Younes and Britt [YB05]. We fit these two data sets (red dashed curve). The ENDF/B-VII.0 cross section (solid black curve) does not agree with either data set.

$$
\text { 2. }{ }^{240} \mathrm{Am}
$$

We rebuilt this evaluation using our new evaluation methodology: talys in "default mode". The resonance region, fission neutron spectrum and $\bar{\nu}$ were taken directly from the ENDF/B-VII.0 ${ }^{242} \mathrm{Am}$ evaluation. The fission cross section was taken from Younes et al. [YBB04] and the competing cross sections were rescaled according to Eq. (9). Since there is no data, we present no illustrations. This evaluation has been submitted for inclusion in ENDF/B-VII.1.

\section{CHARGE-PARTICLE INCIDENT REACTION DATA}

The charged particle sublibraries are undergoing extensive revisions in FY09-FY10 in support of the National Ignition Facility (NIF) as well as the stockpile program. Figure 32 summarizes the work performed to date, detailed in this section.

\section{A. Inverse kinematics}

A limited functionality to boost data for a particular target into the projectile rest frame has been added to the Computation Nuclear Physics group's FUDGE package (toZAsFrame in the module endlZA). The conversion works only for targets with cross section $(I=0)$, multiplicity ( $I=9)$, two-body angular data $(I=1)$ and energyangle data given as Legendre moments $(\mathrm{I}=4)$ with $\ell=0$ data. Furthermore, the target must correspond to a valid ENDL projectile. 
U-239(n,2n)
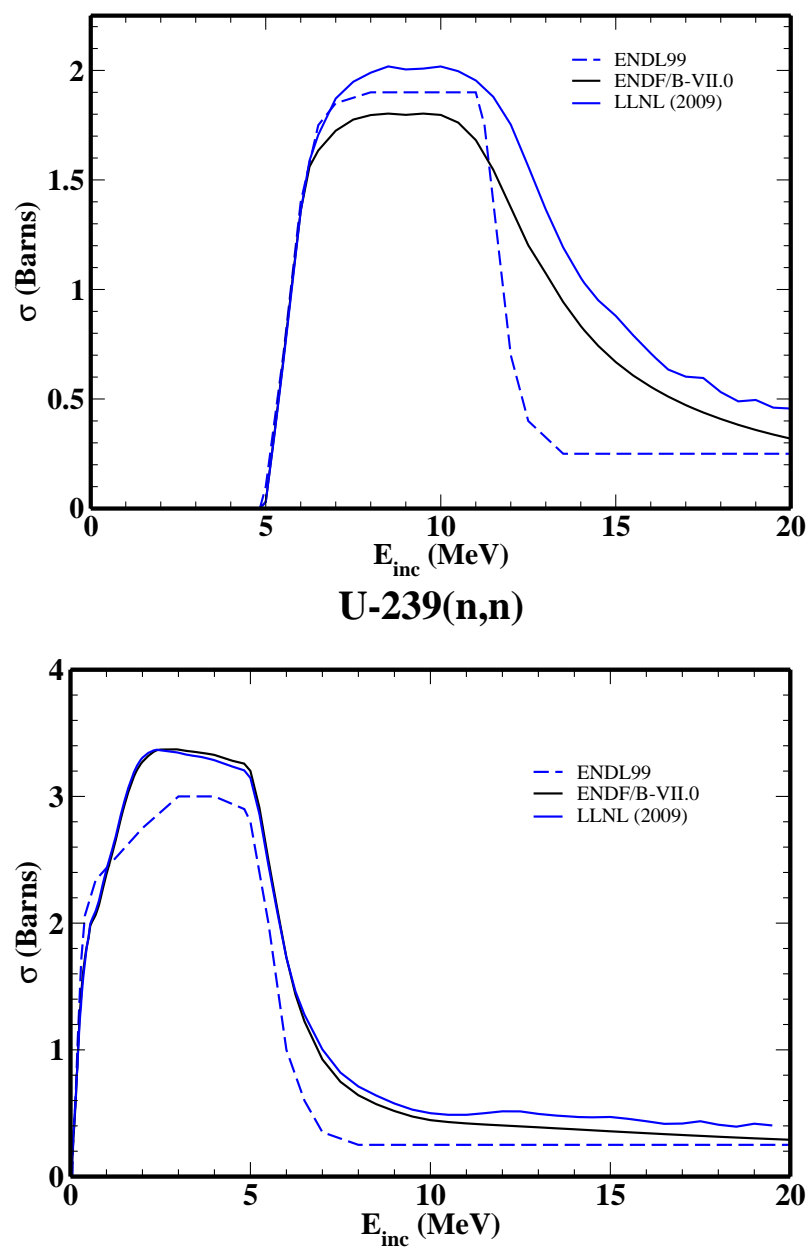

$\mathrm{U}-239(n, 3 n)$

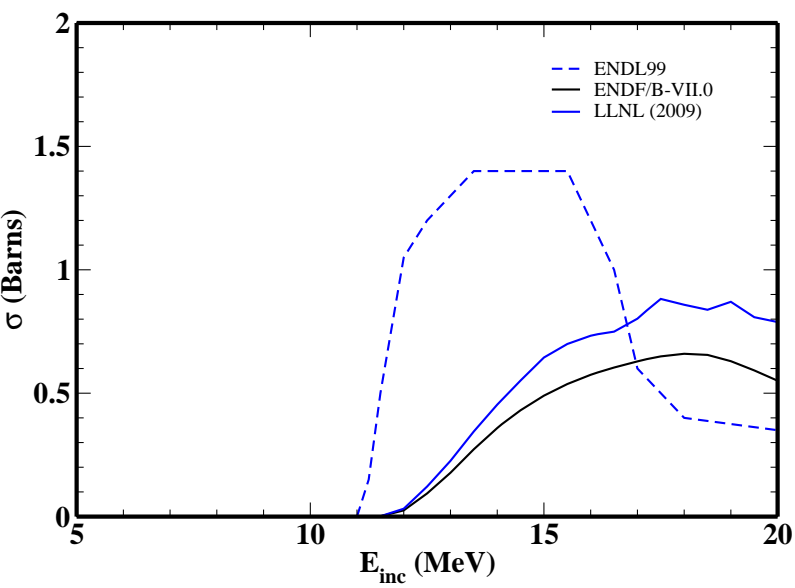

$\mathrm{U}-239(\mathbf{n}, \mathrm{g})$

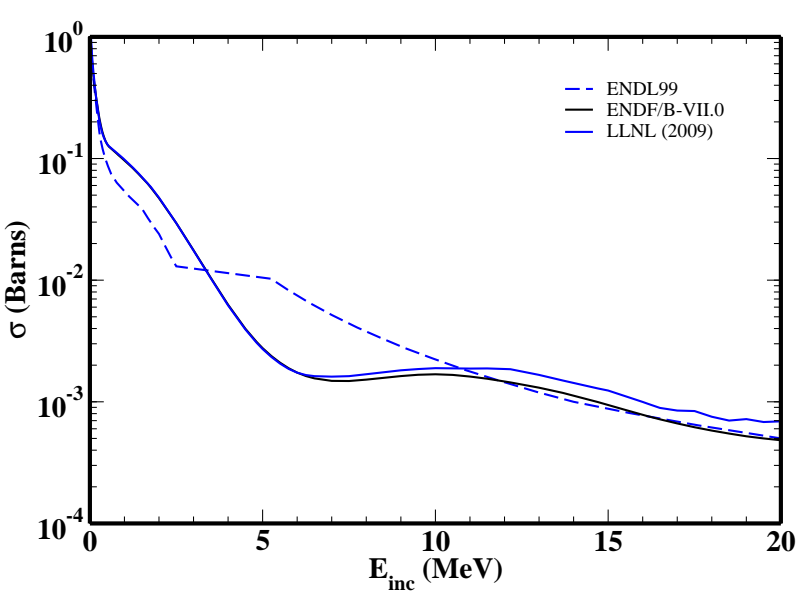

FIG. 30: The high energy ${ }^{239} \mathrm{U}$ cross sections after correcting for the improved fission cross section. The lower left plot, "U-239(n,n)", shows the sum over all the $\left(n, n^{\prime}\right)$ discrete level cross sections.

\section{B. $p+\mathbf{t}$}

A recent effort was made to cull the world's available data on the $\mathrm{t}(p, \gamma) \alpha$ reaction cross section since the $\gamma$ emitted in this reaction is a promising ignition diagnostic for NIF experiments. Figure 33 shows the data $\left[\mathrm{C}^{+} 02\right.$, MWRT82, PJBJ55, $\mathrm{C}^{+} 83$, HBK95] that was used in the new evaluation for this ENDL release.

\section{C. $d+d$}

A new ENDL2009 evaluation of $d+d$ reactions was completed by P. Navratil, D. A. Brown and C. Hagmann.

The $\mathrm{d}+\mathrm{d} \rightarrow n+{ }^{3} \mathrm{He}$ reaction cross section was newly evaluated $(\mathrm{C}=11)$. We adopted a recent $S$-factor $R$ matrix fit by Descouvemont et al. [DAA $\left.{ }^{+} 04\right]$ for energies up to $1.96 \mathrm{MeV}$. The Evaluated Charged Particle Library (ECPL) evaluation [WRW91] was adapted for energies above $5 \mathrm{MeV}$. Between 1.96 and $5 \mathrm{MeV}$, we performed a spline fit to match the two evaluations as well as some of the data from Ref. [SCOW72]. The resulting $S$ factor is shown in Fig. 34. At $E=0$, $S=52.4 \pm 3.5 \mathrm{keV}$ b $\left[\mathrm{DAA}^{+} 04\right]$. The new evaluated cross section is compared to the data and some earlier evaluations in Fig. 35. The angular distributions were taken from ECPL [WRW91].

Likewise, the $\mathrm{d}+\mathrm{d} \rightarrow p+\mathrm{t}$ cross section was also evaluated $(\mathrm{C}=40)$. The methodology is the same as the $\mathrm{d}+\mathrm{d} \rightarrow n+{ }^{3}$ He evaluation. In this case, the $S$ factor, shown in Fig. 36, takes the value $57.1 \pm 0.8 \mathrm{keV}$ b at $E=0\left[\mathrm{DAA}^{+} 04\right]$. The evaluated cross section is shown in Fig. 37.

The small mass difference between the proton and neutron and between the $\mathrm{t}$ and ${ }^{3} \mathrm{He}$ were ignored in generating the ECPL angular distributions. Thus, the proton angular distribution $(\mathrm{C}=40)$ in the $\mathrm{d}+\mathrm{d} \rightarrow p+\mathrm{t}$ reaction is the same as the neutron angular distribution in the $\mathrm{d}+\mathrm{d} \rightarrow n+{ }^{3} \mathrm{He}(\mathrm{C}=11)$ reaction. Likewise the ${ }^{3} \mathrm{He}$ distribution in the $\mathrm{C}=11$ file is the same as the $\mathrm{t}$ 
U-239(n,tot)

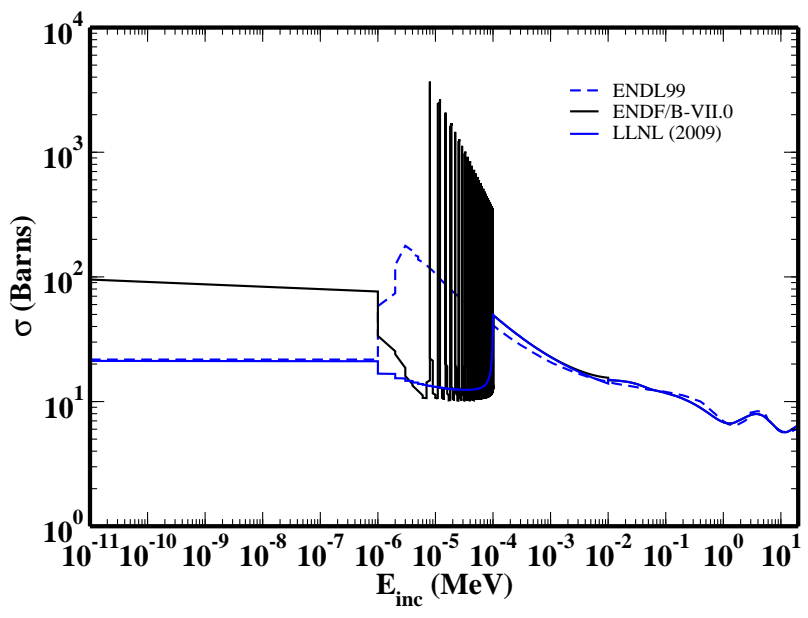

U-239(n,f)

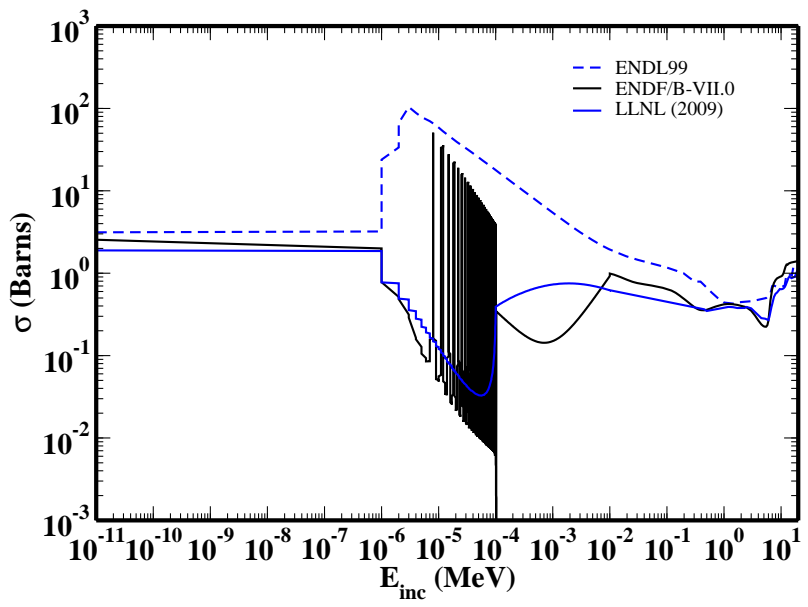

U-239(n,el)

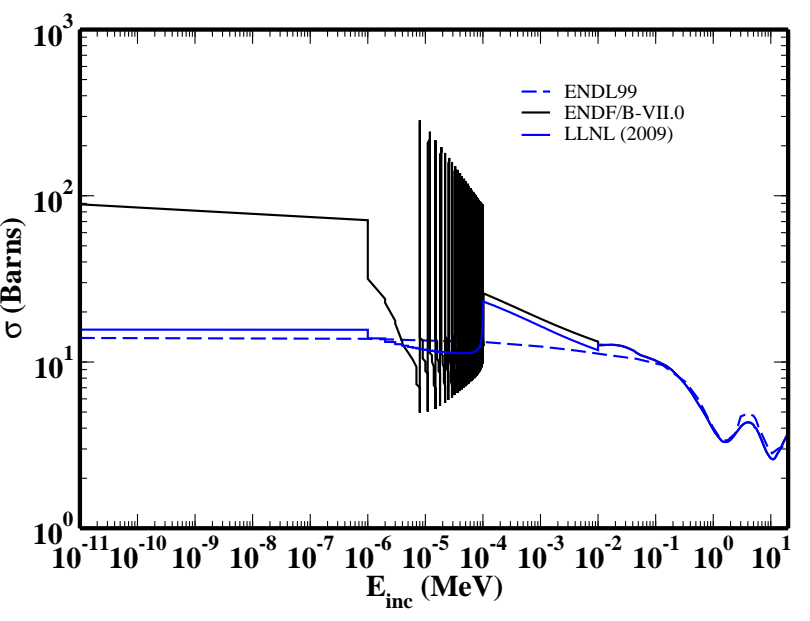

U-239(n,g)

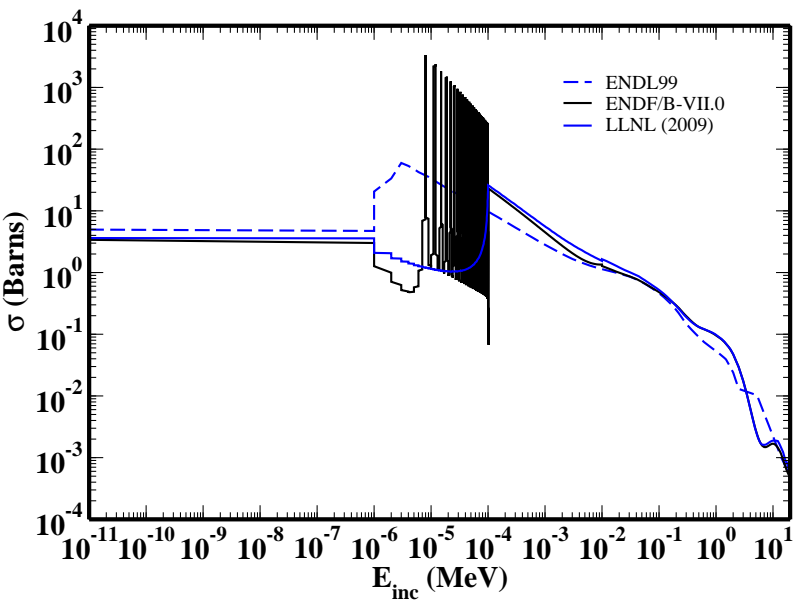

FIG. 31: Original and corrected resonance regions for ${ }^{239} \mathrm{U}$.

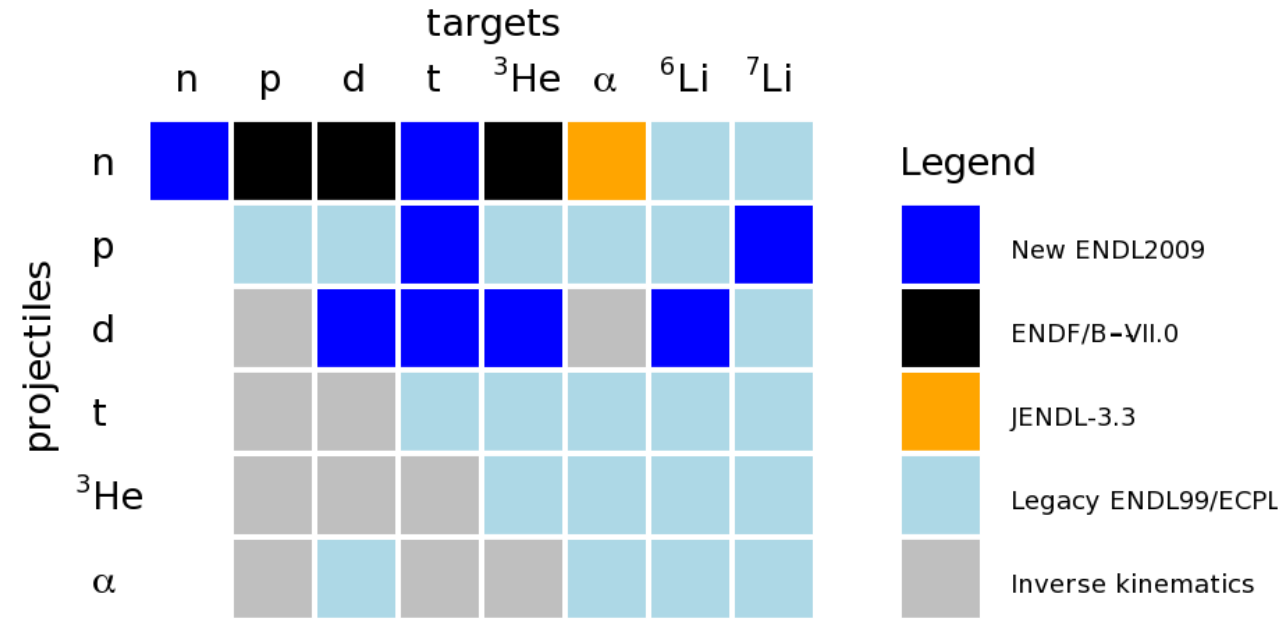

FIG. 32: Summary of thermonuclear reaction sources in ENDL2009. 


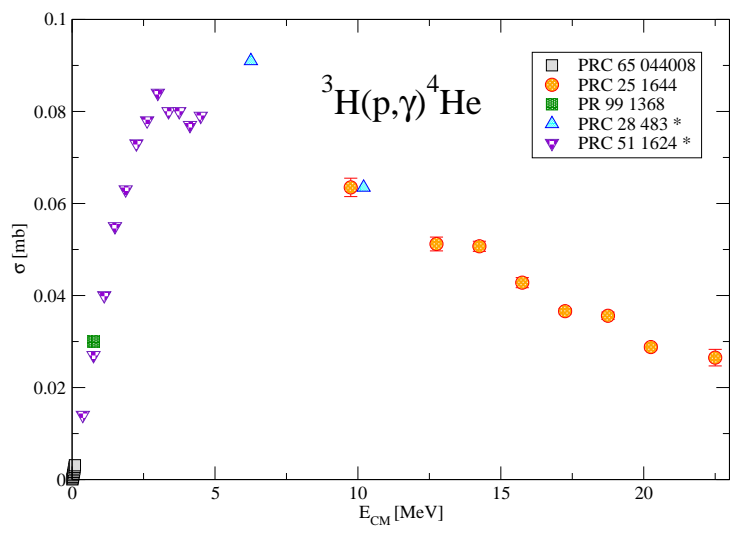

FIG. 33: Cross section measurements of $\mathrm{t}(p, \gamma) \alpha$.

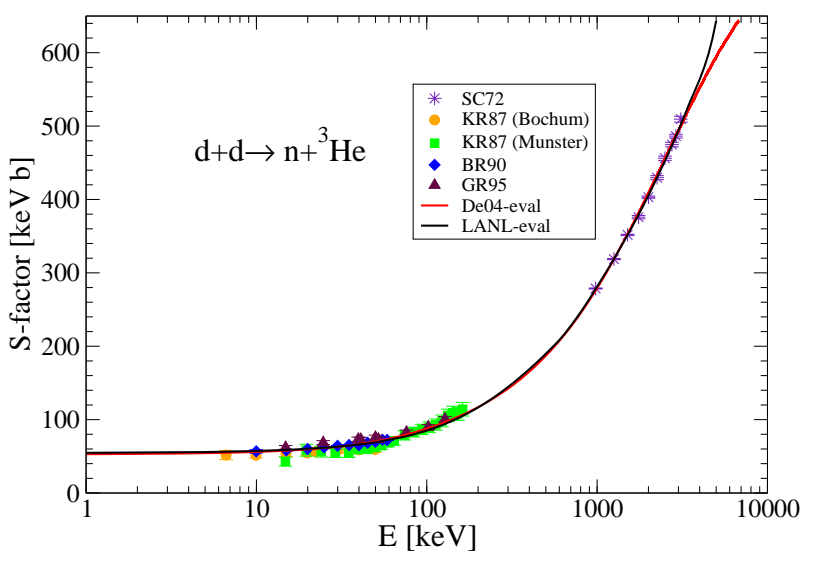

FIG. 34: The $S$-factor for the $\mathrm{d}(\mathrm{d}, n)^{3} \mathrm{He}$ reaction.

distribution in the $\mathrm{C}=40$ file.

The Large Angle Coulomb scattering (LACS) data $(\mathrm{C}=8)$ were calculated based on Ref [PC81b].

The elastic scattering cross section, including Coulomb interference $(\mathrm{C}=9)$ was taken from ECPL [WRW91].

\section{D. $\mathbf{d}+\mathbf{t}$}

A new ENDL2009 evaluation of $d+t$ reactions was completed by P. Navratil, D. A. Brown, C. Hagmann, G. H. Hale (LANL), and M. Drosg (U. Vienna).

The $\mathrm{d}+\mathrm{t} \rightarrow n+{ }^{4}$ He reaction cross section was evaluated $(\mathrm{C}=11)$. We adopted the $S$-factor $R$-matrix fit by Descouvemont et al. $\left[\mathrm{DAA}^{+} 04\right]$ and matched it to the higher energies of the ECPL [WRW91] data using a spline fit. The latest data are reproduced very well, see Figs. 38 and 39. The recommended cross section has a peak of $4.85 \mathrm{~b}$ at $105 \mathrm{keV}$, consistent with the TUNL evaluation (peak cross section of $4.88 \mathrm{~b}$ at $105 \mathrm{keV}$. The ENDL2008 evaluation has a maximum of $4.99 \mathrm{~b}$ at $107 \mathrm{keV}$ while

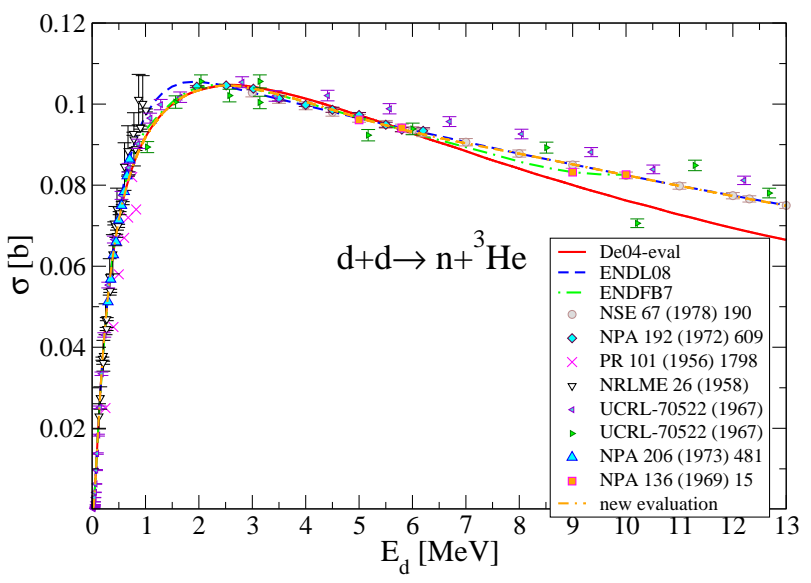

FIG. 35: The $\mathrm{d}(\mathrm{d}, n)^{3}$ He reaction cross section.

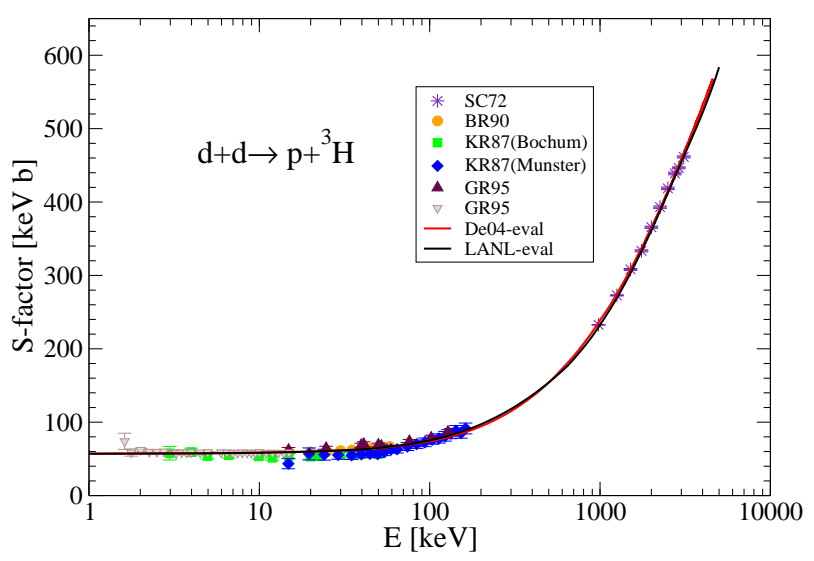

FIG. 36: The $S$ factor for the $\mathrm{d}(\mathrm{d}, p)^{3}$ He reaction.

the ENDF value is $5.01 \mathrm{~b}$ at $108 \mathrm{keV}$, see Fig. 40. At $E=0, S=11.7 \pm 0.2 \mathrm{keV}$ b $\left[\mathrm{DAA}^{+} 04\right]$. The angular distributions were taken from ECPL [WRW91].

We also evaluated the $\mathrm{d}+\mathrm{t} \rightarrow \gamma^{5} \mathrm{He}^{*} \rightarrow \gamma+n+{ }^{4} \mathrm{He}$ reaction cross section $(\mathrm{C}=30)$. Our $\mathrm{t}(\mathrm{d}, \gamma)$ evaluation is based on Ref. $\left[\mathrm{KHS}^{+} 93\right]$, which reviews the experimental situation. Several experiments agree that the ratio of the $\mathrm{t}(\mathrm{d}, \gamma)$ and $\mathrm{t}(\mathrm{d}, n)$ cross sections is constant at resonance. At higher energies, the ratio appears to rise. This was observed for deuteron energies up to $9 \mathrm{MeV}$ Ref. $\left[\mathrm{KHS}^{+}\right.$93]. Therefore, below $0.4 \mathrm{MeV}$, we assigned the value $1.2 \times 10^{-4}\left[\mathrm{KHS}^{+} 93\right]$ to the ratio. From 0.4 to $9 \mathrm{MeV}$ linearly increases to $7 \times 10^{-4}\left[\mathrm{KHS}^{+} 93\right]$. At higher energies, there is no information. Therefore, we used the value of the ratio at $9 \mathrm{MeV}$ at higher energies. Our evauated cross section is shown in Fig. 41.

We note that the EXFOR files for the Ref. [CW84] data appear to be incorrect. The previous ENDL evaluation was also unrealistic.

The angular distributions are taken from ECPL [WRW91].

The $\mathrm{d}+\mathrm{t} \rightarrow n+{ }^{4} \mathrm{He}^{*} \rightarrow n+p+\mathrm{t}$ evaluation $(\mathrm{C}=20)$ was taken from the ENDF/B-VII.0 evaluation. This eval- 


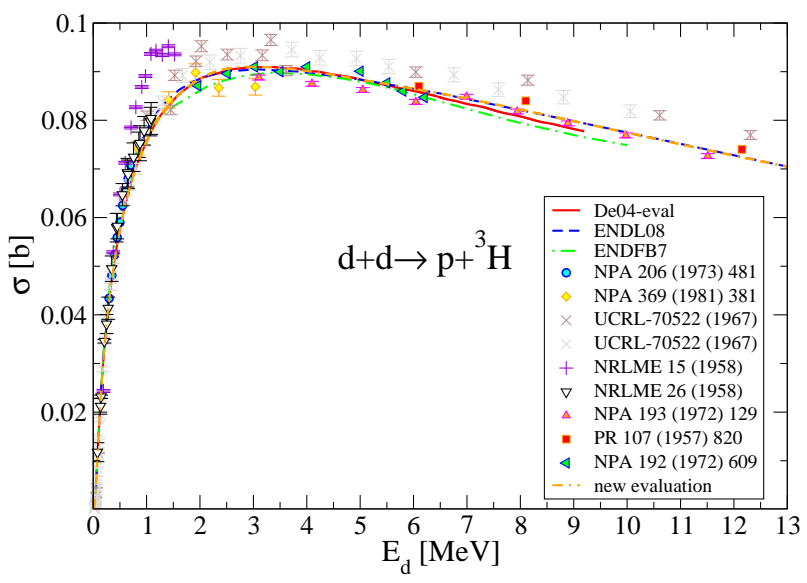

FIG. 37: The $\mathrm{d}(\mathrm{d}, p)^{3} \mathrm{H}$ reaction cross section.

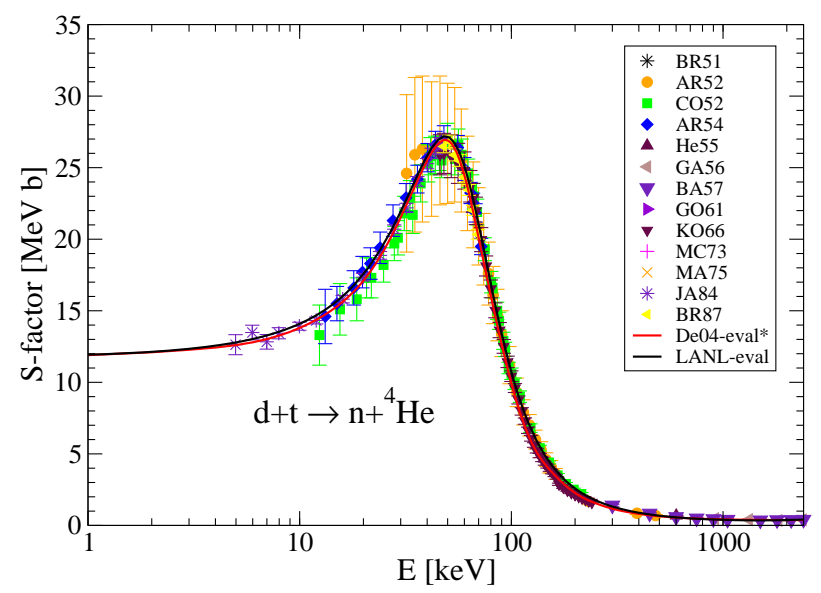

FIG. 38: The $S$ factor for the $\mathrm{t}(\mathrm{d}, n)^{4} \mathrm{He}$ reaction.

uation contains integrated cross sections and angular distributions for reactions initiated by deuterons with energies up to $10 \mathrm{MeV}$. The energy range of the $\mathrm{t}(\mathrm{d}, n)^{4} \mathrm{He}$ reaction has been extended to $30 \mathrm{MeV}$ by matching to the Legendre coefficients obtained by Drosg. The information below $10 \mathrm{MeV}$ comes primarily from the parameters obtained from an extensive multi-channel $R$-matrix analysis of reactions in the ${ }^{5} \mathrm{He}$ system, including $n+\alpha$ elastic scattering, for deuteron energies up to $10 \mathrm{MeV}$, corresponding to neutron energies of up to $29 \mathrm{MeV}$. They found $\chi^{2} /$ dof $=1.6$.

The cross section data included 11 points, including a measurement of the zero-degree excitation function and an angular distribution at one energy, by Poppe [PHB63].

Angular distributions were obtained from two-body Legendre coefficients up to $L=2$ (ENDF format $\mathrm{LAW}=2$ ) for energies up to $10 \mathrm{MeV}$. The residual ${ }^{4} \mathrm{He}^{*} \rightarrow$ $p+\mathrm{t}$ decay is approximated by a phase-space representation (ENDF format LAW $=6$ ).

The $\mathrm{d}+\mathrm{t} \rightarrow n+n+{ }^{3} \mathrm{He}$ cross section $(\mathrm{C}=12)$. The TUNL evaluation provides no reference. This process must have a small cross section at low energies since the

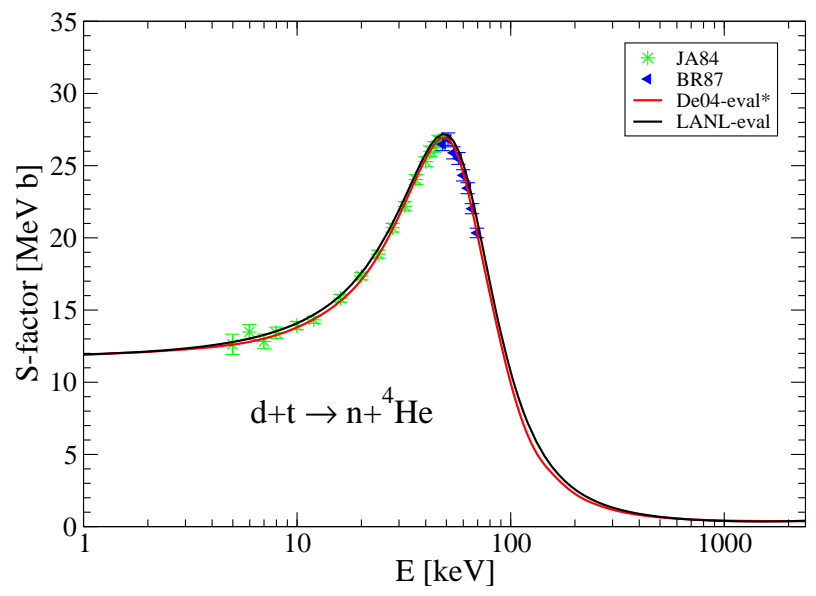

FIG. 39: The $S$ factor for the $\mathrm{t}(\mathrm{d}, n)^{4}$ He reaction.

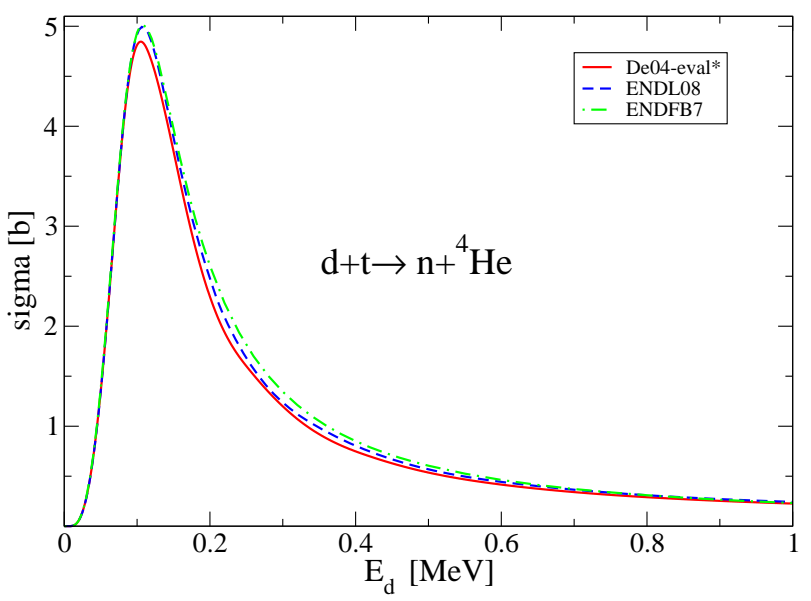

FIG. 40: The $\mathrm{t}(\mathrm{d}, n)^{4}$ He reaction cross section.

deuteron must first break up and then form ${ }^{4} \mathrm{He}$, followed by breakup into $n+{ }^{3} \mathrm{He}$.

The Large Angle Coulomb scattering (LACS) data ( $\mathrm{C}=8$ ) were calculated based on Ref [PC81b].

The elastic scattering cross section, including Coulomb interference $(\mathrm{C}=9)$ was taken from ECPL [WRW91].

Finally, we note that the slight mass difference between the proton and neutron as well as between $\mathrm{t}$ and ${ }^{3} \mathrm{He}$ were ignored in the creation of the ECPL angular distributions. Thus, the neutron angular distribution $(\mathrm{C}=11)$ in the $\mathrm{d}+\mathrm{t} \rightarrow n+{ }^{4} \mathrm{He}$ reaction is the same as the proton angular distribution in the $\mathrm{d}+{ }^{3} \mathrm{He} \rightarrow p+{ }^{4}$ He reaction $(\mathrm{C}=40)$. Likewise the $\mathrm{t}$ distribution in the $\mathrm{C}=40$ file is the same as the ${ }^{3} \mathrm{He}$ distribution in the $\mathrm{C}=11$ file.

$$
\text { E. } \mathbf{d}+{ }^{3} \mathrm{He}
$$

The ENDL2009 $d+{ }^{3}$ He evaluation was performed by P. Navratil, D. A. Brown and C. Hagmann.

The $\mathrm{d}+{ }^{3} \mathrm{He} \rightarrow p+{ }^{4} \mathrm{He}$ reaction cross section $(\mathrm{C}=40)$ was evaluated. We adopted the $S$-factor $R$-matrix fit by 


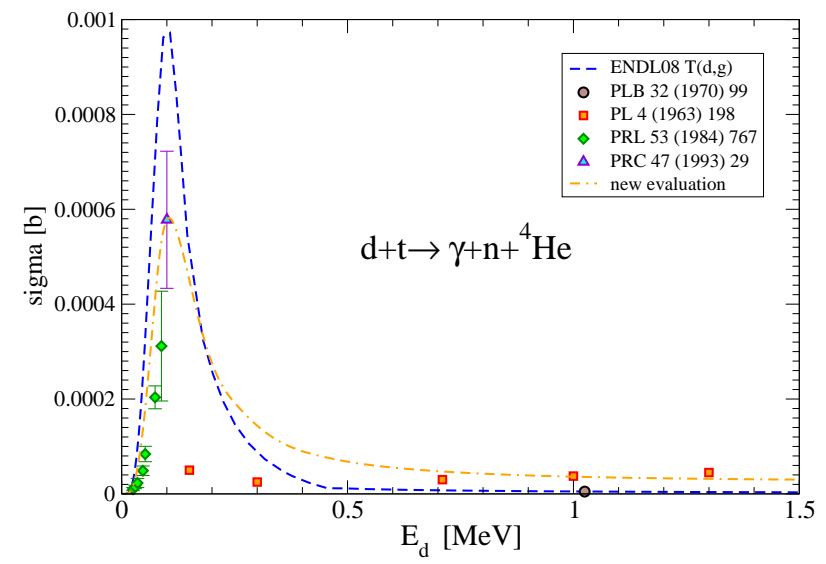

FIG. 41: The $\mathrm{t}(\mathrm{d}, \gamma)^{5}$ He reaction cross section.

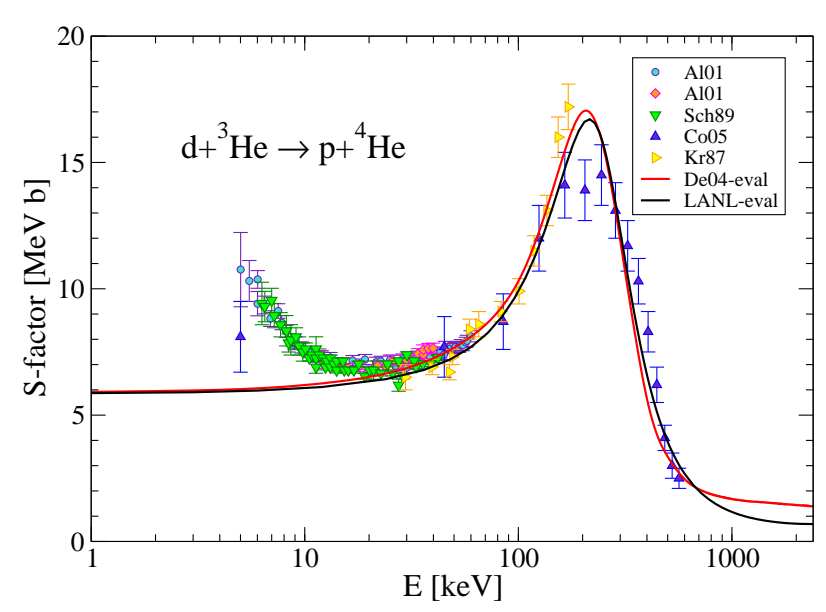

FIG. 42: The $S$ factor for the ${ }^{3} \mathrm{He}(\mathrm{d}, p){ }^{4} \mathrm{He}$ reaction.

Descouvemont et al. [DAA $\left.{ }^{+} 04\right]$, matched to the higher energies in the ECPL [WRW91] using a spline fit. See Figs. 42 and 43 respectively for the $S$ factor and cross section. Strong electron screening impacts the measured cross section at low energy, as seen in the deviation of the measured data from the evaluated $S$ factor for energies less than $30 \mathrm{keV}$, Fig. 42). At $E=0$, the evaluated $S$ factor is $S=5.9 \pm 0.3 \mathrm{MeV}$ b $\left[\mathrm{DAA}^{+} 04\right]$. The angular distributions were taken from ECPL [WRW91].

The Large Angle Coulomb scattering (LACS) data were computed based on Ref. [PC81b] $(\mathrm{C}=8)$.

The elastic scattering cross section, including the Coulomb interference $(\mathrm{C}=9)$, was taken from ECPL [WRW91].

Again, neglecting the proton and neutron mass difference as well as the $\mathrm{t}$ and ${ }^{3} \mathrm{He}$ mass difference, the proton distribution in the $\mathrm{C}=40$ for the reaction $\mathrm{d}+{ }^{3} \mathrm{He} \rightarrow$ $p+{ }^{4} \mathrm{He}$ is the same as that of the neutron in the $\mathrm{C}=11$ file for $\mathrm{d}+\mathrm{t} \rightarrow n+{ }^{4} \mathrm{He}$. Similarly, the ${ }^{3} \mathrm{He} \mathrm{C}=11$ file for $\mathrm{d}+{ }^{3} \mathrm{He} \rightarrow p+{ }^{4} \mathrm{He}$ is the same as the $\mathrm{t}$ dsitribution in $\mathrm{d}+\mathrm{t} \rightarrow n+{ }^{4} \mathrm{He}(\mathrm{C}=40)$.

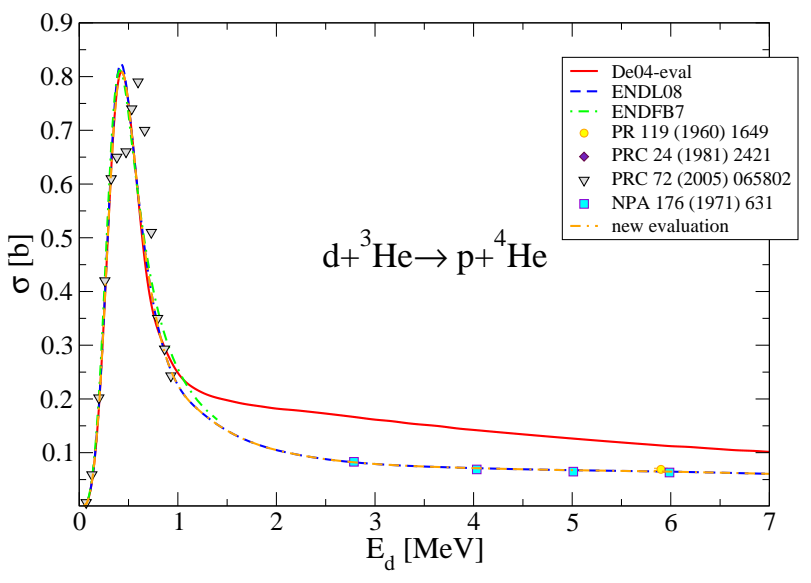

FIG. 43: The ${ }^{3} \mathrm{He}(\mathrm{d}, p){ }^{4} \mathrm{He}$ reaction cross section.

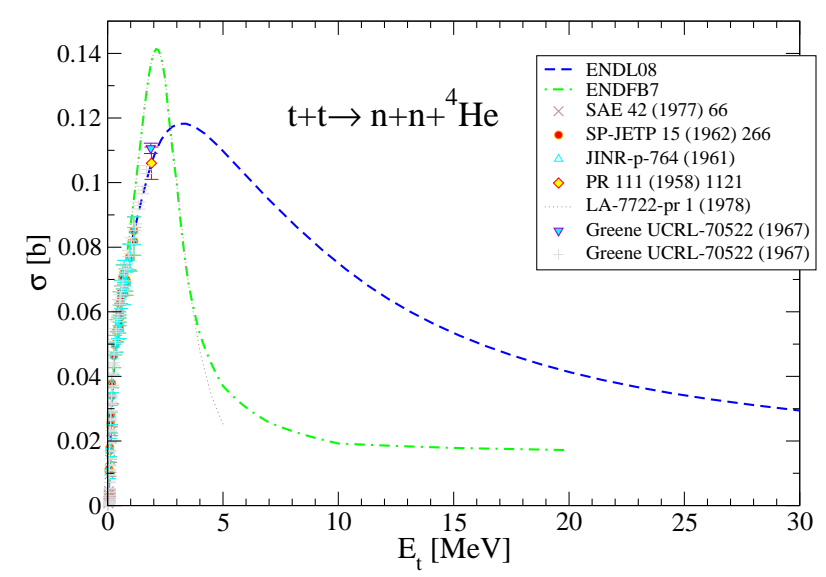

FIG. 44: The $\mathrm{t}(\mathrm{t}, 2 n)^{4} \mathrm{He}$ reaction cross section.

\section{F. $\mathrm{t}+\mathrm{t}$}

We adopt the existing $\mathrm{t}+\mathrm{t}$ evaluation from the Evaluated Charged Particle Library Ref. [WRW91]. The cross section is shown in Fig. 44 with the expanded low energy region $\left(E_{\mathrm{t}}<0.3 \mathrm{MeV}\right)$ shown in Fig. 45 . The cross section is expected to peak at an incident triton energy of $2.3 \mathrm{MeV}$ at a $P$-wave $\left(1^{-}, 2^{-}\right){ }^{6} \mathrm{He}$ resonance $\left(E_{x}=14.6 \mathrm{MeV}\right)$, reflected in the ECPL evaluation but not in ENDF/B-VII.0.

\section{G. $p+{ }^{7} \mathrm{Li}$}

The new ENDL2009 evaluation was completed by P. Navratil and D. A. Brown.

The $p+{ }^{7} \mathrm{Li} \rightarrow n+{ }^{7}$ Be reaction cross section $\mathrm{C}=11$ was newly evaluated. Both the ENDL99 and ENDF/BVII.0 cross sections were discarded. This evaluation is based purely on data. To evaluate the cross section for the ground state production of ${ }^{7} \mathrm{Be}$, we used the following data sets in the given proton energy regions: $0<E_{p}<$ $2.35 \mathrm{MeV}$ [SLKG76]; $2.4<E_{p}<3.6 \mathrm{MeV}$ [BLL74]; $3.6<$ 


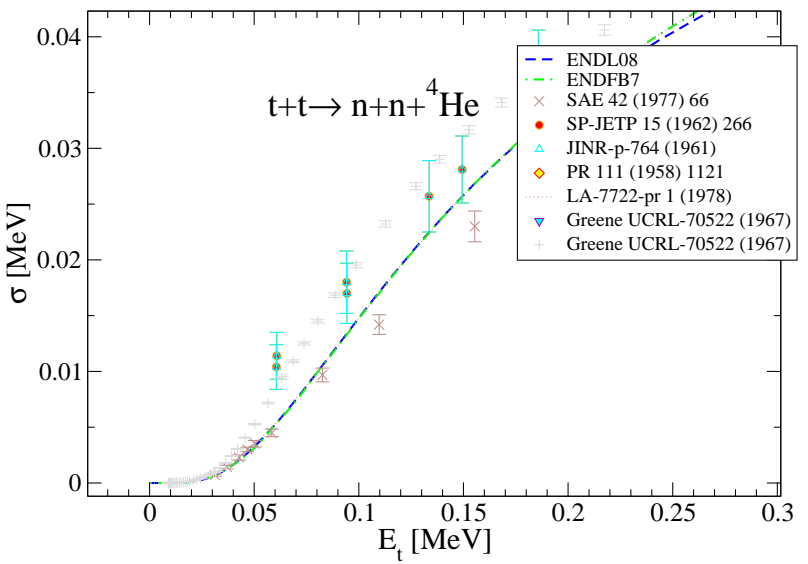

FIG. 45: Expansion of the $\mathrm{t}(\mathrm{t}, 2 n)^{4} \mathrm{He}$ reaction cross section for triton energies less than $0.3 \mathrm{MeV}$.

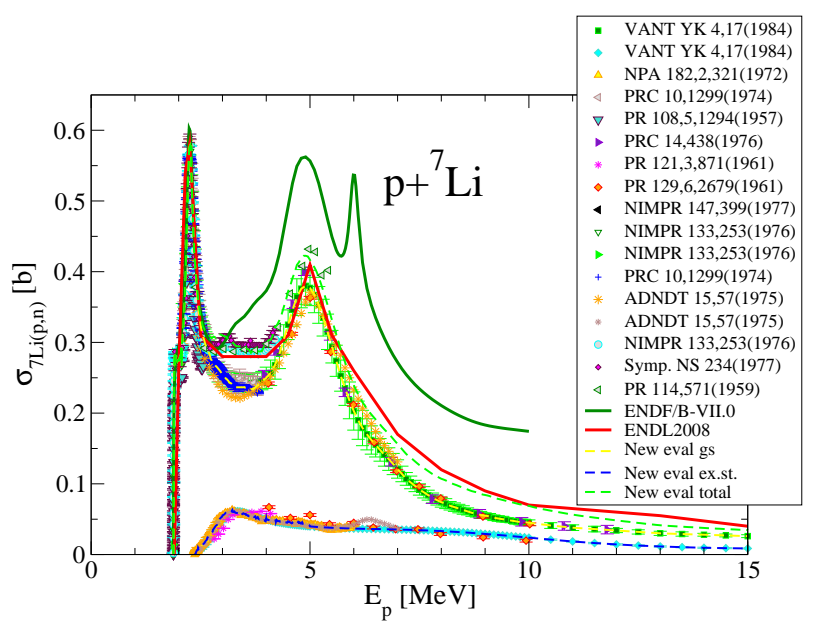

FIG. 46: The ${ }^{7} \operatorname{Li}(p, n)^{7}$ Be reaction cross section. The ground state and first excitated state cross sections are shown along with the total cross section.

$E_{p}<25 \mathrm{MeV}$ [AGZZ84]; $25<E_{p}<26 \mathrm{MeV}\left[\mathrm{PAD}^{+} 76\right.$ ]. Spline fits that match selected experimental points were used to generate the evaluated cross section.

To evaluate the cross section for production of the $0.4291 \mathrm{MeV} 1 / 2^{-}$excited state of ${ }^{7} \mathrm{Be}$, we used the following data sets: $2.3<E_{p}<5 \mathrm{MeV}$ [PB72]; $5<E_{p}<$ $25 \mathrm{MeV}$ [AGZZ84]; $25<E_{p}<26 \mathrm{MeV}\left[\mathrm{PAD}^{+} 76\right]$. Spline fits that joined the energy regions were also used to generate the evaluated cross section.

The total ${ }^{7}$ Be production cross section, the sum of the ground state and first excited state cross sections, is presented in Fig. 46, along with the two contributions to the sum.

The angular distributions were taken from the ENDF/B-VII.0 evaluation [Pag04]. The excited state distribution is the same as that of the ground state but the threshold is shifted.

The $p+{ }^{7} \mathrm{Li} \rightarrow \alpha+\alpha$ cross section $(\mathrm{C}=45)$ was obtained from the $R$-matrix analysis of ${ }^{8} \mathrm{Be}$ reactions system. We

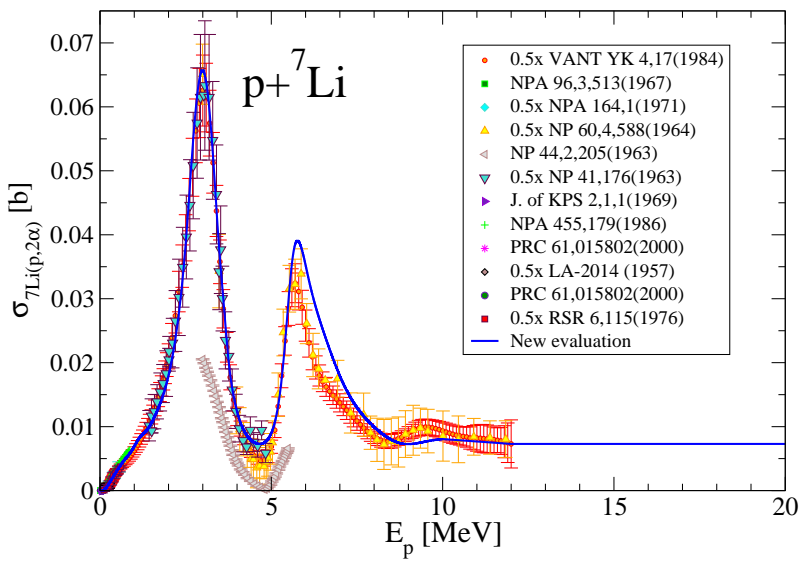

FIG. 47: The ${ }^{7} \operatorname{Li}(p, \alpha){ }^{4}$ He reaction cross section.

adopted the $S$-factor from the $R$-matrix fit by Descouvemont et al. $\left[\mathrm{DAA}^{+} 04\right]$ up to $2.6 \mathrm{MeV}$. Between 2.6 and $3.15 \mathrm{MeV}$, we used three experimental points from the Rice measurement $\left[\mathrm{CJM}^{+} 62\right.$, tag63]. Above 3.15 $\mathrm{MeV}$, we adopted the evaluation by P. Page [Pag04]. A spline fit was used to match the separate components, see Fig. 47. At $E=0, S=67 \pm 4 \mathrm{keV}$ b $\left[\mathrm{DAA}^{+} 04\right]$.

The EXFOR data file has been superseded by Ref. $\left[\mathrm{CJM}^{+} 62\right]$. (The EXFOR data needs to be scaled by factor 10/7, see the erratum [tag63].) A further factor of two reduction is required since the normalization was based on a 1958 measurement that counted single alpha particles.

The angular distributions were taken from the ENDF/B-VII.0 evaluation [Pag04].

The $p+{ }^{7} \mathrm{Li} \rightarrow \mathrm{d}+{ }^{6} \mathrm{Li}$ reaction cross section $(\mathrm{C}=41)$ was calculated from an $R$-matrix analysis of ${ }^{8} \mathrm{Be}$ reactions [Pag04]. The ${ }^{7} \operatorname{Li}(p, \mathrm{~d})$ evaluation was obtained without fitting any experimental data even though the reaction is constrained by the time-inverse reaction, for which there is substantial data. The magnitude and shape of the reaction cross section for proton energies between 3 and 7 $\mathrm{MeV}$ changed considerably during the analysis. We extended this part of the evaluation to $10 \mathrm{MeV}$. To further extrapolate to $30 \mathrm{MeV}$, we integrated the cross section measured with $33.6 \mathrm{MeV}$ incident protons, see Fig. 6 of Ref. [Kul67], to obtain $24 \mathrm{mb}$. We thus recommend using $24 \mathrm{mb}$ at $30 \mathrm{MeV}$. We linearly interpolate to the $10 \mathrm{MeV}$ point of the ENDF/B-VII.0 evaluation [Pag04].

The angular distributions were taken from the ENDF/B-VII.0 evaluation [Pag04].

The Large Angle Coulomb scattering (LACS) data $(\mathrm{C}=8)$ were calculated based on Ref. [PC81b].

The elastic scattering cross section, including the Coulomb interference $(\mathrm{C}=9)$ was taken from ECPL [WRW91].

Since this evaluation is partly based on the ENDF/BVII.0 evaluation [Pag04], we present some highlights from the ENDF/B-VII.0 documentation.

The reactions ${ }^{7} \operatorname{Li}(p, p), \quad{ }^{7} \operatorname{Li}(p, n), \quad{ }^{7} \operatorname{Li}(p, d)$ and 


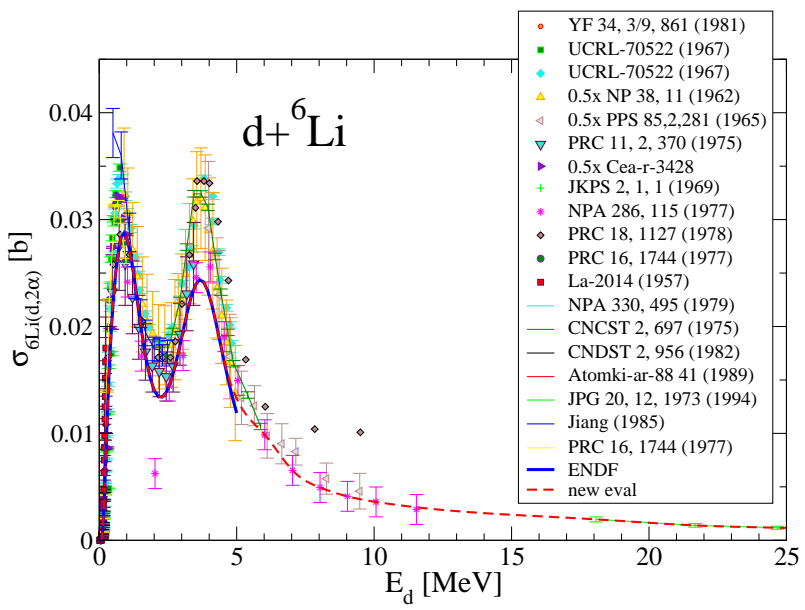

FIG. 48: Cross section of the ${ }^{6} \operatorname{Li}(d, \alpha){ }^{4}$ He reaction.

${ }^{7} \mathrm{Li}(p, \alpha)$ were calculated from the $R$-matrix analysis of ${ }^{8} \mathrm{Be}$ reactions.

The evaluation ecompasses proton energies, $E_{p}$, up to $10 \mathrm{MeV}$. The ${ }^{7} \operatorname{Li}(p, d)$ evaluation was obtained without fitting any experimental data. However, the reaction is constrained by the time-inverse reaction where there are substantial data.

Many measurements are available for ${ }^{7} \operatorname{Li}(p, p)$ and ${ }^{7} \mathrm{Li}(p, n)$ for proton energies up to $3 \mathrm{MeV}$, and for ${ }^{7} \mathrm{Li}(p, \alpha)$ with $E_{\mathrm{p}}<1 \mathrm{MeV}$ due to astrophysical interest. The data are discussed Ref. [Pag04].

Care was taken to make all the ${ }^{7} \operatorname{Li}(p, \alpha)$ data consistent with the convention that the integrated cross section should be divided by a factor of two since there are two outgoing $\alpha$ 's.

The Legendre moments of the angular distributions were calculated from an $R$-matrix analysis. The data that determine the moments have, for the most part, been included for ${ }^{7} \mathrm{Li}(p, p),{ }^{7} \mathrm{Li}(p, n)$ and ${ }^{7} \operatorname{Li}(p, \alpha)$ up to proton energies of $10 \mathrm{MeV}$. However, such data have not been included for ${ }^{7} \operatorname{Li}(p, p)$ in the interval $7<E_{p}<$ $10 \mathrm{MeV}$ and for ${ }^{7} \operatorname{Li}(p, n)$ when $E_{p}>5.5 \mathrm{MeV}$.

\section{H. $\quad \mathrm{d}+{ }^{6} \mathrm{Li}$}

We adopted the $R$-matrix evaluation of the ${ }^{6} \mathrm{Li}(\mathrm{d}, \alpha)^{4} \mathrm{He}$ reaction [Pag04] for deuteron energies, $E_{\mathrm{d}}$, up to $5 \mathrm{MeV}$. It was extended to higher energies using experimental data $\left[\mathrm{RGD}^{+} 77, \mathrm{ABC}^{+} 94\right]$. To make a good spline match, we took the $R$-matrix evaluation up to $4.55 \mathrm{MeV}$ rather than $5 \mathrm{MeV}$. Since the $R$-matrix evaluation appears low relative to the bulk of the data, see Fig. 48, it might be worthwhile to revisit this reaction in the near future.

\section{Large-Angle Coulomb Scattering (LACS)}

The LACS cross sections $(\mathrm{C}=8)$ for charged projectiles $\left(p, \mathrm{~d}, \mathrm{t},{ }^{3} \mathrm{He}\right.$, and $\left.{ }^{4} \mathrm{He}\right)$ on newly-added target isotopes were calculated using the methodology developed by Perkins and Cullen [PC81a] for ECPL85. The differential cross sections are analytic [DS71], and with the COM scattering cosine $\mu$ arbitrarily cut off at $0.94\left(20^{\circ}\right)$. No attempt was made to determine 'nuclear plus interference' cross sections $(\mathrm{C}=9)$ for these isotopes.

\section{OUTLOOK}

The ENDF files for the stable isotope evaluations described in these proceedings as well as a few others $\left({ }^{237} \mathrm{U}\right.$, $\left.{ }^{239} \mathrm{U},{ }^{240} \mathrm{Am}\right)$ are available in the ENDF/B-VII.1 $\beta$ library. Other ENDF files are in preparation, namely ${ }^{62-73} \mathrm{Zn},{ }^{57-61} \mathrm{Co}$ and several unstable $\mathrm{Al}, \mathrm{Ta}, \mathrm{W}, \mathrm{Re}, \mathrm{Au}$ isotopes. While these proceedings focused on the neutron sublibrary, ENDL2009 also contains a sizable chargedparticle sublibrary updating the Evaluated Charged Particle Library (ECPL) [WRW91]. These data may also be made available if there is sufficient interest.

This new library can be found on LLNL's Open and Secure Computing facilities. In addition, the data may be viewed in the Nuclear and Atomic Data System data viewer at http://nuclear.1lnl.gov/NADS. The ENDL formatted library and specific ENDF formatted evaluations are also available from the corresponding author (D. Brown, brown170@llnl.gov).

\section{Acknowledgements}

This work performed under the auspices of the U.S. Department of Energy by Lawrence Livermore National Laboratory under Contract DE-AC52-07NA27344.

\section{Appendix A: Evaluation sources}

Here we list every evaluation in ENDL2009 along its source library. An asterisk $\left(^{*}\right)$ next to the source library indicates that this evaluation contains covariance/uncertainty data.

TABLE IX: Incident neutron evaluation sources for ENDL2009.

\begin{tabular}{crl}
\hline \hline Symbol $\quad Z A$ & $\begin{array}{l}\text { natural } \\
\text { abund. }\end{array}$ \\
\hline \hline Neutron & $\begin{array}{l}\text { evaluation } \\
\text { source }\end{array}$ \\
\hline${ }^{1} \mathrm{n}$ za000001 & \\
\hline Hydrogen & LANL-2006 \\
\hline${ }^{1} \mathrm{H}$ za001001 & 99.985000 & ENDF.B-VII.0* \\
${ }^{2} \mathrm{H}$ za001002 & 0.015000 & ENDF.B-VII.0* \\
${ }^{3} \mathrm{H}$ za001003 & LANL-2006* \\
\hline Helium & \\
\hline
\end{tabular}


TABLE IX: Incident neutron evaluation sources for ENDL2009.

\begin{tabular}{|c|c|c|}
\hline Symbol & $\begin{array}{l}\text { natural } \\
\text { abund. (\%) }\end{array}$ & $\begin{array}{l}\text { evaluation } \\
\text { source }\end{array}$ \\
\hline${ }^{3} \mathrm{He}$ za002003 & 0.000137 & ENDF.B-VII.0* \\
\hline${ }^{4} \mathrm{He}$ za002004 & 99.999863 & JENDL- $3.3^{*}$ \\
\hline \multicolumn{3}{|l|}{ Lithium } \\
\hline${ }^{6} \mathrm{Li}$ za003006 & 7.59 & ENDL99 \\
\hline${ }^{7} \mathrm{Li} \quad \mathrm{za} 003007$ & 93.41 & ENDL99 \\
\hline \multicolumn{3}{|l|}{ Beryllium } \\
\hline${ }^{7} \mathrm{Be}$ za004007 & & ENDF.B-VII.0* \\
\hline${ }^{8} \mathrm{Be}$ za004008 & & $\mathrm{N} / \mathrm{A}$ \\
\hline${ }^{9} \mathrm{Be}$ za004009 & 100.000000 & ENDF.B-VII.0* \\
\hline \multicolumn{3}{|c|}{ Boron } \\
\hline${ }^{10} \mathrm{~B}$ za005010 & 19.8 & ENDL99 \\
\hline${ }^{11} \mathrm{~B}$ za005011 & 80.200000 & ENDF.B-VII.0* \\
\hline \multicolumn{3}{|l|}{ Carbon } \\
\hline${ }^{12} \mathrm{C}$ za006012 & 98.89 & ENDL99 \\
\hline${ }^{13} \mathrm{C}$ za006013 & 1.11 & ENDL99 \\
\hline \multicolumn{3}{|l|}{ Nitrogen } \\
\hline${ }^{14} \mathrm{~N}$ za007014 & 99.634 & ENDL99 \\
\hline${ }^{15} \mathrm{~N}$ za007015 & 0.366 & ENDL99 \\
\hline \multicolumn{3}{|l|}{ Oxygen } \\
\hline${ }^{16} \mathrm{O}$ za008016 & 99.762000 & ENDF.B-VII.0* \\
\hline${ }^{17} \mathrm{O} \quad \mathrm{za} 008017$ & 0.038 & $\mathrm{~N} / \mathrm{A}$ \\
\hline${ }^{18} \mathrm{O} \quad$ za008018 & 0.2 & $\mathrm{~N} / \mathrm{A}$ \\
\hline \multicolumn{3}{|l|}{ Fluorine } \\
\hline${ }^{19} \mathrm{~F}$ za009019 & 100.000000 & ENDF.B-VII.0* \\
\hline \multicolumn{3}{|l|}{ Neon } \\
\hline${ }^{20} \mathrm{Ne}$ za010020 & 90.48 & ENDL99 \\
\hline${ }^{21} \mathrm{Ne} \quad \mathrm{za} 010021$ & 0.27 & $\mathrm{~N} / \mathrm{A}$ \\
\hline${ }^{22} \mathrm{Ne} \quad$ za010022 & 9.25 & $\mathrm{~N} / \mathrm{A}$ \\
\hline \multicolumn{3}{|l|}{ Sodium } \\
\hline${ }^{22} \mathrm{Na} \quad$ za011022 & & ENDF.A-7.2009* \\
\hline${ }^{23} \mathrm{Na} \quad$ za011023 & 100.000000 & JENDL-3.3* \\
\hline \multicolumn{3}{|l|}{ Magnesium } \\
\hline${ }^{24} \mathrm{Mg}$ za012024 & 78.990000 & ENDF.B-VII.0* \\
\hline${ }^{25} \mathrm{Mg}$ za012025 & 10.000000 & ENDF.B-VII.0* \\
\hline${ }^{26} \mathrm{Mg} \quad \mathrm{za} 012026$ & 11.010000 & ENDF.B-VII.0* \\
\hline \multicolumn{3}{|l|}{ Aluminium } \\
\hline${ }^{25} \mathrm{Al} \mathrm{za013025}$ & & LLNL-2009 \\
\hline${ }^{26} \mathrm{Al} \mathrm{za013026}$ & & LLNL-2009 \\
\hline${ }^{27} \mathrm{Al} \quad \mathrm{za0} 013027$ & 100.000000 & ENDF.B-VII.0* \\
\hline${ }^{28} \mathrm{Al}$ za013028 & & LLNL-2009 \\
\hline${ }^{29} \mathrm{Al}$ za013029 & & LLNL-2009 \\
\hline \multicolumn{3}{|l|}{ Silicon } \\
\hline${ }^{28} \mathrm{Si}$ za014028 & 92.230000 & ENDF.B-VII.0* \\
\hline${ }^{29} \mathrm{Si}$ za014029 & 4.683000 & ENDF.B-VII.0* \\
\hline${ }^{30} \mathrm{Si}$ za014030 & 3.087000 & ENDF.B-VII.0* \\
\hline \multicolumn{3}{|l|}{ Phosphorus } \\
\hline${ }^{31} \mathrm{P}$ za015031 & 100.000000 & ENDF.B-VII.0* \\
\hline \multicolumn{3}{|l|}{ Sulphur } \\
\hline${ }^{32} \mathrm{~S}$ za016032 & 95.020000 & ENDF.B-VII.0* \\
\hline${ }^{33} \mathrm{~S}$ za016033 & 0.750000 & ENDF.B-VII.0* \\
\hline${ }^{34} \mathrm{~S}$ za016034 & 4.210000 & ENDF.B-VII.0* \\
\hline${ }^{35} \mathrm{~S}$ za016035 & & $\mathrm{N} / \mathrm{A}$ \\
\hline${ }^{36} \mathrm{~S}$ za016036 & 0.020000 & ENDF.B-VII.0* \\
\hline \multicolumn{3}{|l|}{ Chlorine } \\
\hline${ }^{35} \mathrm{Cl} \mathrm{za017035}$ & 75.770000 & ENDF.A-7.2009* \\
\hline${ }^{36} \mathrm{Cl} \quad \mathrm{za} 017036$ & & $\mathrm{~N} / \mathrm{A}$ \\
\hline${ }^{37} \mathrm{Cl} \quad \mathrm{za} 017037$ & 24.230000 & ENDF.A-7.2009* \\
\hline Argon & & \\
\hline
\end{tabular}

TABLE IX: Incident neutron evaluation sources for ENDL2009

\begin{tabular}{|c|c|c|}
\hline Symbol & $\begin{array}{l}\text { natural } \\
\text { abund. (\%) }\end{array}$ & $\begin{array}{l}\text { evaluation } \\
\text { source }\end{array}$ \\
\hline${ }^{34} \mathrm{Ar}$ za018034 & & LLNL-2009 \\
\hline${ }^{35} \mathrm{Ar}$ za018035 & & LLNL-2009 \\
\hline${ }^{36}$ Ar za018036 & 0.336500 & LLNL-2009* \\
\hline${ }^{37}$ Ar za018037 & & $\mathrm{N} / \mathrm{A}$ \\
\hline${ }^{38} \mathrm{Ar}$ za018038 & 0.063200 & ENDF.B-VII.0* \\
\hline${ }^{39}$ Ar za018039 & & $\mathrm{N} / \mathrm{A}$ \\
\hline${ }^{40} \mathrm{Ar}$ za018040 & 99.600300 & ENDF.B-VII.0* \\
\hline \multicolumn{3}{|l|}{ Potassium } \\
\hline${ }^{39} \mathrm{~K}$ za019039 & 93.258100 & ENDF.A-7.2009* \\
\hline${ }^{40} \mathrm{~K}$ za019040 & 0.011700 & ENDF.B-VII.0* \\
\hline${ }^{41} \mathrm{~K} \quad$ za019041 & 6.730200 & ENDF.A-7.2009* \\
\hline \multicolumn{3}{|l|}{ Calcium } \\
\hline${ }^{40} \mathrm{Ca} \mathrm{za020040}$ & 96.940000 & ENDF.B-VII.0* \\
\hline${ }^{41} \mathrm{Ca} \quad \mathrm{za020041}$ & & HoffmanRadChem \\
\hline${ }^{42} \mathrm{Ca}$ za020042 & 0.647000 & ENDF.B-VII.0* \\
\hline${ }^{43} \mathrm{Ca} \quad$ za020043 & 0.135000 & ENDF.B-VII.0* \\
\hline${ }^{44} \mathrm{Ca} \quad$ za020044 & 2.090000 & ENDF.B-VII.0* \\
\hline${ }^{45} \mathrm{Ca} \quad \mathrm{za} 020045$ & & HoffmanRadChem \\
\hline${ }^{46} \mathrm{Ca} \quad$ za020046 & 0.004000 & ENDF.B-VII.0* \\
\hline${ }^{47} \mathrm{Ca} \quad$ za020047 & & HoffmanRadChem \\
\hline${ }^{48} \mathrm{Ca} \quad$ za020048 & 0.187000 & ENDF.B-VII.0* \\
\hline \multicolumn{3}{|l|}{ Scandium } \\
\hline${ }^{41} \mathrm{Sc} \quad \mathrm{za0} 21041$ & & HoffmanRadChem \\
\hline${ }^{42} \mathrm{Sc} \quad \mathrm{za} 021042$ & & HoffmanRadChem \\
\hline${ }^{43} \mathrm{Sc} \quad \mathrm{za} 021043$ & & HoffmanRadChem \\
\hline${ }^{44} \mathrm{Sc} \quad$ za021044 & & HoffmanRadChem \\
\hline${ }^{45} \mathrm{Sc} \quad$ za021045 & 100.000000 & JEFF-3.1* \\
\hline${ }^{46}$ Sc za021046 & & HoffmanRadChem \\
\hline${ }^{47} \mathrm{Sc} \quad \mathrm{za} 021047$ & & HoffmanRadChem \\
\hline${ }^{48} \mathrm{Sc} \quad$ za021048 & & HoffmanRadChem \\
\hline${ }^{49} \mathrm{Sc} \quad$ za021049 & & HoffmanRadChem \\
\hline${ }^{50} \mathrm{Sc} \quad \mathrm{za} 021050$ & & HoffmanRadChem \\
\hline \multicolumn{3}{|l|}{ Titanium } \\
\hline${ }^{44} \mathrm{Ti} \quad$ za022044 & & HoffmanRadChem \\
\hline${ }^{45} \mathrm{Ti} \quad$ za022045 & & HoffmanRadChem \\
\hline${ }^{46} \mathrm{Ti} \quad$ za022046 & 8.250000 & ENDF.A-7.2009* \\
\hline${ }^{47} \mathrm{Ti} \quad$ za022047 & 7.440000 & ENDF.A-7.2009* \\
\hline${ }^{48} \mathrm{Ti} \quad$ za022048 & 73.720000 & ENDF.A-7.2009* \\
\hline${ }^{49} \mathrm{Ti} \quad$ za022049 & 5.410000 & ENDF.A-7.2009* \\
\hline${ }^{50} \mathrm{Ti}$ za022050 & 5.180000 & ENDF.A-7.2009* \\
\hline${ }^{51} \mathrm{Ti}$ za022051 & & HoffmanRadChem \\
\hline${ }^{52} \mathrm{Ti} \quad \mathrm{za} 022052$ & & HoffmanRadChem \\
\hline \multicolumn{3}{|l|}{ Vanadium } \\
\hline${ }^{n a t} \mathrm{~V}$ za023000 & $\mathrm{N} / \mathrm{A}$ & JENDL-3.3 \\
\hline${ }^{46} \mathrm{~V}$ za023046 & & HoffmanRadChem \\
\hline${ }^{47} \mathrm{~V} \quad$ za023047 & & HoffmanRadChem \\
\hline${ }^{48} \mathrm{~V}$ za023048 & & HoffmanRadChem \\
\hline${ }^{49} \mathrm{~V}$ za023049 & & HoffmanRadChem \\
\hline${ }^{50} \mathrm{~V}$ za023050 & 0.25 & ENDL99 \\
\hline${ }^{51} \mathrm{~V}$ za023051 & 99.75 & ENDL99 \\
\hline${ }^{52} \mathrm{~V}$ za023052 & & HoffmanRadChem \\
\hline${ }^{53} \mathrm{~V}$ za023053 & & HoffmanRadChem \\
\hline \multicolumn{3}{|l|}{ Chromium } \\
\hline${ }^{47} \mathrm{Cr} \quad$ za024047 & & HoffmanRadChem \\
\hline${ }^{48} \mathrm{Cr} \quad$ za024048 & & HoffmanRadChem \\
\hline${ }^{49} \mathrm{Cr} \quad$ za024049 & & HoffmanRadChem \\
\hline${ }^{50} \mathrm{Cr}$ za024050 & 4.345000 & ENDF.B-VII.0* \\
\hline${ }^{51} \mathrm{Cr}$ za024051 & & HoffmanRadChem \\
\hline${ }^{52} \mathrm{Cr} \quad$ za024052 & 83.789000 & ENDF.B-VII.0* \\
\hline${ }^{53} \mathrm{Cr} \quad$ za024053 & 9.501000 & ENDF.B-VII.0* \\
\hline
\end{tabular}


TABLE IX: Incident neutron evaluation sources for ENDL2009.

\begin{tabular}{|c|c|c|}
\hline Symbol & $\begin{array}{l}\text { natural } \\
\text { abund. (\%) }\end{array}$ & $\begin{array}{l}\text { evaluation } \\
\text { source }\end{array}$ \\
\hline${ }^{54} \mathrm{Cr} \quad$ za024054 & 2.365000 & ENDF.B-VII.0* \\
\hline${ }^{55} \mathrm{Cr} \quad \mathrm{za} 024055$ & & HoffmanRadChem \\
\hline${ }^{56} \mathrm{Cr} \quad$ za024056 & & HoffmanRadChem \\
\hline \multicolumn{3}{|l|}{ Manganese } \\
\hline${ }^{50} \mathrm{Mn} \mathrm{za025050}$ & & HoffmanRadChem \\
\hline${ }^{51} \mathrm{Mn} \mathrm{za025051}$ & & HoffmanRadChem \\
\hline${ }^{52} \mathrm{Mn} \mathrm{za025052}$ & & HoffmanRadChem \\
\hline${ }^{53} \mathrm{Mn} \mathrm{za025053}$ & & HoffmanRadChem \\
\hline${ }^{54} \mathrm{Mn}$ za025054 & & HoffmanRadChem \\
\hline${ }^{55} \mathrm{Mn} \mathrm{za025055}$ & 100.000000 & ENDF.A-7.2009* \\
\hline${ }^{56} \mathrm{Mn} \mathrm{za025056}$ & & HoffmanRadChem \\
\hline${ }^{57} \mathrm{Mn} \mathrm{za025057}$ & & HoffmanRadChem \\
\hline \multicolumn{3}{|l|}{ Iron } \\
\hline${ }^{52} \mathrm{Fe} \quad$ za026052 & & HoffmanRadChem \\
\hline${ }^{53} \mathrm{Fe}$ za026053 & & HoffmanRadChem \\
\hline${ }^{54} \mathrm{Fe} \quad \mathrm{za0} 26054$ & 5.845000 & ENDF.B-VII.0* \\
\hline${ }^{55} \mathrm{Fe} \quad \mathrm{za} 026055$ & & HoffmanRadChem \\
\hline${ }^{56} \mathrm{Fe} \quad \mathrm{za} 026056$ & 91.754000 & ENDF.B-VII.0* \\
\hline${ }^{57} \mathrm{Fe} \quad \mathrm{za0} 26057$ & 2.119000 & LLNL-2009* \\
\hline${ }^{58} \mathrm{Fe} \quad \mathrm{za0} 26058$ & 0.282000 & ENDF.B-VII.0* \\
\hline${ }^{59} \mathrm{Fe} \quad \mathrm{za} 026059$ & & HoffmanRadChem \\
\hline \multicolumn{3}{|l|}{ Cobalt } \\
\hline${ }^{57} \mathrm{Co} \mathrm{za027057}$ & & LLNL-2009 \\
\hline${ }^{58} \mathrm{Co} \mathrm{za027058}$ & & LLNL-2009 \\
\hline${ }^{59} \mathrm{Co}$ za027059 & 100.000000 & LLNL-2009* \\
\hline${ }^{60} \mathrm{Co} \mathrm{za027060}$ & & LLNL-2009 \\
\hline${ }^{61} \mathrm{Co} \mathrm{za027061}$ & & LLNL-2009 \\
\hline \multicolumn{3}{|l|}{ Nickel } \\
\hline${ }^{56} \mathrm{Ni} \quad$ za028056 & & LLNL-2008 \\
\hline${ }^{57} \mathrm{Ni} \quad \mathrm{za0} 28057$ & & LLNL-2008 \\
\hline${ }^{58} \mathrm{Ni} \quad \mathrm{za0} 28058$ & 68.077000 & ENDF.B-VII.0* \\
\hline${ }^{59} \mathrm{Ni} \quad$ za028059 & & ENDF.B-VII.0 \\
\hline${ }^{60} \mathrm{Ni} \quad \mathrm{za0} 28060$ & 26.223000 & ENDF.B-VII.0* \\
\hline${ }^{61} \mathrm{Ni} \quad$ za028061 & 1.140000 & ENDF.B-VII.0* \\
\hline${ }^{62} \mathrm{Ni} \quad$ za028062 & 3.634000 & ENDF.B-VII.0* \\
\hline${ }^{63} \mathrm{Ni}$ za028063 & & LLNL-2008 \\
\hline${ }^{64} \mathrm{Ni} \quad$ za028064 & 0.926000 & ENDF.B-VII.0* \\
\hline${ }^{65} \mathrm{Ni} \quad \mathrm{za} 028065$ & & LLNL-2008 \\
\hline${ }^{66} \mathrm{Ni} \quad$ za028066 & & LLNL-2008 \\
\hline${ }^{67} \mathrm{Ni} \quad$ za028067 & & LLNL-2008 \\
\hline \multicolumn{3}{|l|}{ Copper } \\
\hline${ }^{62} \mathrm{Cu}$ za029062 & & LLNL-2008 \\
\hline${ }^{63} \mathrm{Cu} \quad$ za029063 & 69.170000 & ENDF.B-VII.0* \\
\hline${ }^{64} \mathrm{Cu} \quad$ za029064 & & LLNL-2008 \\
\hline${ }^{65} \mathrm{Cu} \quad$ za029065 & 30.830000 & ENDF.B-VII.0* \\
\hline${ }^{66} \mathrm{Cu} \quad$ za029066 & & LLNL-2008 \\
\hline${ }^{67} \mathrm{Cu} \quad$ za029067 & & LLNL-2008 \\
\hline${ }^{68} \mathrm{Cu} \quad$ za029068 & & LLNL-2008 \\
\hline \multicolumn{3}{|l|}{ Zinc } \\
\hline${ }^{62} \mathrm{Zn} \mathrm{za030062}$ & & LLNL-2008 \\
\hline${ }^{63} \mathrm{Zn} \mathrm{za030063}$ & & LLNL-2008 \\
\hline${ }^{64} \mathrm{Zn} \mathrm{za030064}$ & 48.63 & LLNL-2008 \\
\hline${ }^{65} \mathrm{Zn} \mathrm{za030065}$ & & LLNL-2008 \\
\hline${ }^{66} \mathrm{Zn} \mathrm{za030066}$ & 27.9 & LLNL-2008 \\
\hline${ }^{67} \mathrm{Zn} \quad \mathrm{za} 030067$ & 4.1 & LLNL-2008 \\
\hline${ }^{68} \mathrm{Zn} \mathrm{za030068}$ & 18.75 & LLNL-2008 \\
\hline${ }^{69} \mathrm{Zn} \mathrm{za030069}$ & & LLNL-2008 \\
\hline${ }^{70} \mathrm{Zn} \mathrm{za030070}$ & 0.62 & LLNL-2008 \\
\hline${ }^{71} \mathrm{Zn} \quad$ za030071 & & LLNL-2008 \\
\hline${ }^{72} \mathrm{Zn} \quad \mathrm{za} 030072$ & & LLNL-2008 \\
\hline
\end{tabular}

TABLE IX: Incident neutron evaluation sources for ENDL2009

\begin{tabular}{|c|c|c|}
\hline Symbol & $\begin{array}{l}\text { natural } \\
\text { abund. (\%) }\end{array}$ & $\begin{array}{l}\text { evaluation } \\
\text { source }\end{array}$ \\
\hline${ }^{73} \mathrm{Zn} \quad$ za030073 & & LLNL-2008 \\
\hline \multicolumn{3}{|l|}{ Gallium } \\
\hline${ }^{68} \mathrm{Ga}$ za031068 & & LLNL-2008 \\
\hline${ }^{69} \mathrm{Ga} \quad$ za031069 & 60.108000 & ENDF.B-VII.0* \\
\hline${ }^{70} \mathrm{Ga} \quad$ za031070 & & LLNL-2008 \\
\hline${ }^{71} \mathrm{Ga} \quad$ za031071 & 39.892000 & ENDF.B-VII.0* \\
\hline${ }^{72} \mathrm{Ga} \quad$ za031072 & & LLNL-2008 \\
\hline \multicolumn{3}{|l|}{ Germanium } \\
\hline${ }^{70} \mathrm{Ge}$ za032070 & 20.370000 & ENDF.B-VII.0* \\
\hline${ }^{71} \mathrm{Ge}$ za032071 & & $\mathrm{N} / \mathrm{A}$ \\
\hline${ }^{72} \mathrm{Ge}$ za032072 & 27.310000 & ENDF.B-VII.0* \\
\hline${ }^{73} \mathrm{Ge} \quad$ za032073 & 7.760000 & ENDF.B-VII.0* \\
\hline${ }^{74} \mathrm{Ge}$ za032074 & 36.730000 & ENDF.B-VII.0* \\
\hline${ }^{75} \mathrm{Ge}$ za032075 & & $\mathrm{N} / \mathrm{A}$ \\
\hline${ }^{76} \mathrm{Ge}$ za032076 & 7.830000 & ENDF.B-VII.0* \\
\hline \multicolumn{3}{|l|}{ Arsenic } \\
\hline${ }^{73} \mathrm{As}$ za033073 & & LLNL-2009 \\
\hline${ }^{74}$ As za033074 & & LLNL-2009* \\
\hline${ }^{75}$ As za033075 & 100.000000 & LLNL-2009* \\
\hline \multicolumn{3}{|l|}{ Selenium } \\
\hline${ }^{74} \mathrm{Se}$ za034074 & 0.890000 & ENDF.B-VII.0* \\
\hline${ }^{75} \mathrm{Se}$ za034075 & & HoffmanRadChem \\
\hline${ }^{76}$ Se za034076 & 9.370000 & ENDF.B-VII.0* \\
\hline${ }^{77}$ Se za034077 & 7.630000 & ENDF.B-VII.0* \\
\hline${ }^{78} \mathrm{Se}$ za034078 & 23.770000 & ENDF.B-VII.0* \\
\hline${ }^{79}$ Se za034079 & & ENDF.B-VII.0* \\
\hline${ }^{80} \mathrm{Se} \quad \mathrm{za0} 34080$ & 49.610000 & ENDF.B-VII.0* \\
\hline${ }^{81}$ Se za034081 & & HoffmanRadChem \\
\hline${ }^{82} \mathrm{Se}$ za034082 & 8.730000 & ENDF.B-VII.0* \\
\hline \multicolumn{3}{|l|}{ Bromine } \\
\hline${ }^{75} \mathrm{Br}$ za035075 & & HoffmanRadChem \\
\hline${ }^{76} \mathrm{Br} \quad$ za035076 & & HoffmanRadChem \\
\hline${ }^{77} \mathrm{Br} \quad \mathrm{za} 035077$ & & HoffmanRadChem \\
\hline${ }^{78} \mathrm{Br}$ za035078 & & HoffmanRadChem \\
\hline${ }^{79} \mathrm{Br} \quad$ za035079 & 50.690000 & ENDF.B-VII.0* \\
\hline${ }^{80} \mathrm{Br} \quad \mathrm{za0} 035080$ & & HoffmanRadChem \\
\hline${ }^{81} \mathrm{Br}$ za035081 & 49.310000 & ENDF.B-VII.0* \\
\hline${ }^{82} \mathrm{Br} \quad$ za035082 & & HoffmanRadChem \\
\hline \multicolumn{3}{|l|}{ Krypton } \\
\hline${ }^{76} \mathrm{Kr} \quad$ za036076 & & LLNL-2009 \\
\hline${ }^{77} \mathrm{Kr} \quad \mathrm{za} 036077$ & & LLNL-2009 \\
\hline${ }^{78} \mathrm{Kr}$ za036078 & 0.350000 & LLNL-2009* \\
\hline${ }^{79} \mathrm{Kr}$ za036079 & & HoffmanRadChem \\
\hline${ }^{80} \mathrm{Kr}$ za036080 & 2.280000 & ENDF.B-VII.0** \\
\hline${ }^{81} \mathrm{Kr}$ za036081 & & HoffmanRadChem \\
\hline${ }^{82} \mathrm{Kr}$ za036082 & 11.580000 & ENDF.B-VII.0* \\
\hline${ }^{83} \mathrm{Kr} \quad$ za036083 & 11.490000 & ENDF.B-VII.0* \\
\hline${ }^{84} \mathrm{Kr} \quad \mathrm{za} 036084$ & 57.000000 & ENDF.B-VII.0* \\
\hline${ }^{85} \mathrm{Kr} \quad \mathrm{za} 036085$ & & ENDF.B-VII.0* \\
\hline${ }^{86} \mathrm{Kr}$ za036086 & 17.300000 & ENDF.B-VII.0* \\
\hline \multicolumn{3}{|l|}{ Rubidium } \\
\hline${ }^{77} \mathrm{Rb} \quad$ za037077 & & HoffmanRadChem \\
\hline${ }^{78} \mathrm{Rb}$ za037078 & & HoffmanRadChem \\
\hline${ }^{79} \mathrm{Rb} \quad$ za037079 & & HoffmanRadChem \\
\hline${ }^{80} \mathrm{Rb} \quad$ za037080 & & HoffmanRadChem \\
\hline${ }^{81} \mathrm{Rb} \quad$ za037081 & & HoffmanRadChem \\
\hline${ }^{82} \mathrm{Rb} \quad$ za037082 & & HoffmanRadChem \\
\hline${ }^{83} \mathrm{Rb}$ za037083 & & HoffmanRadChem \\
\hline${ }^{84} \mathrm{Rb} \quad$ za037084 & & HoffmanRadChem \\
\hline${ }^{85} \mathrm{Rb}$ za037085 & 72.170000 & ENDF.B-VII.0* \\
\hline
\end{tabular}


TABLE IX: Incident neutron evaluation sources for ENDL2009.

\begin{tabular}{|c|c|c|}
\hline Symbol & $\begin{array}{l}\text { natural } \\
\text { abund. (\%) }\end{array}$ & $\begin{array}{l}\text { evaluation } \\
\text { source }\end{array}$ \\
\hline${ }^{86} \mathrm{Rb} \quad \mathrm{za037086}$ & & ENDF.B-VII.0* \\
\hline${ }^{87} \mathrm{Rb} \quad \mathrm{za} 037087$ & 27.830000 & ENDF.A-7.2009* \\
\hline \multicolumn{3}{|l|}{ Strontium } \\
\hline${ }^{84} \mathrm{Sr}$ za038084 & 0.560000 & ENDF.B-VII.0* \\
\hline${ }^{85} \mathrm{Sr} \quad \mathrm{za0} 038085$ & & $\mathrm{~N} / \mathrm{A}$ \\
\hline${ }^{86} \mathrm{Sr} \quad \mathrm{za} 038086$ & 9.860000 & ENDF.B-VII.0* \\
\hline${ }^{87} \mathrm{Sr} \quad \mathrm{za} 038087$ & 7.000000 & ENDF.B-VII.0* \\
\hline${ }^{88} \mathrm{Sr} \quad \mathrm{za} 038088$ & 82.580000 & ENDF.B-VII.0* \\
\hline${ }^{89} \mathrm{Sr} \quad$ za038089 & & ENDF.B-VII.0* \\
\hline${ }^{90} \mathrm{Sr}$ za038090 & & ENDF.B-VII.0* \\
\hline \multicolumn{3}{|l|}{ Yttrium } \\
\hline${ }^{86} \mathrm{Y}$ za039086 & & $\mathrm{N} / \mathrm{A}$ \\
\hline${ }^{87} \mathrm{Y} \quad \mathrm{za039087}$ & & $\mathrm{N} / \mathrm{A}$ \\
\hline${ }^{88} \mathrm{Y}$ za039088 & & ENDL99 \\
\hline${ }^{89} \mathrm{Y}$ za039089 & 100.000000 & ENDF.A-7.2009* \\
\hline${ }^{90} \mathrm{Y}$ za039090 & & ENDF.B-VII.0* \\
\hline${ }^{91} \mathrm{Y}$ za039091 & & ENDF.B-VII.0* \\
\hline${ }^{92} \mathrm{Y}$ za039092 & & $\mathrm{N} / \mathrm{A}$ \\
\hline \multicolumn{3}{|l|}{ Zirconium } \\
\hline${ }^{87} \mathrm{Zr} \quad$ za040087 & & $\mathrm{N} / \mathrm{A}$ \\
\hline${ }^{88} \mathrm{Zr} \quad \mathrm{za0} 00088$ & & $\mathrm{~N} / \mathrm{A}$ \\
\hline${ }^{89} \mathrm{Zr} \quad \mathrm{za0} 40089$ & & $\mathrm{~N} / \mathrm{A}$ \\
\hline${ }^{90} \mathrm{Zr} \quad \mathrm{za0} 40090$ & 51.450000 & ENDF.A-7.2009* \\
\hline${ }^{91} \mathrm{Zr} \quad \mathrm{za040091}$ & 11.220000 & ENDF.B-VII.0* \\
\hline${ }^{92} \mathrm{Zr} \quad \mathrm{za0} 040092$ & 17.150000 & ENDF.B-VII.0* \\
\hline${ }^{93} \mathrm{Zr} \quad \mathrm{za0} 00093$ & & ENDF.B-VII.0* \\
\hline${ }^{94} \mathrm{Zr} \quad \mathrm{za0} 040094$ & 17.380000 & ENDF.B-VII.0* \\
\hline${ }^{95} \mathrm{Zr} \quad$ za040095 & & ENDF.B-VII.0* \\
\hline${ }^{96} \mathrm{Zr} \quad$ za040096 & 2.800000 & ENDF.A-7.2009* \\
\hline \multicolumn{3}{|l|}{ Niobium } \\
\hline${ }^{91} \mathrm{Nb} \quad$ za041091 & & $\mathrm{N} / \mathrm{A}$ \\
\hline${ }^{92} \mathrm{Nb} \quad$ za041092 & & $\mathrm{N} / \mathrm{A}$ \\
\hline${ }^{93} \mathrm{Nb} \quad$ za041093 & 100.000000 & ENDF.B-VII.0* \\
\hline${ }^{94} \mathrm{Nb} \quad$ za041094 & & ENDF.B-VII.0* \\
\hline${ }^{95} \mathrm{Nb} \quad z a 041095$ & & ENDF.B-VII.0* \\
\hline \multicolumn{3}{|l|}{ Molybdenum } \\
\hline${ }^{91}$ Mo za042091 & & $\mathrm{N} / \mathrm{A}$ \\
\hline${ }^{92}$ Mo za042092 & 14.840000 & ENDF.B-VII.0* \\
\hline${ }^{93}$ Mo za042093 & & $\mathrm{N} / \mathrm{A}$ \\
\hline${ }^{94}$ Mo za042094 & 9.250000 & ENDF.B-VII.0* \\
\hline${ }^{95}$ Mo za042095 & 15.920000 & ENDF.B-VII.0* \\
\hline${ }^{96}$ Mo za042096 & 16.680000 & ENDF.B-VII.0* \\
\hline${ }^{97}$ Mo za042097 & 9.550000 & ENDF.A-7.2009* \\
\hline${ }^{98} \mathrm{Mo} \mathrm{za042098}$ & 24.130000 & ENDF.B-VII.0* \\
\hline${ }^{99} \mathrm{Mo} \mathrm{za042099}$ & & ENDF.B-VII.0* \\
\hline${ }^{100}$ Mo za042100 & 9.630000 & ENDF.B-VII.0* \\
\hline \multicolumn{3}{|l|}{ Technetium } \\
\hline${ }^{99}$ Tc za043099 & & JEFF-3.1.1* \\
\hline \multicolumn{3}{|l|}{ Ruthenium } \\
\hline${ }^{96} \mathrm{Ru} \mathrm{za044096}$ & 5.540000 & ENDF.B-VII.0* \\
\hline${ }^{97} \mathrm{Ru} \quad \mathrm{za0} 04097$ & & $\mathrm{~N} / \mathrm{A}$ \\
\hline${ }^{98} \mathrm{Ru} \mathrm{za044098}$ & 1.870000 & ENDF.B-VII.0* \\
\hline${ }^{99} \mathrm{Ru} \quad$ za044099 & 12.760000 & ENDF.B-VII.0* \\
\hline${ }^{100} \mathrm{Ru} \quad \mathrm{za0} 04100$ & 12.600000 & ENDF.B-VII.0* \\
\hline${ }^{101} \mathrm{Ru} \quad \mathrm{za0} 44101$ & 17.060000 & ENDF.B-VII.0* \\
\hline${ }^{102} \mathrm{Ru} \quad \mathrm{za0} 04102$ & 31.550000 & ENDF.B-VII.0* \\
\hline${ }^{103} \mathrm{Ru} \quad$ za044103 & & ENDF.B-VII.0* \\
\hline${ }^{104} \mathrm{Ru} \quad \mathrm{za0} 04104$ & 18.620000 & ENDF.B-VII.0* \\
\hline${ }^{105} \mathrm{Ru} \quad \mathrm{za0} 04105$ & & ENDF.B-VII.0* \\
\hline${ }^{106} \mathrm{Ru} \quad \mathrm{za0} 44106$ & & ENDF.B-VII.0* \\
\hline
\end{tabular}

TABLE IX: Incident neutron evaluation sources for ENDL2009.

\begin{tabular}{|c|c|c|}
\hline Symbol & $\begin{array}{l}\text { natural } \\
\text { abund. (\%) }\end{array}$ & $\begin{array}{l}\text { evaluation } \\
\text { source }\end{array}$ \\
\hline \multicolumn{3}{|l|}{ Rhodium } \\
\hline${ }^{103} \mathrm{Rh}$ za045103 & 100.000000 & JEFF-3.1* \\
\hline${ }^{104} \mathrm{Rh}$ za045104 & & $\mathrm{N} / \mathrm{A}$ \\
\hline${ }^{105} \mathrm{Rh}$ za045105 & & ENDF.B-VII.0* \\
\hline \multicolumn{3}{|l|}{ Palladium } \\
\hline${ }^{102} \mathrm{Pd}$ za046102 & 1.020000 & JENDL-3.3* \\
\hline${ }^{103} \mathrm{Pd}$ za046103 & & $\mathrm{N} / \mathrm{A}$ \\
\hline${ }^{104} \mathrm{Pd}$ za046104 & 11.140000 & ENDF.B-VII.0* \\
\hline${ }^{105} \mathrm{Pd}$ za046105 & 22.330000 & ENDF.B-VII.0* \\
\hline${ }^{106} \mathrm{Pd}$ za046106 & 27.330000 & ENDF.B-VII.0* \\
\hline${ }^{107} \mathrm{Pd} \quad$ za046107 & & ENDF.B-VII.0* \\
\hline${ }^{108} \mathrm{Pd}$ za046108 & 26.460000 & ENDF.B-VII.0* \\
\hline${ }^{109} \mathrm{Pd} \quad$ za046109 & & $\mathrm{N} / \mathrm{A}$ \\
\hline${ }^{110} \mathrm{Pd}$ za046110 & 11.720000 & ENDF.B-VII.0* \\
\hline \multicolumn{3}{|l|}{ Silver } \\
\hline${ }^{107} \mathrm{Ag} \quad$ za047107 & 51.839000 & ENDF.B-VII.0* \\
\hline${ }^{108} \mathrm{Ag} \quad \mathrm{za} 047108$ & & $\mathrm{~N} / \mathrm{A}$ \\
\hline${ }^{109} \mathrm{Ag} \quad \mathrm{za0} 04109$ & 48.161000 & ENDF.B-VII.0* \\
\hline${ }^{110} \mathrm{Ag} \quad \mathrm{za0} 04110$ & & $\mathrm{~N} / \mathrm{A}$ \\
\hline${ }^{111} \mathrm{Ag} \quad \mathrm{za0} 04711$ & & ENDF.B-VII.0* \\
\hline \multicolumn{3}{|l|}{ Cadmium } \\
\hline${ }^{106} \mathrm{Cd}$ za048106 & 1.250000 & ENDF.B-VII.0* \\
\hline${ }^{107} \mathrm{Cd} \quad \mathrm{za} 048107$ & & $\mathrm{~N} / \mathrm{A}$ \\
\hline${ }^{108} \mathrm{Cd}$ za048108 & 0.890000 & ENDF.B-VII.0* \\
\hline${ }^{109} \mathrm{Cd}$ za048109 & & $\mathrm{N} / \mathrm{A}$ \\
\hline${ }^{110} \mathrm{Cd}$ za048110 & 12.490000 & JENDL-3.3* \\
\hline${ }^{111} \mathrm{Cd}$ za048111 & 12.800000 & ENDF.B-VII.0* \\
\hline${ }^{112} \mathrm{Cd}$ za048112 & 24.130000 & ENDF.B-VII.0* \\
\hline${ }^{113} \mathrm{Cd}$ za048113 & 12.220000 & ENDF.A-7.2009* \\
\hline${ }^{114} \mathrm{Cd}$ za048114 & 28.730000 & ENDF.B-VII.0* \\
\hline${ }^{115} \mathrm{Cd} \quad \mathrm{za} 048115$ & & $\mathrm{~N} / \mathrm{A}$ \\
\hline${ }^{116} \mathrm{Cd} \quad$ za048116 & 7.490000 & ENDF.B-VII.0* \\
\hline \multicolumn{3}{|l|}{ Indium } \\
\hline${ }^{113}$ In za049113 & 4.290000 & ENDF.B-VII.0* \\
\hline${ }^{114}$ In za049114 & & $\mathrm{N} / \mathrm{A}$ \\
\hline${ }^{115}$ In za049115 & 95.710000 & ENDF.B-VII.0* \\
\hline \multicolumn{3}{|l|}{ Tin } \\
\hline${ }^{112} \mathrm{Sn} \mathrm{za050112}$ & 0.970000 & ENDF.B-VII.0* \\
\hline${ }^{113} \mathrm{Sn} \mathrm{za050113}$ & & ENDF.B-VII.0* \\
\hline${ }^{114} \mathrm{Sn} \quad \mathrm{za} 050114$ & 0.660000 & ENDF.B-VII.0* \\
\hline${ }^{115} \mathrm{Sn} \mathrm{za050115}$ & 0.340000 & ENDF.B-VII.0* \\
\hline${ }^{116} \mathrm{Sn} \mathrm{za050116}$ & 14.540000 & ENDF.B-VII.0* \\
\hline${ }^{117} \mathrm{Sn} \quad \mathrm{za} 050117$ & 7.680000 & ENDF.B-VII.0* \\
\hline${ }^{118} \mathrm{Sn} \quad \mathrm{za} 050118$ & 24.220000 & ENDF.B-VII.0* \\
\hline${ }^{119} \mathrm{Sn} \quad \mathrm{za} 050119$ & 8.590000 & ENDF.B-VII.0* \\
\hline${ }^{120} \mathrm{Sn} \mathrm{za050120}$ & 32.580000 & ENDF.B-VII.0* \\
\hline${ }^{121} \mathrm{Sn} \quad \mathrm{za} 050121$ & & $\mathrm{~N} / \mathrm{A}$ \\
\hline${ }^{122} \mathrm{Sn}$ za050122 & 4.630000 & ENDF.B-VII.0* \\
\hline${ }^{123} \mathrm{Sn} \mathrm{za050123}$ & & ENDF.B-VII.0* \\
\hline${ }^{124} \mathrm{Sn} \quad \mathrm{za} 050124$ & 5.790000 & ENDF.B-VII.0* \\
\hline${ }^{125} \mathrm{Sn} \mathrm{za050125}$ & & ENDF.B-VII.0* \\
\hline${ }^{126} \mathrm{Sn} \mathrm{za050126}$ & & ENDF.B-VII.0* \\
\hline \multicolumn{3}{|l|}{ Antimony } \\
\hline${ }^{121} \mathrm{Sb}$ za051121 & 57.210000 & ENDF.B-VII.0* \\
\hline${ }^{122} \mathrm{Sb} \quad$ za051122 & & $\mathrm{N} / \mathrm{A}$ \\
\hline${ }^{123} \mathrm{Sb}$ za051123 & 42.790000 & ENDF.B-VII.0* \\
\hline${ }^{124} \mathrm{Sb} \quad$ za051124 & & ENDF.B-VII.0* \\
\hline${ }^{125} \mathrm{Sb}$ za051125 & & ENDF.B-VII.0* \\
\hline${ }^{126} \mathrm{Sb} \mathrm{za051126}$ & & ENDF.B-VII.0* \\
\hline Tellurium & & \\
\hline
\end{tabular}


TABLE IX: Incident neutron evaluation sources for ENDL2009.

\begin{tabular}{|c|c|c|}
\hline Symbol & $\begin{array}{l}\text { natural } \\
\text { abund. (\%) }\end{array}$ & $\begin{array}{l}\text { evaluation } \\
\text { source }\end{array}$ \\
\hline${ }^{120} \mathrm{Te}$ za052120 & 0.090000 & ENDF.B-VII.0* \\
\hline${ }^{121} \mathrm{Te}$ za052121 & & $\mathrm{N} / \mathrm{A}$ \\
\hline${ }^{122} \mathrm{Te}$ za052122 & 2.550000 & ENDF.B-VII.0* \\
\hline${ }^{123} \mathrm{Te}$ za052123 & 0.890000 & ENDF.B-VII.0* \\
\hline${ }^{124} \mathrm{Te}$ za052124 & 4.740000 & ENDF.B-VII.0* \\
\hline${ }^{125} \mathrm{Te}$ za052125 & 7.070000 & ENDF.B-VII.0* \\
\hline${ }^{126}$ Te za052126 & 18.840000 & ENDF.B-VII.0* \\
\hline${ }^{127} \mathrm{Te} \quad \mathrm{za} 052127$ & & HoffmanRadChem \\
\hline${ }^{128} \mathrm{Te}$ za052128 & 31.740000 & ENDF.B-VII.0* \\
\hline${ }^{129} \mathrm{Te}$ za052129 & & $\mathrm{N} / \mathrm{A}$ \\
\hline${ }^{130}$ Te za052130 & 34.080000 & ENDF.B-VII.0* \\
\hline${ }^{131} \mathrm{Te}$ za052131 & & $\mathrm{N} / \mathrm{A}$ \\
\hline${ }^{132} \mathrm{Te}$ za052132 & & ENDF.B-VII.0* \\
\hline \multicolumn{3}{|l|}{ Iodine } \\
\hline${ }^{124} \mathrm{I}$ za053124 & & HoffmanRadChem \\
\hline${ }^{125} \mathrm{I} \quad \mathrm{za} 053125$ & & HoffmanRadChem \\
\hline${ }^{126}$ I za053126 & & HoffmanRadChem \\
\hline${ }^{127}$ I za053127 & 100.000000 & ENDF.B-VII.0* \\
\hline${ }^{128}$ I za053128 & & HoffmanRadChem \\
\hline${ }^{129} \mathrm{I}$ za053129 & & ENDF.B-VII.0* \\
\hline${ }^{130} \mathrm{I}$ za053130 & & ENDF.B-VII.0* \\
\hline${ }^{131}$ I za053131 & & ENDF.B-VII.0* \\
\hline${ }^{132}$ I za053132 & & $\mathrm{N} / \mathrm{A}$ \\
\hline${ }^{133}$ I za053133 & & $\mathrm{N} / \mathrm{A}$ \\
\hline${ }^{134}$ I za053134 & & $\mathrm{N} / \mathrm{A}$ \\
\hline${ }^{135}$ I za053135 & & ENDF.B-VII.0* \\
\hline \multicolumn{3}{|l|}{ Xenon } \\
\hline${ }^{122}$ Xe za054122 & & LLNL-2009 \\
\hline${ }^{123} \mathrm{Xe}$ za054123 & & LLNL-2009* \\
\hline${ }^{124} \mathrm{Xe}$ za054124 & 0.095000 & LLNL-2009* \\
\hline${ }^{125} \mathrm{Xe}$ za054125 & & HoffmanRadChem \\
\hline${ }^{126} \mathrm{Xe}$ za054126 & 0.089000 & ENDF.B-VII.0* \\
\hline${ }^{127} \mathrm{Xe}$ za054127 & & HoffmanRadChem \\
\hline${ }^{128} \mathrm{Xe}$ za054128 & 1.910000 & ENDF.B-VII.0* \\
\hline${ }^{129}$ Xe za054129 & 26.400000 & ENDF.B-VII.0* \\
\hline${ }^{130}$ Xe za054130 & 4.071000 & JENDL-3.3* \\
\hline${ }^{131} \mathrm{Xe}$ za054131 & 21.232000 & ENDF.B-VII.0* \\
\hline${ }^{132} \mathrm{Xe}$ za054132 & 26.909000 & ENDF.B-VII.0* \\
\hline${ }^{133}$ Xe za054133 & & ENDF.B-VII.0* \\
\hline${ }^{134}$ Xe za054134 & 10.436000 & ENDF.B-VII.0* \\
\hline${ }^{135} \mathrm{Xe}$ za054135 & & ENDF.B-VII.0* \\
\hline${ }^{136}$ Xe za054136 & 8.857000 & ENDF.B-VII.0* \\
\hline \multicolumn{3}{|l|}{ Cesium } \\
\hline${ }^{133} \mathrm{Cs}$ za055133 & 100.000000 & ENDF.B-VII.0* \\
\hline${ }^{134} \mathrm{Cs} \quad \mathrm{za0} 55134$ & & ENDF.B-VII.0* \\
\hline${ }^{135} \mathrm{Cs}$ za055135 & & ENDF.B-VII.0* \\
\hline${ }^{136} \mathrm{Cs}$ za055136 & & ENDF.B-VII.0* \\
\hline${ }^{137} \mathrm{Cs} \quad$ za055137 & & ENDF.B-VII.0* \\
\hline \multicolumn{3}{|l|}{ Barium } \\
\hline${ }^{130} \mathrm{Ba}$ za056130 & 0.106000 & ENDF.B-VII.0* \\
\hline${ }^{131} \mathrm{Ba} \quad$ za056131 & & $\mathrm{N} / \mathrm{A}$ \\
\hline${ }^{132} \mathrm{Ba} \quad$ za056132 & 0.101000 & ENDF.B-VII.0* \\
\hline${ }^{133} \mathrm{Ba} \mathrm{za056133}$ & & ENDF.B-VII.0* \\
\hline${ }^{134} \mathrm{Ba} \mathrm{za056134}$ & 2.417000 & ENDF.B-VII.0* \\
\hline${ }^{135} \mathrm{Ba} \mathrm{za056135}$ & 6.592000 & ENDF.B-VII.0* \\
\hline${ }^{136} \mathrm{Ba} \mathrm{za056136}$ & 7.854000 & ENDF.B-VII.0* \\
\hline${ }^{137} \mathrm{Ba} \mathrm{za056137}$ & 11.232000 & ENDF.B-VII.0* \\
\hline${ }^{138} \mathrm{Ba} \quad$ za056138 & 71.698000 & ENDF.B-VII.0* \\
\hline${ }^{139} \mathrm{Ba} \mathrm{za056139}$ & & $\mathrm{N} / \mathrm{A}$ \\
\hline${ }^{140} \mathrm{Ba} \quad \mathrm{za} 056140$ & & JENDL-3.3* \\
\hline
\end{tabular}

TABLE IX: Incident neutron evaluation sources for ENDL2009

\begin{tabular}{|c|c|c|}
\hline Symbol & $\begin{array}{l}\text { natural } \\
\text { abund. (\%) }\end{array}$ & $\begin{array}{l}\text { evaluation } \\
\text { source }\end{array}$ \\
\hline \multicolumn{3}{|l|}{ Lanthanum } \\
\hline${ }^{138} \mathrm{La} \quad$ za057138 & 0.090000 & ENDF.B-VII.0* \\
\hline${ }^{139}$ La za057139 & 99.910000 & ENDF.B-VII.0* \\
\hline${ }^{140} \mathrm{La} \quad \mathrm{za} 057140$ & & ENDF.B-VII.0* \\
\hline \multicolumn{3}{|l|}{ Cerium } \\
\hline${ }^{136} \mathrm{Ce}$ za058136 & 0.185000 & ENDF.B-VII.0* \\
\hline${ }^{137} \mathrm{Ce} \quad$ za058137 & & $\mathrm{N} / \mathrm{A}$ \\
\hline${ }^{138} \mathrm{Ce}$ za058138 & 0.251000 & ENDF.B-VII.0* \\
\hline${ }^{139} \mathrm{Ce}$ za058139 & & ENDF.B-VII.0* \\
\hline${ }^{140} \mathrm{Ce}$ za058140 & 88.450000 & ENDF.B-VII.0* \\
\hline${ }^{141} \mathrm{Ce} \quad \mathrm{za} 058141$ & & ENDF.B-VII.0* \\
\hline${ }^{142} \mathrm{Ce}$ za058142 & 11.114000 & ENDF.B-VII.0* \\
\hline${ }^{143} \mathrm{Ce}$ za058143 & & ENDF.B-VII.0* \\
\hline${ }^{144} \mathrm{Ce} \quad$ za058144 & & ENDF.B-VII.0* \\
\hline \multicolumn{3}{|l|}{ Praseodymium } \\
\hline${ }^{141} \mathrm{Pr} \quad$ za059141 & 100.000000 & ENDF.B-VII.0* \\
\hline${ }^{142} \operatorname{Pr}$ za059142 & & ENDF.B-VII.0* \\
\hline${ }^{143} \operatorname{Pr}$ za059143 & & ENDF.B-VII.0* \\
\hline \multicolumn{3}{|l|}{ Neodymium } \\
\hline${ }^{142} \mathrm{Nd}$ za060142 & 27.200000 & ENDF.B-VII.0* \\
\hline${ }^{143} \mathrm{Nd} \quad$ za060143 & 12.200000 & ENDF.B-VII.0* \\
\hline${ }^{144} \mathrm{Nd} \quad \mathrm{za0} 60144$ & 23.800000 & ENDF.B-VII.0* \\
\hline${ }^{145} \mathrm{Nd} \quad \mathrm{za} 060145$ & 8.300000 & ENDF.B-VII.0* \\
\hline${ }^{146} \mathrm{Nd} \quad \mathrm{za0} 00146$ & 17.200000 & ENDF.B-VII.0* \\
\hline${ }^{147} \mathrm{Nd} \quad \mathrm{za0} 00147$ & & ENDF.B-VII.0* \\
\hline${ }^{148} \mathrm{Nd}$ za060148 & 5.700000 & ENDF.B-VII.0* \\
\hline${ }^{149} \mathrm{Nd} \quad$ za060149 & & $\mathrm{N} / \mathrm{A}$ \\
\hline${ }^{150} \mathrm{Nd}$ za060150 & 5.600000 & ENDF.B-VII.0* \\
\hline \multicolumn{3}{|l|}{ Promethium } \\
\hline${ }^{147} \mathrm{Pm} \mathrm{za061147}$ & & ENDF.B-VII.0* \\
\hline${ }^{148} \mathrm{Pm} \mathrm{za061148}$ & & ENDF.B-VII.0* \\
\hline${ }^{149} \mathrm{Pm} \mathrm{za061149}$ & & ENDF.B-VII.0* \\
\hline${ }^{150} \mathrm{Pm} \mathrm{za061150}$ & & $\mathrm{N} / \mathrm{A}$ \\
\hline${ }^{151} \mathrm{Pm} \quad$ za061151 & & ENDF.B-VII.0* \\
\hline \multicolumn{3}{|l|}{ Samarium } \\
\hline${ }^{144} \mathrm{Sm} \mathrm{za062144}$ & 3.070000 & ENDF.B-VII.0* \\
\hline${ }^{145} \mathrm{Sm} \mathrm{za062145}$ & & $\mathrm{N} / \mathrm{A}$ \\
\hline${ }^{146} \mathrm{Sm} \mathrm{za062146}$ & & $\mathrm{N} / \mathrm{A}$ \\
\hline${ }^{147} \mathrm{Sm} \mathrm{za062147}$ & 14.990000 & ENDF.B-VII.0* \\
\hline${ }^{148} \mathrm{Sm} \mathrm{za062148}$ & 11.240000 & ENDF.B-VII.0* \\
\hline${ }^{149} \mathrm{Sm} \mathrm{za062149}$ & 13.820000 & ENDF.B-VII.0* \\
\hline${ }^{150} \mathrm{Sm} \mathrm{za062150}$ & 7.380000 & ENDF.B-VII.0* \\
\hline${ }^{151} \mathrm{Sm} \mathrm{za062151}$ & & ENDF.B-VII.0* \\
\hline${ }^{152} \mathrm{Sm} \mathrm{za062152}$ & 26.750000 & ENDF.B-VII.0* \\
\hline${ }^{153} \mathrm{Sm} \mathrm{za062153}$ & & ENDF.B-VII.0* \\
\hline${ }^{154} \mathrm{Sm} \mathrm{za062154}$ & 22.750000 & ENDF.B-VII.0* \\
\hline${ }^{155} \mathrm{Sm} \mathrm{za062155}$ & & $\mathrm{N} / \mathrm{A}$ \\
\hline \multicolumn{3}{|l|}{ Europium } \\
\hline${ }^{145} \mathrm{Eu} \mathrm{za063145}$ & & $\mathrm{N} / \mathrm{A}$ \\
\hline${ }^{146} \mathrm{Eu} \quad$ za063146 & & $\mathrm{N} / \mathrm{A}$ \\
\hline${ }^{147} \mathrm{Eu} \quad \mathrm{za} 063147$ & & $\mathrm{~N} / \mathrm{A}$ \\
\hline${ }^{148} \mathrm{Eu} \quad$ za063148 & & $\mathrm{N} / \mathrm{A}$ \\
\hline${ }^{149} \mathrm{Eu} \quad$ za063149 & & $\mathrm{N} / \mathrm{A}$ \\
\hline${ }^{150} \mathrm{Eu} \mathrm{za063150}$ & & $\mathrm{N} / \mathrm{A}$ \\
\hline${ }^{151} \mathrm{Eu} \quad$ za063151 & 47.810000 & ENDF.B-VII.0* \\
\hline${ }^{152} \mathrm{Eu} \quad$ za063152 & & ENDF.B-VII.0* \\
\hline${ }^{153} \mathrm{Eu} \mathrm{za063153}$ & 52.190000 & ENDF.B-VII.0* \\
\hline${ }^{154} \mathrm{Eu} \quad$ za063154 & & ENDF.B-VII.0* \\
\hline${ }^{155} \mathrm{Eu} \mathrm{za063155}$ & & ENDF.B-VII.0* \\
\hline${ }^{156} \mathrm{Eu} \mathrm{za063156}$ & & ENDF.B-VII.0* \\
\hline
\end{tabular}


TABLE IX: Incident neutron evaluation sources for ENDL2009.

\begin{tabular}{|c|c|c|}
\hline Symbol & $\begin{array}{l}\text { natural } \\
\text { abund. (\%) }\end{array}$ & $\begin{array}{l}\text { evaluation } \\
\text { source }\end{array}$ \\
\hline${ }^{157}$ Eu za063157 & & ENDF.B-VII.0* \\
\hline \multicolumn{3}{|l|}{ Gadolinium } \\
\hline${ }^{146} \mathrm{Gd}$ za064146 & & $\mathrm{N} / \mathrm{A}$ \\
\hline${ }^{147} \mathrm{Gd} \quad \mathrm{za} 064147$ & & $\mathrm{~N} / \mathrm{A}$ \\
\hline${ }^{148}$ Gd za064148 & & $\mathrm{N} / \mathrm{A}$ \\
\hline${ }^{149}$ Gd za064149 & & $\mathrm{N} / \mathrm{A}$ \\
\hline${ }^{150} \mathrm{Gd} \quad \mathrm{za064150}$ & & $\mathrm{N} / \mathrm{A}$ \\
\hline${ }^{151} \mathrm{Gd} \quad \mathrm{za0} 04151$ & & $\mathrm{~N} / \mathrm{A}$ \\
\hline${ }^{152} \mathrm{Gd}$ za064152 & 0.200000 & ENDF.B-VII.0* \\
\hline${ }^{153} \mathrm{Gd}$ za064153 & & ENDF.B-VII.0* \\
\hline${ }^{154} \mathrm{Gd} \quad$ za064154 & 2.180000 & ENDF.B-VII.0* \\
\hline${ }^{155} \mathrm{Gd}$ za064155 & 14.800000 & ENDF.B-VII.0* \\
\hline${ }^{156} \mathrm{Gd}$ za064156 & 20.470000 & ENDF.B-VII.0* \\
\hline${ }^{157} \mathrm{Gd} \quad \mathrm{za} 064157$ & 15.650000 & ENDF.B-VII.0* \\
\hline${ }^{158} \mathrm{Gd}$ za064158 & 24.840000 & ENDF.B-VII.0* \\
\hline${ }^{159} \mathrm{Gd}$ za064159 & & $\mathrm{N} / \mathrm{A}$ \\
\hline${ }^{160} \mathrm{Gd}$ za064160 & 21.860000 & ENDF.B-VII.0* \\
\hline \multicolumn{3}{|l|}{ Terbium } \\
\hline${ }^{159} \mathrm{~Tb}$ za065159 & 100.000000 & ENDF.B-VII.0* \\
\hline${ }^{160} \mathrm{~Tb}$ za065160 & & ENDF.B-VII.0* \\
\hline \multicolumn{3}{|l|}{ Dysprosium } \\
\hline${ }^{156}$ Dy za066156 & 0.060000 & ENDF.B-VII.0* \\
\hline${ }^{157}$ Dy za066157 & & $\mathrm{N} / \mathrm{A}$ \\
\hline${ }^{158}$ Dy za066158 & 0.100000 & ENDF.B-VII.0* \\
\hline${ }^{159}$ Dy za066159 & & $\mathrm{N} / \mathrm{A}$ \\
\hline${ }^{160}$ Dy za066160 & 2.340000 & ENDF.B-VII.0* \\
\hline${ }^{161}$ Dy za066161 & 18.910000 & ENDF.B-VII.0* \\
\hline${ }^{162}$ Dy za066162 & 25.510000 & ENDF.B-VII.0* \\
\hline${ }^{163}$ Dy za066163 & 24.900000 & ENDF.B-VII.0* \\
\hline${ }^{164}$ Dy za066164 & 28.180000 & ENDF.B-VII.0* \\
\hline \multicolumn{3}{|l|}{ Holmium } \\
\hline${ }^{165}$ Ho za067165 & 100.000000 & ENDF.B-VII.0* \\
\hline${ }^{166}$ Ho za067166 & & $\mathrm{N} / \mathrm{A}$ \\
\hline \multicolumn{3}{|l|}{ Erbium } \\
\hline${ }^{162} \operatorname{Er}$ za068162 & 0.139000 & ENDF.B-VII.0* \\
\hline${ }^{163} \operatorname{Er}$ za068163 & & $\mathrm{N} / \mathrm{A}$ \\
\hline${ }^{164} \operatorname{Er}$ za068164 & 1.601000 & ENDF.B-VII.0* \\
\hline${ }^{165} \operatorname{Er}$ za068165 & & $\mathrm{N} / \mathrm{A}$ \\
\hline${ }^{166} \operatorname{Er}$ za068166 & 33.503000 & ENDF.B-VII.0* \\
\hline${ }^{167} \operatorname{Er}$ za068167 & 22.869000 & ENDF.B-VII.0* \\
\hline${ }^{168} \operatorname{Er}$ za068168 & 26.978000 & ENDF.B-VII.0* \\
\hline${ }^{169} \operatorname{Er}$ za068169 & & $\mathrm{N} / \mathrm{A}$ \\
\hline${ }^{170} \operatorname{Er}$ za068170 & 14.910000 & ENDF.B-VII.0* \\
\hline \multicolumn{3}{|l|}{ Thulium } \\
\hline${ }^{166} \mathrm{Tm}$ za069166 & & $\mathrm{N} / \mathrm{A}$ \\
\hline${ }^{167}$ Tm za069167 & & $\mathrm{N} / \mathrm{A}$ \\
\hline${ }^{168} \mathrm{Tm} \mathrm{za069168}$ & & $\mathrm{N} / \mathrm{A}$ \\
\hline${ }^{169} \mathrm{Tm} \mathrm{za069169}$ & 100.000000 & TENDL-2008 \\
\hline${ }^{170} \mathrm{Tm}$ za069170 & & $\mathrm{N} / \mathrm{A}$ \\
\hline${ }^{171} \mathrm{Tm}$ za069171 & & TENDL-2008 \\
\hline${ }^{172} \mathrm{Tm}$ za069172 & & $\mathrm{N} / \mathrm{A}$ \\
\hline${ }^{173} \mathrm{Tm} \mathrm{za069173}$ & & $\mathrm{N} / \mathrm{A}$ \\
\hline \multicolumn{3}{|l|}{ Ytterbium } \\
\hline${ }^{168} \mathrm{Yb} \mathrm{za070168}$ & 0.130000 & TENDL-2008 \\
\hline${ }^{169} \mathrm{Yb} \quad$ za070169 & & TENDL-2008 \\
\hline${ }^{170} \mathrm{Yb}$ za070170 & 3.040000 & TENDL-2008 \\
\hline${ }^{171} \mathrm{Yb} \quad$ za070171 & 14.280000 & TENDL-2008 \\
\hline${ }^{172} \mathrm{Yb} \quad$ za070172 & 21.830000 & TENDL-2008 \\
\hline${ }^{173} \mathrm{Yb} \quad$ za070173 & 16.130000 & TENDL-2008 \\
\hline${ }^{174} \mathrm{Yb} \quad$ za070174 & 31.830000 & TENDL-2008 \\
\hline
\end{tabular}

TABLE IX: Incident neutron evaluation sources for ENDL2009.

\begin{tabular}{|c|c|c|}
\hline Symbol & $\begin{array}{l}\text { natural } \\
\text { abund. (\%) }\end{array}$ & $\begin{array}{l}\text { evaluation } \\
\text { source }\end{array}$ \\
\hline${ }^{175} \mathrm{Yb} \quad$ za070175 & & $\mathrm{N} / \mathrm{A}$ \\
\hline${ }^{176} \mathrm{Yb} \quad \mathrm{za} 070176$ & 12.760000 & TENDL-2008 \\
\hline \multicolumn{3}{|l|}{ Lutetium } \\
\hline${ }^{170} \mathrm{Lu} \quad \mathrm{za0} 1170$ & & $\mathrm{~N} / \mathrm{A}$ \\
\hline${ }^{171} \mathrm{Lu} \quad \mathrm{za} 071171$ & & $\mathrm{~N} / \mathrm{A}$ \\
\hline${ }^{172} \mathrm{Lu} \quad \mathrm{za} 071172$ & & $\mathrm{~N} / \mathrm{A}$ \\
\hline${ }^{173} \mathrm{Lu} \quad \mathrm{za} 071173$ & & $\mathrm{~N} / \mathrm{A}$ \\
\hline${ }^{174} \mathrm{Lu} \quad$ za071174 & & $\mathrm{N} / \mathrm{A}$ \\
\hline${ }^{175} \mathrm{Lu} \quad \mathrm{za} 071175$ & 97.410000 & ENDF.B-VII.0* \\
\hline${ }^{176} \mathrm{Lu} \quad$ za071176 & 2.590000 & ENDF.B-VII.0* \\
\hline${ }^{177} \mathrm{Lu} \quad$ za071177 & & $\mathrm{N} / \mathrm{A}$ \\
\hline${ }^{178} \mathrm{Lu} \quad \mathrm{za} 071178$ & & $\mathrm{~N} / \mathrm{A}$ \\
\hline${ }^{179} \mathrm{Lu} \quad$ za071179 & & $\mathrm{N} / \mathrm{A}$ \\
\hline \multicolumn{3}{|l|}{ Hafnium } \\
\hline${ }^{174} \mathrm{Hf} \quad$ za072174 & 0.160000 & ENDF.A-9.2009* \\
\hline${ }^{175} \mathrm{Hf} \quad \mathrm{za0} 072175$ & & $\mathrm{~N} / \mathrm{A}$ \\
\hline${ }^{176} \mathrm{Hf}$ za072176 & 5.260000 & ENDF.A-9.2009* \\
\hline${ }^{177} \mathrm{Hf} \quad \mathrm{za0} 072177$ & 18.600000 & ENDF.A-9.2009* \\
\hline${ }^{178} \mathrm{Hf}$ za072178 & 27.280000 & ENDF.A-9.2009* \\
\hline${ }^{179} \mathrm{Hf}$ za072179 & 13.620000 & ENDF.A-9.2009* \\
\hline${ }^{180} \mathrm{Hf}$ za072180 & 35.080000 & ENDF.A-9.2009* \\
\hline \multicolumn{3}{|l|}{ Tantalum } \\
\hline${ }^{178} \mathrm{Ta} \quad$ za073178 & & LLNL-2009 \\
\hline${ }^{179}$ Ta za073179 & & LLNL-2009 \\
\hline${ }^{180} \mathrm{Ta} \quad \mathrm{za} 073180$ & 0.012000 & LLNL-2009 \\
\hline${ }^{181} \mathrm{Ta} \quad \mathrm{za} 073181$ & 99.988000 & LLNL-2009* \\
\hline${ }^{182} \mathrm{Ta} \quad \mathrm{za} 073182$ & & LLNL-2009* \\
\hline${ }^{183} \mathrm{Ta} \quad$ za073183 & & LLNL-2009 \\
\hline${ }^{184} \mathrm{Ta} \quad$ za073184 & & $\mathrm{N} / \mathrm{A}$ \\
\hline \multicolumn{3}{|l|}{ Tungsten } \\
\hline${ }^{178} \mathrm{~W} \quad \mathrm{za} 074178$ & & LLNL-2009 \\
\hline${ }^{179} \mathrm{~W} \quad$ za074179 & & LLNL-2009 \\
\hline${ }^{180} \mathrm{~W}$ za074180 & 0.120000 & IAEA-W-CRP-2009* \\
\hline${ }^{181} \mathrm{~W} \quad$ za074181 & & LLNL-2009 \\
\hline${ }^{182} \mathrm{~W} \quad$ za074182 & 26.500000 & IAEA-W-CRP-2009* \\
\hline${ }^{183} \mathrm{~W} \quad$ za074183 & 14.310000 & IAEA-W-CRP-2009* \\
\hline${ }^{184} \mathrm{~W} \quad \mathrm{za} 074184$ & 30.640000 & IAEA-W-CRP-2009* \\
\hline${ }^{185} \mathrm{~W}$ za074185 & & LLNL-2009 \\
\hline${ }^{186} \mathrm{~W} \quad \mathrm{za} 074186$ & 28.430000 & IAEA-W-CRP-2009* \\
\hline${ }^{187} \mathrm{~W} \quad$ za074187 & & LLNL-2009 \\
\hline${ }^{188} \mathrm{~W} \quad$ za074188 & & LLNL-2009 \\
\hline \multicolumn{3}{|l|}{ Rhenium } \\
\hline${ }^{183} \mathrm{Re}$ za075183 & & LLNL-2009 \\
\hline${ }^{184}$ Re za075184 & & LLNL-2009 \\
\hline${ }^{185}$ Re za075185 & 37.400000 & LLNL-2009* \\
\hline${ }^{186}$ Re za075186 & & LLNL-2009 \\
\hline${ }^{187}$ Re za075187 & 62.600000 & LLNL-2009* \\
\hline${ }^{188}$ Re za075188 & & LLNL-2009 \\
\hline${ }^{189}$ Re za075189 & & LLNL-2009 \\
\hline \multicolumn{3}{|l|}{ Osmium } \\
\hline${ }^{n a t}$ Os za076000 & $\mathrm{N} / \mathrm{A}$ & JEFF-3.1 \\
\hline${ }^{184}$ Os za076184 & 0.020000 & TENDL-2008 \\
\hline${ }^{185}$ Os za076185 & & $\mathrm{N} / \mathrm{A}$ \\
\hline${ }^{186}$ Os za076186 & 1.590000 & TENDL-2008 \\
\hline${ }^{187}$ Os $\mathrm{za} 076187$ & 1.600000 & TENDL-2008 \\
\hline${ }^{188}$ Os za076188 & 13.290000 & TENDL-2008 \\
\hline${ }^{189}$ Os za076189 & 16.210000 & TENDL-2008 \\
\hline${ }^{190}$ Os za076190 & 26.360000 & TENDL-2008 \\
\hline${ }^{191}$ Os za076191 & & TENDL-2008 \\
\hline${ }^{192}$ Os za076192 & 40.930000 & TENDL-2008 \\
\hline
\end{tabular}


TABLE IX: Incident neutron evaluation sources for ENDL2009.

\begin{tabular}{|c|c|c|}
\hline Symbol & $\begin{array}{l}\text { natural } \\
\text { abund. (\%) }\end{array}$ & $\begin{array}{l}\text { evaluation } \\
\text { source }\end{array}$ \\
\hline${ }^{193}$ Os za076193 & & TENDL-2008 \\
\hline \multicolumn{3}{|l|}{ Iridium } \\
\hline${ }^{187} \mathrm{Ir} \quad \mathrm{za0} 77187$ & & $\mathrm{~N} / \mathrm{A}$ \\
\hline${ }^{188}$ Ir za077188 & & $\mathrm{N} / \mathrm{A}$ \\
\hline${ }^{189} \mathrm{Ir} \quad \mathrm{za} 077189$ & & $\mathrm{~N} / \mathrm{A}$ \\
\hline${ }^{190} \mathrm{Ir} \quad \mathrm{za} 077190$ & & $\mathrm{~N} / \mathrm{A}$ \\
\hline${ }^{191}$ Ir za077191 & 37.300000 & ENDF.B-VII.0* \\
\hline${ }^{192}$ Ir za077192 & & $\mathrm{N} / \mathrm{A}$ \\
\hline${ }^{193}$ Ir za077193 & 62.700000 & ENDF.B-VII.0* \\
\hline${ }^{194}$ Ir za077194 & & $\mathrm{N} / \mathrm{A}$ \\
\hline${ }^{195}$ Ir za077195 & & $\mathrm{N} / \mathrm{A}$ \\
\hline \multicolumn{3}{|l|}{ Platinum } \\
\hline${ }^{n a t} \mathrm{Pt}$ za078000 & $\mathrm{N} / \mathrm{A}$ & JEFF-3.1 \\
\hline${ }^{190} \mathrm{Pt}$ za078190 & 0.014000 & TENDL-2008 \\
\hline${ }^{192} \mathrm{Pt}$ za078192 & 0.782000 & TENDL-2008 \\
\hline${ }^{193} \mathrm{Pt}$ za078193 & & $\mathrm{N} / \mathrm{A}$ \\
\hline${ }^{194} \mathrm{Pt}$ za078194 & 32.967000 & TENDL-2008 \\
\hline${ }^{195} \mathrm{Pt}$ za078195 & 33.832000 & TENDL-2008 \\
\hline${ }^{196} \mathrm{Pt}$ za078196 & 25.242000 & TENDL-2008 \\
\hline${ }^{197} \mathrm{Pt} \quad$ za078197 & & $\mathrm{N} / \mathrm{A}$ \\
\hline${ }^{198} \mathrm{Pt}$ za078198 & 7.163000 & TENDL-2008 \\
\hline \multicolumn{3}{|l|}{ Gold } \\
\hline${ }^{193} \mathrm{Au}$ za079193 & & $\mathrm{N} / \mathrm{A}$ \\
\hline${ }^{194} \mathrm{Au} \quad \mathrm{za079194}$ & & $\mathrm{N} / \mathrm{A}$ \\
\hline${ }^{195} \mathrm{Au} \quad \mathrm{za079195}$ & & LLNL-2009 \\
\hline${ }^{196} \mathrm{Au} \mathrm{za079196}$ & & LLNL-2009 \\
\hline${ }^{197} \mathrm{Au} \quad \mathrm{za0} 079197$ & 100.000000 & ENDF.B-VII.0* \\
\hline${ }^{198} \mathrm{Au} \quad$ za079198 & & $\mathrm{N} / \mathrm{A}$ \\
\hline${ }^{199} \mathrm{Au} \quad$ za079199 & & $\mathrm{N} / \mathrm{A}$ \\
\hline \multicolumn{3}{|l|}{ Mercury } \\
\hline${ }^{196} \mathrm{Hg}$ za080196 & 0.150000 & ENDF.B-VII.0* \\
\hline${ }^{197} \mathrm{Hg} \quad$ za080197 & & $\mathrm{N} / \mathrm{A}$ \\
\hline${ }^{198} \mathrm{Hg} \quad$ za080198 & 9.970000 & ENDF.B-VII.0* \\
\hline${ }^{199} \mathrm{Hg} \quad$ za080199 & 16.870000 & ENDF.B-VII.0* \\
\hline${ }^{200} \mathrm{Hg} \quad$ za080200 & 23.100000 & ENDF.B-VII.0* \\
\hline${ }^{201} \mathrm{Hg} \quad \mathrm{za0} 00201$ & 13.180000 & ENDF.B-VII.0* \\
\hline${ }^{202} \mathrm{Hg} \quad \mathrm{za0} 00202$ & 29.860000 & ENDF.B-VII.0* \\
\hline${ }^{203} \mathrm{Hg} \quad \mathrm{za} 080203$ & & $\mathrm{~N} / \mathrm{A}$ \\
\hline${ }^{204} \mathrm{Hg} \quad$ za080204 & 6.870000 & ENDF.B-VII.0* \\
\hline \multicolumn{3}{|l|}{ Thallium } \\
\hline${ }^{n a t} \mathrm{Tl}$ za081000 & $\mathrm{N} / \mathrm{A}$ & JEFF-3.1 \\
\hline${ }^{203} \mathrm{Tl}$ za081203 & 29.524000 & TENDL-2008 \\
\hline${ }^{204} \mathrm{Tl}$ za081204 & & TENDL-2008 \\
\hline${ }^{205} \mathrm{Tl}$ za081205 & 70.476000 & TENDL-2008 \\
\hline \multicolumn{3}{|l|}{ Lead } \\
\hline${ }^{202} \mathrm{~Pb}$ za082202 & & LLNL-2009 \\
\hline${ }^{203} \mathrm{~Pb} \quad$ za082203 & & LLNL-2009 \\
\hline${ }^{204} \mathrm{~Pb} \quad$ za082204 & 1.400000 & LLNL-2009* \\
\hline${ }^{205} \mathrm{~Pb} \quad$ za082205 & & LLNL-2009 \\
\hline${ }^{206} \mathrm{~Pb} \quad$ za082206 & 24.100000 & LLNL-2009* \\
\hline${ }^{207} \mathrm{~Pb} \quad$ za082207 & 22.100000 & LLNL-2009* \\
\hline${ }^{208} \mathrm{~Pb} \quad$ za082208 & 52.400000 & LLNL-2009* \\
\hline${ }^{209} \mathrm{~Pb} \quad$ za082209 & & LLNL-2009 \\
\hline${ }^{210} \mathrm{~Pb} \quad$ za082210 & & LLNL-2009 \\
\hline \multicolumn{3}{|l|}{ Bismuth } \\
\hline${ }^{204} \mathrm{Bi}$ za083204 & & $\mathrm{N} / \mathrm{A}$ \\
\hline${ }^{205} \mathrm{Bi}$ za083205 & & $\mathrm{N} / \mathrm{A}$ \\
\hline${ }^{206} \mathrm{Bi}$ za083206 & & $\mathrm{N} / \mathrm{A}$ \\
\hline${ }^{207} \mathrm{Bi} \quad \mathrm{za} 083207$ & & $\mathrm{~N} / \mathrm{A}$ \\
\hline${ }^{208} \mathrm{Bi} \quad \mathrm{za} 083208$ & & $\mathrm{~N} / \mathrm{A}$ \\
\hline
\end{tabular}

TABLE IX: Incident neutron evaluation sources for ENDL2009.

\begin{tabular}{|c|c|c|}
\hline Symbol & $\begin{array}{l}\text { natural } \\
\text { abund. (\%) }\end{array}$ & $\begin{array}{l}\text { evaluation } \\
\text { source }\end{array}$ \\
\hline${ }^{209} \mathrm{Bi}$ za083209 & 100.000000 & $\mathrm{JEFF}-3.1^{*}$ \\
\hline${ }^{210} \mathrm{Bi} \mathrm{za} 083210$ & & $\mathrm{~N} / \mathrm{A}$ \\
\hline \multicolumn{3}{|l|}{ Polonium } \\
\hline${ }^{209} \mathrm{Po}$ za084209 & & TENDL-2008 \\
\hline \multicolumn{3}{|l|}{ Radium } \\
\hline${ }^{223} \mathrm{Ra}$ za088223 & & ENDF.B-VII.0 \\
\hline${ }^{224} \mathrm{Ra} \quad$ za088224 & & ENDF.B-VII.0 \\
\hline${ }^{225} \mathrm{Ra}$ za088225 & & ENDF.B-VII.0 \\
\hline${ }^{226} \mathrm{Ra} \quad \mathrm{za} 088226$ & & ENDF.B-VII.0 \\
\hline \multicolumn{3}{|l|}{ Actinium } \\
\hline${ }^{225}$ Ac za089225 & & JENDL-AC-2008* \\
\hline${ }^{226}$ Ac za089226 & & JENDL-AC-2008* \\
\hline${ }^{227}$ Ac $\quad$ za089227 & & JENDL-AC-2008* \\
\hline \multicolumn{3}{|l|}{ Thorium } \\
\hline${ }^{227} \mathrm{Th}$ za090227 & & JENDL-AC-2008* \\
\hline${ }^{228} \mathrm{Th}$ za090228 & & JENDL-AC-2008* \\
\hline${ }^{229} \mathrm{Th}$ za090229 & & JENDL-AC-2008* \\
\hline${ }^{230} \mathrm{Th} \mathrm{za090230}$ & & JENDL-AC-2008* \\
\hline${ }^{231} \mathrm{Th}$ za090231 & & JENDL-AC-2008 \\
\hline${ }^{232} \mathrm{Th}$ za090232 & 100.000000 & ENDF.B-VII.0* \\
\hline${ }^{233} \mathrm{Th}$ za090233 & & ENDF.B-VII.0* \\
\hline${ }^{234} \mathrm{Th}$ za090234 & & JENDL-AC-2008* \\
\hline \multicolumn{3}{|l|}{ Protactinium } \\
\hline${ }^{229} \mathrm{~Pa} \quad$ za091229 & & JENDL-AC-2008 \\
\hline${ }^{230} \mathrm{~Pa}$ za091230 & & JENDL-AC-2008 \\
\hline${ }^{231} \mathrm{~Pa} \quad$ za091231 & & JENDL-AC-2008* \\
\hline${ }^{232} \mathrm{~Pa} \quad \mathrm{za} 091232$ & & JENDL-AC-2008* \\
\hline${ }^{233} \mathrm{~Pa} \quad$ za091233 & & ENDF.B-VII.0* \\
\hline \multicolumn{3}{|l|}{ Uranium } \\
\hline${ }^{230} \mathrm{U}$ za092230 & & JENDL-AC-2008 \\
\hline${ }^{231} \mathrm{U}$ za092231 & & JENDL-AC-2008 \\
\hline${ }^{232} \mathrm{U} \quad$ za092232 & & ENDF.B-VII.0* \\
\hline${ }^{233} \mathrm{U} \quad \mathrm{za} 092233$ & & ENDF.B-VII.0* \\
\hline${ }^{234} \mathrm{U} \quad$ za092234 & 0.005400 & ENDF.B-VII.0* \\
\hline${ }^{235} \mathrm{U} \quad \mathrm{za} 092235$ & 0.720400 & ENDF.B-VII.0* \\
\hline${ }^{236} \mathrm{U}$ za092236 & & ENDF.A-9.2009* \\
\hline${ }^{237} \mathrm{U}$ za092237 & & LLNL-2009* \\
\hline${ }^{238} \mathrm{U}$ za092238 & 99.274200 & ENDF.B-VII.0* \\
\hline${ }^{239} \mathrm{U}$ za092239 & & LLNL-2009* \\
\hline${ }^{240} \mathrm{U} \quad \mathrm{za} 092240$ & & ENDF.B-VII.0* \\
\hline${ }^{241} \mathrm{U} \quad$ za092241 & & ENDF.B-VII.0* \\
\hline \multicolumn{3}{|l|}{ Neptunium } \\
\hline${ }^{234} \mathrm{~Np} \quad$ za093234 & & JENDL-AC-2008 \\
\hline${ }^{235} \mathrm{~Np} \quad$ za093235 & & JENDL-AC-2008* \\
\hline${ }^{236} \mathrm{~Np}$ za093236 & & JENDL-AC-2008* \\
\hline${ }^{237} \mathrm{~Np} \quad$ za093237 & & JENDL-AC-2008* \\
\hline${ }^{238} \mathrm{~Np}$ za093238 & & JENDL-AC-2008* \\
\hline${ }^{239} \mathrm{~Np} \quad$ za093239 & & JENDL-AC-2008* \\
\hline \multicolumn{3}{|l|}{ Plutonium } \\
\hline${ }^{236} \mathrm{Pu}$ za094236 & & JENDL-AC-2008* \\
\hline${ }^{237} \mathrm{Pu} \quad$ za094237 & & JENDL-AC-2008* \\
\hline${ }^{238} \mathrm{Pu} \quad$ za094238 & & JENDL-AC-2008* \\
\hline${ }^{239} \mathrm{Pu} \quad$ za094239 & & ENDF.B-VII.0* \\
\hline${ }^{240} \mathrm{Pu} \quad$ za094240 & & ENDF.A-9.2009* \\
\hline${ }^{241} \mathrm{Pu} \quad$ za094241 & & JENDL-AC-2008* \\
\hline${ }^{242} \mathrm{Pu} \quad$ za094242 & & JENDL-AC-2008* \\
\hline${ }^{243} \mathrm{Pu} \quad$ za094243 & & $\mathrm{N} / \mathrm{A}$ \\
\hline${ }^{244} \mathrm{Pu} \quad$ za094244 & & JENDL-AC-2008* \\
\hline${ }^{245} \mathrm{Pu} \quad$ za094245 & & $\mathrm{N} / \mathrm{A}$ \\
\hline${ }^{246} \mathrm{Pu} \quad$ za094246 & & JENDL-AC-2008* \\
\hline
\end{tabular}


TABLE IX: Incident neutron evaluation sources for ENDL2009.

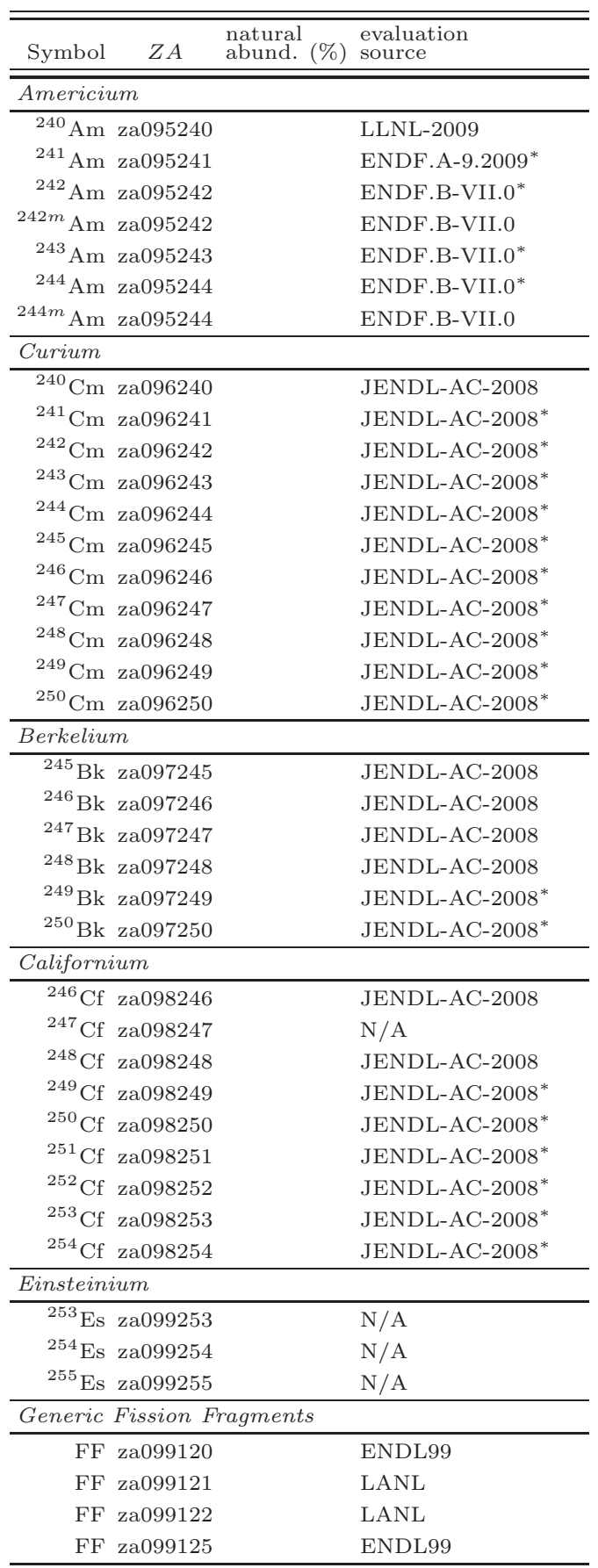

TABLE X: Incident proton evaluation sources for ENDL2009.

\begin{tabular}{crl}
\hline \hline Symbol $\quad Z A$ & $\begin{array}{l}\text { natural } \\
\text { abund. (\%) }\end{array}$ & $\begin{array}{l}\text { evaluation } \\
\text { source }\end{array}$ \\
\hline \hline Hydrogen & & \\
\hline${ }^{1} \mathrm{H}$ za001001 & 99.985000 & ECPL \\
${ }^{2} \mathrm{H}$ za001002 & 0.015000 & ECPL \\
${ }^{3} \mathrm{H}$ za001003 & LLNL-2009 \\
\hline Helium & & \\
\hline${ }^{3} \mathrm{He}$ za002003 & 0.000137 & $\mathrm{ECPL}$ \\
${ }^{4} \mathrm{He}$ za002004 & 99.999863 & $\mathrm{ECPL}$ \\
\hline Lithium & & \\
\hline
\end{tabular}

TABLE X: Incident proton evaluation sources for ENDL2009.

\begin{tabular}{|c|c|c|}
\hline Symbol & $\begin{array}{l}\text { natural } \\
\text { abund. (\%) }\end{array}$ & $\begin{array}{l}\text { evaluation } \\
\text { source }\end{array}$ \\
\hline $\begin{array}{ll}{ }^{6} \mathrm{Li} & \mathrm{za} 003006\end{array}$ & 7.590000 & ECPL \\
\hline${ }^{7} \mathrm{Li} \quad$ za003007 & 92.410000 & LLNL-2009 \\
\hline \multicolumn{3}{|l|}{ Beryllium } \\
\hline${ }^{7} \mathrm{Be}$ za004007 & & ECPL \\
\hline${ }^{9} \mathrm{Be}$ za004009 & 100.000000 & ECPL \\
\hline \multicolumn{3}{|l|}{ Boron } \\
\hline${ }^{10} \mathrm{~B}$ za005010 & 19.800000 & ECPL \\
\hline${ }^{11} \mathrm{~B}$ za005011 & 80.200000 & ECPL \\
\hline \multicolumn{3}{|l|}{ Carbon } \\
\hline${ }^{12} \mathrm{C}$ za006012 & 98.890000 & ECPL \\
\hline \multicolumn{3}{|l|}{ Nitrogen } \\
\hline${ }^{14} \mathrm{~N}$ za007014 & 99.634000 & ECPL \\
\hline \multicolumn{3}{|l|}{ Oxygen } \\
\hline${ }^{16} \mathrm{O}$ za008016 & 99.762000 & ECPL \\
\hline \multicolumn{3}{|l|}{ Yttrium } \\
\hline${ }^{89} \mathrm{Y}$ za039089 & 100.000000 & ECPL \\
\hline
\end{tabular}

TABLE XI: Incident deuteron evaluation sources for ENDL2009.

\begin{tabular}{|c|c|c|}
\hline Symbol & $\begin{array}{l}\text { natural } \\
\text { abund. (\%) }\end{array}$ & $\begin{array}{l}\text { evaluation } \\
\text { source }\end{array}$ \\
\hline \multicolumn{3}{|l|}{ Hydrogen } \\
\hline${ }^{1} \mathrm{H}$ za001001 & 99.985000 & inverse kinematics \\
\hline${ }^{2} \mathrm{H}$ za001002 & 0.015000 & LLNL-2009 \\
\hline${ }^{3} \mathrm{H} \mathrm{za001003}$ & & LLNL-2009 \\
\hline \multicolumn{3}{|l|}{ Helium } \\
\hline${ }^{3} \mathrm{He}$ za002003 & 0.000137 & LLNL-2009 \\
\hline${ }^{4} \mathrm{He}$ za002004 & 99.999863 & ECPL \\
\hline \multicolumn{3}{|l|}{ Lithium } \\
\hline${ }^{6} \mathrm{Li} \mathrm{za003006}$ & 7.590000 & LLNL-2009 \\
\hline${ }^{7} \mathrm{Li} \quad$ za003007 & 92.410000 & ECPL \\
\hline \multicolumn{3}{|l|}{ Beryllium } \\
\hline${ }^{7}$ Be za004007 & & ECPL \\
\hline${ }^{9} \mathrm{Be} \quad$ za004009 & 100.000000 & ECPL \\
\hline \multicolumn{3}{|l|}{ Boron } \\
\hline${ }^{10} \mathrm{~B}$ za005010 & 19.800000 & ECPL \\
\hline${ }^{11} \mathrm{~B} \quad \mathrm{za} 005011$ & 80.200000 & ECPL \\
\hline \multicolumn{3}{|l|}{ Carbon } \\
\hline${ }^{12} \mathrm{C}$ za006012 & 98.890000 & ECPL \\
\hline \multicolumn{3}{|l|}{ Nitrogen } \\
\hline${ }^{14} \mathrm{~N}$ za007014 & 99.634000 & ECPL \\
\hline \multicolumn{3}{|l|}{ Oxygen } \\
\hline${ }^{16} \mathrm{O}$ za008016 & 99.762000 & ECPL \\
\hline
\end{tabular}

TABLE XII: Incident triton evaluation sources in ENDL2009.

\begin{tabular}{crl}
\hline \hline Symbol $\quad Z A$ & $\begin{array}{l}\text { natural } \\
\text { abund. (\%) }\end{array}$ & $\begin{array}{l}\text { evaluation } \\
\text { source }\end{array}$ \\
\hline \hline Hydrogen & & \\
\hline${ }^{1} \mathrm{H}$ za001001 & 99.985000 & inverse kinematics \\
${ }^{2} \mathrm{H}$ za001002 & 0.015000 & inverse kinematics \\
& & LLNL-2009 \\
${ }^{3} \mathrm{H}$ za001003 & & \\
\hline Helium & & \\
\hline${ }^{3} \mathrm{He}$ za002003 & 0.000137 inverse kinematics \\
${ }^{4} \mathrm{He}$ za002004 & 99.999863 ECPL \\
\hline Lithium & \\
\hline
\end{tabular}


TABLE XII: Incident triton evaluation sources in ENDL2009.

\begin{tabular}{|c|c|c|}
\hline Symbol & $\begin{array}{l}\text { natural } \\
\text { abund. (\%) }\end{array}$ & $\begin{array}{l}\text { evaluation } \\
\text { source }\end{array}$ \\
\hline${ }^{6} \mathrm{Li} \quad \mathrm{za003006}$ & 7.590000 & ECPL \\
\hline${ }^{7} \mathrm{Li} \quad \mathrm{za} 003007$ & 92.410000 & ECPL \\
\hline \multicolumn{3}{|l|}{ Beryllium } \\
\hline${ }^{7} \mathrm{Be}$ za004007 & & ECPL \\
\hline${ }^{9}$ Be za004009 & 100.000000 & ECPL \\
\hline \multicolumn{3}{|l|}{ Boron } \\
\hline${ }^{10} \mathrm{~B}$ za005010 & 19.800000 & ECPL \\
\hline${ }^{11} \mathrm{~B}$ za005011 & 80.200000 & ECPL \\
\hline \multicolumn{3}{|l|}{ Carbon } \\
\hline${ }^{12} \mathrm{C}$ za006012 & 98.890000 & ECPL \\
\hline \multicolumn{3}{|l|}{ Nitrogen } \\
\hline${ }^{14} \mathrm{~N}$ za007014 & 99.634000 & ECPL \\
\hline \multicolumn{3}{|l|}{ Oxygen } \\
\hline${ }^{16} \mathrm{O}$ za008016 & 99.762000 & ECPL \\
\hline
\end{tabular}

TABLE XIII: Incident ${ }^{3} \mathrm{He}$ evaluation sources in ENDL2009.

\begin{tabular}{|c|c|c|}
\hline Symbol & $\begin{array}{l}\text { natural } \\
\text { abund. (\%) }\end{array}$ & $\begin{array}{l}\text { evaluation } \\
\text { source }\end{array}$ \\
\hline \multicolumn{3}{|l|}{ Hydrogen } \\
\hline${ }^{1} \mathrm{H}$ za001001 & 99.985000 & inverse kinematics \\
\hline${ }^{2} \mathrm{H} \quad \mathrm{za} 001002$ & 0.015000 & inverse kinematics \\
\hline${ }^{3} \mathrm{H}$ za001003 & & ECPL \\
\hline \multicolumn{3}{|l|}{ Helium } \\
\hline${ }^{3} \mathrm{He}$ za002003 & 0.000137 & ECPL \\
\hline${ }^{4} \mathrm{He}$ za002004 & 99.999863 & ECPL \\
\hline \multicolumn{3}{|l|}{ Lithium } \\
\hline${ }^{6} \mathrm{Li}$ za003006 & 7.590000 & ECPL \\
\hline${ }^{7} \mathrm{Li}$ za003007 & 92.410000 & ECPL \\
\hline \multicolumn{3}{|l|}{ Beryllium } \\
\hline${ }^{7} \mathrm{Be}$ za004007 & & ECPL \\
\hline${ }^{9} \mathrm{Be}$ za004009 & 100.000000 & ECPL \\
\hline \multicolumn{3}{|l|}{ Boron } \\
\hline${ }^{10} \mathrm{~B}$ za005010 & 19.800000 & ECPL \\
\hline${ }^{11} \mathrm{~B}$ za005011 & 80.200000 & ECPL \\
\hline \multicolumn{3}{|l|}{ Carbon } \\
\hline${ }^{12} \mathrm{C}$ za006012 & 98.890000 & ECPL \\
\hline \multicolumn{3}{|l|}{ Nitrogen } \\
\hline${ }^{14} \mathrm{~N}$ za007014 & 99.634000 & ECPL \\
\hline \multicolumn{3}{|l|}{ Oxygen } \\
\hline${ }^{16} \mathrm{O}$ za008016 & 99.762000 & ECPL \\
\hline
\end{tabular}

TABLE XIV: Incident $\alpha$ evaluation sources in ENDL2009.

\begin{tabular}{crl}
\hline \hline Symbol $\quad Z A$ & $\begin{array}{l}\text { natural } \\
\text { abund. (\%) }\end{array}$ & $\begin{array}{l}\text { evaluation } \\
\text { source }\end{array}$ \\
\hline \hline Hydrogen & & \\
\hline${ }^{1} \mathrm{H}$ za001001 & 99.985000 & inverse kinematics \\
${ }^{2} \mathrm{H}$ za001002 & 0.015000 & inverse kinematics \\
${ }^{3} \mathrm{H}$ za001003 & inverse kinematics \\
\hline
\end{tabular}

\begin{tabular}{lr}
\hline Helium \\
\hline${ }^{3} \mathrm{He}$ za002003 & 0.000137 inverse kinematics \\
${ }^{4} \mathrm{He}$ za002004 & $99.999863 \mathrm{ECPL}$ \\
\hline Lithium & \\
\hline${ }^{6} \mathrm{Li} \mathrm{za003006}$ & $7.590000 \mathrm{ECPL}$ \\
${ }^{7} \mathrm{Li} \mathrm{za003007}$ & $92.410000 \mathrm{ECPL}$ \\
\hline Beryllium & \\
\hline
\end{tabular}

TABLE XV: Summary of all tests run on ENDL2009.0.

\begin{tabular}{lll}
\hline Test & ndf1 & mcf1 \\
\hline$Z A$ loop & PASS & ${ }^{148}$ Po missing \\
$Z A(n, \gamma)$ loop & N/A & PASS \\
Criticality & W improved & W improved \\
Activation Ratios & see plots & N/A \\
Goldberg $(n, \gamma)$ & N/A & 5 changes \\
TOF: LLNL pulsed Spheres & N/A & Ta, W improved; \\
& & Au: Energy distribution? \\
TOF: Oktavian Spheres & N/A & Ni, Si, W \\
d $(n, 2 n)$ & N/A & PASS \\
\hline
\end{tabular}

TABLE XIV: Incident $\alpha$ evaluation sources in ENDL2009.

\begin{tabular}{ccc}
\hline \hline Symbol & $Z A$ & $\begin{array}{l}\text { natural } \\
\text { abund. }\end{array}$ \\
\hline \hline & $\begin{array}{l}\text { evaluation } \\
\text { source }\end{array}$ \\
${ }^{7} \mathrm{Be}$ za004007 & $\begin{array}{l}\text { ECPL } \\
{ }^{9} \mathrm{Be} \text { za004009 }\end{array}$ \\
\hline Boron & \\
\hline${ }^{10} \mathrm{~B}$ za005010 & $19.800000 \mathrm{ECPL}$ \\
${ }^{11} \mathrm{~B}$ za005011 & $80.200000 \mathrm{ECPL}$ \\
\hline Carbon & \\
\hline${ }^{12} \mathrm{C}$ za006012 & $98.890000 \mathrm{ECPL}$ \\
\hline Nitrogen & \\
\hline${ }^{14} \mathrm{~N}$ za007014 & $99.634000 \mathrm{ECPL}$ \\
\hline Oxygen & \\
\hline${ }^{16} \mathrm{O}$ za008016 & $99.762000 \mathrm{ECPL}$ \\
\hline
\end{tabular}

\section{Appendix B: Detailed Test Results}

The ENDL2009.0 cross-section library was tested and compared to ENDL2008.2. In this context, a "PASS" is defined as follows, aside from new evaluations: the results simulated with ENDL2009.0 are identical or very similar to those simulated using ENDL2008.2. In the case of criticality benchmark experiments, the simulated $k_{\text {eff }}$ were also compared to available benchmark values. If the simulated result for a given case does not fall within 3 sigma of the benchmark value, the test is considered to have failed. The results are summarized in Table XV. 
TABLE XVI: Summary of critical assembly test results. In the "Passed test?" column, we indicate whether the test passed (i.e. calculated a $k_{\text {eff }}$ within $1 \sigma$ of quoted benchmark standard deviation) or how many standard deviations our calculation is from the quoted benchmark value.

\begin{tabular}{|c|c|c|c|c|c|c|}
\hline $\begin{array}{l}\text { Assembly } \\
\text { Name } \\
\end{array}$ & Core & Reflector & $\begin{array}{r}\text { Benchmark } \\
k_{\text {eff }} \pm d k_{\text {eff }} \\
\end{array}$ & $\begin{array}{l}\text { Mercury } \\
k_{\text {eff }} \pm d k_{\text {eff }} \\
\end{array}$ & $\begin{array}{c}\text { AMTRAN } \\
k_{\text {eff }} \\
\end{array}$ & $\begin{array}{c}\text { Passed test? } \\
\text { Mercury/AMTRAN } \\
\end{array}$ \\
\hline HMF084.1 & $\mathrm{HEU}$ & $\mathrm{Al}$ & $0.9994 \pm 0.0019$ & $0.99936 \pm 0.00010$ & & Pass/ \\
\hline PMF009 & $\mathrm{Pu}$ & $\mathrm{Al}$ & $1.0000 \pm 0.0027$ & $1.00660 \pm 0.00010$ & & $2 \sigma /$ \\
\hline HMF084.15 & $\mathrm{HEU}$ & $\mathrm{Al}_{2} \mathrm{O}_{3}$ & $0.9995 \pm 0.0021$ & $0.99816 \pm 0.00010$ & & Pass/ \\
\hline HMF084.2 & $\mathrm{HEU}$ & $\mathrm{Al}_{2} \mathrm{O}_{3}$ & $0.9994 \pm 0.0021$ & $0.99975 \pm 0.00010$ & & Pass / \\
\hline Godiva & Bare HEU & & $1.0000 \pm 0.0010$ & $1.00006 \pm 0.00010$ & 1.00034 & Pass/Pass \\
\hline Jezebel & Bare $\mathrm{Pu}$ & & $1.0000 \pm 0.0020$ & $1.00070 \pm 0.00010$ & 1.00061 & Pass/Pass \\
\hline PMF029 S & Bare $\mathrm{Pu}$ & & $1.0000 \pm 0.0020$ & $0.99701 \pm 0.00010$ & & $1 \sigma /$ \\
\hline Jezebel-240 & Bare $\mathrm{Pu}$ & & $1.0000 \pm 0.0020$ & $1.00138 \pm 0.00010$ & 1.00110 & Pass/Pass \\
\hline PMF022 & Bare $\mathrm{Pu}$ & & $1.0000 \pm 0.0021$ & $0.99945 \pm 0.00011$ & & Pass / \\
\hline Jezebel-233 & Bare 233U & & $1.0000 \pm 0.0010$ & $0.99930 \pm 0.00014$ & 1.00000 & Pass/Pass \\
\hline MMF001.1 & $\mathrm{Pu}$ core $+\mathrm{HEU}$ shell & & $1.0000 \pm 0.0016$ & $1.00085 \pm 0.00015$ & & Pass / \\
\hline MMF009.1 & $\mathrm{Pu}$ core $+\mathrm{HEU}$ shell & & $1.0000 \pm 0.001$ & $1.00117 \pm 0.00011$ & & $1 \sigma /$ \\
\hline MMF010.1 & $\mathrm{Pu}$ core $+\mathrm{HEU}$ shell & & $1.0000 \pm 0.0009$ & $1.00070 \pm 0.00010$ & & Pass/ \\
\hline PST011 & Solution & & $1.0000 \pm 0.0052$ & $0.96856 \pm 0.00016$ & 1.01191 & $6 \sigma / 2 \sigma$ \\
\hline MMF007.9 & $\mathrm{Pu}+\mathrm{HEU}$ & $\mathrm{Be}$ & $1.0000 \pm 0.0003$ & & 1.00347 & $/ 11 \sigma$ \\
\hline HMF017 & HEU & $\mathrm{Be}$ & $0.9993 \pm 0.0014$ & $0.99789 \pm 0.00010$ & & $1 \sigma /$ \\
\hline HMF041.1 & $\mathrm{HEU}$ & $\mathrm{Be}$ & $1.0013 \pm 0.003$ & & 1.00697 & $/ 1 \sigma$ \\
\hline HMF041.2 & $\mathrm{HEU}$ & $\mathrm{Be}$ & $1.0022 \pm 0.0043$ & & 1.00804 & $/ 1 \sigma$ \\
\hline HMF084.16 & $\mathrm{HEU}$ & $\mathrm{Be}$ & $0.9994 \pm 0.002$ & $0.99757 \pm 0.00010$ & & Pass/ \\
\hline HMF084.3 & $\mathrm{HEU}$ & $\mathrm{Be}$ & $0.9993 \pm 0.0021$ & $0.99707 \pm 0.00010$ & & $1 \sigma /$ \\
\hline PMF019.1 & $\mathrm{Pu}$ & $\mathrm{Be}$ & $0.9992 \pm 0.0015$ & $0.99877 \pm 0.00010$ & & Pass / \\
\hline PMF018 & $\mathrm{Pu}$ & $\mathrm{Be}$ & $1.0000 \pm 0.0030$ & $0.99703 \pm 0.00010$ & 1.00144 & Pass/Pass \\
\hline HMF084.26 & $\mathrm{HEU}$ & $\begin{array}{l}\text { Be inner reflector, } \\
\text { Fe outer reflector }\end{array}$ & $0.9993 \pm 0.0022$ & $0.99887 \pm 0.00010$ & & $\begin{array}{r}\text { Pass / } \\
/\end{array}$ \\
\hline HMF084.27 & small HEU core & $\begin{array}{l}\text { Be inner reflector, } \\
\text { Fe outer reflector }\end{array}$ & $0.9994 \pm 0.002$ & $0.98258 \pm 0.00010$ & & $\begin{array}{r}8 \sigma / \\
/\end{array}$ \\
\hline HMF084.17 & $\mathrm{HEU}$ & $\mathrm{Co}$ & $0.9995 \pm 0.0019$ & $1.02744 \pm 0.00010$ & & $14 \sigma /$ \\
\hline HMF084.5 & $\mathrm{HEU}$ & $\mathrm{Co}$ & $0.9993 \pm 0.0021$ & $1.05147 \pm 0.00010$ & & $24 \sigma /$ \\
\hline Zeus & $\mathrm{HEU}$ & $\mathrm{Cu}$ & $1.0082 \pm 0.0003$ & $1.01229 \pm 0.00013$ & & $13 \sigma /$ \\
\hline HMF084.18 & $\mathrm{HEU}$ & $\mathrm{Cu}$ & $0.9995 \pm 0.0022$ & $0.99779 \pm 0.00010$ & & Pass/ \\
\hline HMF084.6 & $\mathrm{HEU}$ & $\mathrm{Cu}$ & $0.9994 \pm 0.0024$ & $0.99879 \pm 0.00010$ & & Pass/ \\
\hline PMF040 & $\mathrm{Pu}$ & $\mathrm{Cu}$ & $1.0000 \pm 0.0038$ & $1.00138 \pm 0.00010$ & & Pass / \\
\hline HMF085.4 & $\mathrm{HEU}$ & $\mathrm{Cu}-\mathrm{Ni}-\mathrm{Zn}$ alloy & $0.9996 \pm 0.0029$ & $1.01182 \pm 0.00010$ & 1.01635 & $4 \sigma / 5 \sigma$ \\
\hline HMF085.1 & $\mathrm{HEU}$ & $\mathrm{Cu}$ (outer) & $0.9998 \pm 0.0029$ & $1.00028 \pm 0.00010$ & 1.00754 & Pass $/ 2 \sigma$ \\
\hline HMF085.2 & $\mathrm{HEU}$ & $\mathrm{Cu}$ (outer) & $0.9997 \pm 0.0031$ & $1.00441 \pm 0.00010$ & 1.01646 & $1 \sigma / 5 \sigma$ \\
\hline PMF041 & $\mathrm{Pu}$ & D38 & $1.0000 \pm 0.0016$ & $1.00738 \pm 0.00012$ & & $4 \sigma /$ \\
\hline HMF014.1 & $\mathrm{HEU}$ & $\overline{\mathrm{DU}}$ & $0.9989 \pm 0.0017$ & $1.00085 \pm 0.00015$ & & $1 \sigma /$ \\
\hline PMF020.1 & $\mathrm{Pu}$ & DU & $0.9993 \pm 0.0017$ & $0.99975 \pm 0.00010$ & & Pass/ \\
\hline HMF055 & $\mathrm{HEU}$ & DU (ZPR3-23) & $0.9955 \pm 0.0028$ & $1.00055 \pm 0.00216$ & & $1 \sigma /$ \\
\hline PMF039 & $\mathrm{Pu}$ & Duraluminium & $1.0000 \pm 0.0022$ & $0.99291 \pm 0.00010$ & & $3 \sigma /$ \\
\hline HMF085.3 & $\mathrm{HEU}$ & Fe (outer) & $0.9995 \pm 0.0046$ & $0.99824 \pm 0.00010$ & 1.02797 & Pass $/ 6 \sigma$ \\
\hline MMF002.1 & $\mathrm{Pu}+\mathrm{HEU}$ & flattop mixed metal & $1.0000 \pm 0.0042$ & $1.00588 \pm 0.00099$ & 0.99951 & $1 \sigma /$ Pass \\
\hline MMF002.2 & $\mathrm{Pu}+\mathrm{HEU}$ & flattop mixed metal & $1.0000 \pm 0.0044$ & $1.00641 \pm 0.00099$ & 0.99979 & $1 \sigma /$ Pass \\
\hline MMF002.3 & $\mathrm{Pu}+\mathrm{HEU}$ & flattop mixed metal & $1.0000 \pm 0.0048$ & $1.00744 \pm 0.00100$ & 1.00022 & $1 \sigma /$ Pass \\
\hline HMF019 & HEU & graphite & $1.0000 \pm 0.0030$ & $1.01237 \pm 0.00010$ & 1.01296 & $4 \sigma / 4 \sigma$ \\
\hline HMF041.3 & $\mathrm{HEU}$ & graphite & $1.0006 \pm 0.0029$ & & 1.00938 & $/ 3 \sigma$ \\
\hline HMF041.4 & $\mathrm{HEU}$ & graphite & $1.0006 \pm 0.0025$ & & 1.02245 & $/ 8 \sigma$ \\
\hline HMF041.5 & $\mathrm{HEU}$ & graphite & $1.0006 \pm 0.0031$ & & 1.01177 & $/ 3 \sigma$ \\
\hline HMF041.6 & $\mathrm{HEU}$ & graphite & $1.0006 \pm 0.0045$ & & 1.01397 & $/ 2 \sigma$ \\
\hline HMF084.4 & $\mathrm{HEU}$ & graphite & $0.9994 \pm 0.002$ & $1.00340 \pm 0.00010$ & & $1 \sigma /$ \\
\hline PMF030 S & $\mathrm{Pu}$ & graphite & $1.0000 \pm 0.0021$ & $1.01166 \pm 0.00010$ & & $5 \sigma /$ \\
\hline PMF023 & $\mathrm{Pu}$ & graphite & $1.0000 \pm 0.0020$ & $1.00698 \pm 0.00010$ & & $3 \sigma /$ \\
\hline U233MF002 & $233 \mathrm{U}$ & HEU $\left(93 \%{ }^{235} \mathrm{U}\right)$ & $1.0000 \pm 0.0010$ & $0.99871 \pm 0.00014$ & 0.99881 & $1 \sigma / 1 \sigma$ \\
\hline HMF084.20 & $\mathrm{HEU}$ & Mo & $0.9995 \pm 0.0025$ & $1.00343 \pm 0.00010$ & & $1 \sigma /$ \\
\hline HMF084.8 & HEU & Mo & $0.9994 \pm 0.0034$ & $1.00913 \pm 0.00010$ & & $2 \sigma /$ \\
\hline HMF084.21 & $\mathrm{HEU}$ & $\mathrm{MoC}_{2}$ & $0.9995 \pm 0.0045$ & $1.00167 \pm 0.00010$ & & Pass/ \\
\hline HMF084.9 & $\mathrm{HEU}$ & $\mathrm{MoC}_{2}$ & $0.9993 \pm 0.0054$ & $1.00532 \pm 0.00010$ & & $1 \sigma /$ \\
\hline HMF003 & $\mathrm{HEU}$ & $\mathrm{Ni}$ & $1.0000 \pm 0.0030$ & $1.00837 \pm 0.00010$ & 1.05583 & $2 \sigma / 18 \sigma$ \\
\hline
\end{tabular}


TABLE XVI: Summary of critical assembly test results. In the "Passed test?" column, we indicate whether the test passed (i.e. calculated a $k_{\text {eff }}$ within $1 \sigma$ of quoted benchmark standard deviation) or how many standard deviations our calculation is from the quoted benchmark value.

\begin{tabular}{|c|c|c|c|c|c|c|}
\hline $\begin{array}{l}\text { Assembly } \\
\text { Name } \\
\end{array}$ & Core & Reflector & $\begin{array}{r}\text { Benchmark } \\
k_{\text {eff }} \pm d k_{\text {eff }} \\
\end{array}$ & $\begin{array}{l}\text { Mercury } \\
k_{\text {eff }} \pm d k_{\text {eff }} \\
\end{array}$ & $\begin{array}{c}\text { AMTRAN } \\
k_{\text {eff }} \\
\end{array}$ & $\begin{array}{c}\text { Passed test? } \\
\text { Mercury/AMTRAN } \\
\end{array}$ \\
\hline HMF084.10 & $\mathrm{HEU}$ & $\mathrm{Ni}$ & $0.9993 \pm 0.0022$ & $1.00131 \pm 0.00010$ & & Pass/ \\
\hline HMF084.22 & $\mathrm{HEU}$ & $\mathrm{Ni}$ & $0.9994 \pm 0.002$ & $0.99850 \pm 0.00010$ & & Pass/ \\
\hline HMF064.1 & HEU & $\mathrm{Pb}$ & $0.9996 \pm 0.0008$ & $1.01636 \pm 0.00010$ & & $20 \sigma /$ \\
\hline PMF035 & $\mathrm{Pu}$ & $\mathrm{Pb}$ & $1.0000 \pm 0.0016$ & $1.00798 \pm 0.00010$ & & $4 \sigma /$ \\
\hline HMF020 & HEU & polyethylene & $1.0000 \pm 0.0030$ & $1.00207 \pm 0.00010$ & 1.00107 & Pass/Pass \\
\hline PMF024 & $\mathrm{Pu}$ & polyethylene & $1.0000 \pm 0.0020$ & $1.00471 \pm 0.00010$ & & $2 \sigma /$ \\
\hline HMF084.23 & $\mathrm{HEU}$ & $\begin{array}{l}\text { polythene } \\
\text { (isotopic) }\end{array}$ & $0.9993 \pm 0.0024$ & $0.99439 \pm 0.00010$ & & $\begin{array}{r}2 \sigma / \\
/\end{array}$ \\
\hline HMF084.11 & $\mathrm{HEU}$ & $\begin{array}{l}\text { polythene } \\
\text { (isotopic) }\end{array}$ & $0.9995 \pm 0.0019$ & $1.00420 \pm 0.00010$ & & $2 \sigma /$ \\
\hline HMF084.19 & $\mathrm{HEU}$ & steel & $0.9996 \pm 0.0019$ & $0.99786 \pm 0.00010$ & & Pass/ \\
\hline HMF084.7 & $\mathrm{HEU}$ & steel & $0.9995 \pm 0.002$ & $0.99798 \pm 0.00010$ & & Pass/ \\
\hline IMF005 & IEU & steel & $1.0000 \pm 0.0021$ & $1.00440 \pm 0.00011$ & 1.03675 & $2 \sigma / 17 \sigma$ \\
\hline PMF026 S & $\mathrm{Pu}$ & steel & $1.0000 \pm 0.0024$ & $0.99969 \pm 0.00010$ & & Pass/ \\
\hline PMF028 S & $\mathrm{Pu}$ & steel & $1.0000 \pm 0.0022$ & $1.00076 \pm 0.00011$ & & Pass/ \\
\hline PMF032 S & $\mathrm{Pu}$ & steel & $1.0000 \pm 0.0020$ & $0.99919 \pm 0.00010$ & & Pass / \\
\hline PMF025 & $\mathrm{Pu}$ & steel & $1.0000 \pm 0.0020$ & $0.99939 \pm 0.00010$ & & Pass/ \\
\hline Thor & $\mathrm{Pu}$ & $\mathrm{Th}$ & $1.0000 \pm 0.0006$ & $0.99941 \pm 0.00010$ & 0.99991 & Pass/Pass \\
\hline HMF085.5 & $\mathrm{HEU}$ & $\mathrm{Th}$ & $0.9995 \pm 0.0024$ & $1.00110 \pm 0.00010$ & 1.00174 & Pass/Pass \\
\hline HMF079.1 & $\mathrm{HEU}$ & $\mathrm{Ti}$ & $0.9996 \pm 0.0015$ & $1.00060 \pm 0.00010$ & & Pass/ \\
\hline HMF079.2 & $\mathrm{HEU}$ & $\mathrm{Ti}$ & $0.9996 \pm 0.0014$ & $1.00020 \pm 0.00010$ & & Pass / \\
\hline HMF079.3 & $\mathrm{HEU}$ & $\mathrm{Ti}$ & $0.9996 \pm 0.0015$ & $1.00183 \pm 0.00010$ & & $1 \sigma /$ \\
\hline HMF079.4 & $\mathrm{HEU}$ & $\mathrm{Ti}$ & $0.9996 \pm 0.0014$ & $1.00250 \pm 0.00010$ & & $2 \sigma /$ \\
\hline HMF079.5 & $\mathrm{HEU}$ & $\mathrm{Ti}$ & $0.9996 \pm 0.0015$ & $1.00178 \pm 0.00010$ & & $1 \sigma /$ \\
\hline HMF084.12 & $\mathrm{HEU}$ & $\mathrm{Ti}$ & $0.9994 \pm 0.002$ & $0.99968 \pm 0.00010$ & & Pass / \\
\hline HMF084.24 & $\mathrm{HEU}$ & $\mathrm{Ti}$ & $0.9996 \pm 0.0018$ & $0.99933 \pm 0.00010$ & & Pass/ \\
\hline HMF002 & $\mathrm{HEU}$ & tuballoy (topsy 8) & $1.0000 \pm 0.0030$ & $1.00209 \pm 0.00010$ & & Pass/ \\
\hline Flattop-Pu & $\mathrm{Pu}$ & $\mathrm{U}$ & $1.0000 \pm 0.0030$ & $1.00240 \pm 0.00014$ & 0.99946 & Pass/Pass \\
\hline PMF010 & $\mathrm{Pu}$ & $\mathrm{U}$ & $1.0000 \pm 0.0018$ & $1.00115 \pm 0.00010$ & & Pass / \\
\hline Flattop-25 & $\mathrm{HEU}$ & $\mathrm{U}\left(99 \%{ }^{238} \mathrm{U}\right)$ & $1.0000 \pm 0.0030$ & $1.00351 \pm 0.00010$ & 1.00183 & $1 \sigma /$ Pass \\
\hline HMF038 & $\mathrm{HEU}$ & $\mathrm{U}\left(99 \%{ }^{238} \mathrm{U}\right)+\mathrm{Be}$ & $0.9999 \pm 0.0007$ & $1.00147 \pm 0.00012$ & & $2 \sigma /$ \\
\hline HMF084.13 & $\mathrm{HEU}$ & ${ }^{n a t} \mathrm{U}$ & $0.9994 \pm 0.0022$ & $0.99991 \pm 0.00011$ & & Pass/ \\
\hline Big Ten & IEU & ${ }^{n a t} \mathrm{U}$ & $0.9948 \pm 0.0013$ & $0.99239 \pm 0.00040$ & 0.98907 & $1 \sigma / 4 \sigma$ \\
\hline U233MF003.1 & $233 \mathrm{U}$ & ${ }^{n a t} \mathrm{U}$ & $1.0000 \pm 0.0010$ & $0.99923 \pm 0.00042$ & & Pass/ \\
\hline U233MF006.1 & $233 \mathrm{U}$ & ${ }^{n a t} \mathrm{U}$ & $1.0000 \pm 0.0014$ & $0.99963 \pm 0.00014$ & 1.00830 & Pass $/ 5 \sigma$ \\
\hline HMF084.14 & $\mathrm{HEU}$ & $\mathrm{W}$ & $0.9994 \pm 0.0019$ & $0.99883 \pm 0.00010$ & & Pass/ \\
\hline HMF084.25 & $\mathrm{HEU}$ & $\mathrm{W}$ & $0.9995 \pm 0.002$ & $0.99733 \pm 0.00010$ & & $1 \sigma /$ \\
\hline PMF005 & $\mathrm{Pu}$ & $\mathrm{W}$ & $1.0000 \pm 0.0013$ & $1.00366 \pm 0.00010$ & & $2 \sigma /$ \\
\hline U233MF004 & $233 \mathrm{U}$ & W & $1.0000 \pm 0.0007$ & $0.99944 \pm 0.00014$ & 1.00057 & Pass/Pass \\
\hline HMF085.6 & $\mathrm{HEU}$ & $\mathrm{W}$ & $0.9997 \pm 0.0029$ & $1.00727 \pm 0.00010$ & 1.00814 & $2 \sigma / 2 \sigma$ \\
\hline PMF011 & $\mathrm{Pu}$ & water & $1.0000 \pm 0.0010$ & $1.01062 \pm 0.00010$ & 0.97411 & $10 \sigma / 25 \sigma$ \\
\hline
\end{tabular}

\section{1. ndf File Tests}

The ndf file was tested by running three types of tests with AMTRAN, a deterministic particle transport code.

\section{a. ZA Loop}

Test: A python script iterates through all isotopes in the ENDL2009.0 ndf file and launches a quick calculation to ensure that the code runs without crashing.
Status: PASS for all isotopes

\section{b. Criticality Benchmarks}

Test: Run AMTRAN simulations of 15 fast criticality benchmark assemblies. Since ENDL2008.2, the ndf 1 file has been updated to include delayed neutrons data, AMTRAN was run with the flag for delayed neutrons ON (delayed_neutrons $=1$ ).

Status: PASS. In 14 of the cases, $k_{\text {eff }}$ was identical for ENDL2009.0 and ENDL2008.2. In summer 2009, 
new cases were added with results existing only for ENDL2009.0.

Notes: Comparison to benchmark $k_{\text {eff }}$ data:

- PASS for 23/36 assemblies. The new W evaluation brings $k_{\text {eff }}$ for the W-reflected assembly to within 1 sigma of the benchmark value.

- FAILED for 13/36 assemblies with the following reflectors: all $\mathrm{Co}, \mathrm{Ni}, \mathrm{C}, \mathrm{Fe}$ and steel, some ${ }^{\text {nat }} \mathrm{U}$ and $\mathrm{H}_{2} \mathrm{O}$.

\section{c. Activation Ratios}

Test: Simulations of $(n, f),(n, \gamma)$, and $(n, 2 n)$ reaction rates on a large selection of isotopes. Foils were placed inside well-characterized benchmark critical assemblies such as Big Ten, Godiva, Jezebel and Flattop-25.

Status: Regardless of the assemblies, the fission ratios were all $2-3 \%$ lower than the experimental values. Table ?? summarizes the test results for all assemblies.

\section{Notes:}

- The $\mathrm{C} / \mathrm{E}$ ratio for ${ }^{55} \mathrm{Mn}(n, \gamma)$ is $8 \%$ higher in Big Ten and $12-16 \%$ higher in Godiva, depending on the experimental results.

- In Big Ten, the $\mathrm{C} / \mathrm{E}$ ratio was high for ${ }^{197} \mathrm{Au}$ $(n, 2 n)$ and for $(n, \gamma)$ reactions on ${ }^{58} \mathrm{Fe},{ }^{59} \mathrm{Co}$, ${ }^{241} \mathrm{Am}$. The $\mathrm{C} / \mathrm{E}$ ratio was low for $(n, 2 n)$ reactions on ${ }^{59} \mathrm{Co},{ }^{89} \mathrm{Y}$ and ${ }^{169} \mathrm{Tm}$ and for $(n, \gamma)$ reactions on ${ }^{89} \mathrm{Y}$ and ${ }^{180} \mathrm{~W}$.

- In Jezebel, the $\mathrm{C} / \mathrm{E}$ ratio was high for ${ }^{169} \mathrm{Tm}$ $(n, 2 n)$ and for $(n, \gamma)$ reactions on ${ }^{93} \mathrm{Nb},{ }^{121} \mathrm{Sb}$, ${ }^{193} \mathrm{Ir}$, and $\mathrm{C} / \mathrm{E}$ was low for $(n, \gamma)$ reactions on ${ }^{51} \mathrm{~V}$ and ${ }^{107} \mathrm{Ag}$.

- In Godiva, the $\mathrm{C} / \mathrm{E}$ ratio was high for $(n, \gamma)$ reactions on ${ }^{93} \mathrm{Nb},{ }^{121} \mathrm{Sb},{ }^{193} \mathrm{Ir},{ }^{209} \mathrm{Bi}$. The $\mathrm{C} / \mathrm{E}$ ratio was low for $(n, \gamma)$ reactions on ${ }^{81} \mathrm{Br}$ and ${ }^{85} \mathrm{Rb},{ }^{89} \mathrm{Y},{ }^{107} \mathrm{Ag}$, and ${ }^{205} \mathrm{Tl}$.

\section{2. mcf File Tests}

The mcf file was tested by running five types of tests with Mercury, a Monte Carlo particle transport code.

\section{a. ZA Loop}

Test: A python script iterates through all isotopes in the ENDL2009.0 mcf file and launches a quick calculation to ensure the code runs without crashing.

Status: Neutron transport PASS for all isotopes.

\section{Notes:}

- One isotope is missing: ${ }^{148} \mathrm{Po}$.

- Most isotopes PASS $(n, \gamma)$ production except ${ }^{148} \mathrm{Po}$ and 33 other isotopes. PASS means that the value calculated for the average gamma energy leaked per source neutron is nearly identical to ENDL2008.2 and ENDL2008.1.

- There are no gamma emission data for ${ }^{3} \mathrm{H}$ and ${ }^{4} \mathrm{He}$, similar to ENDL99 and ENDF/B-VII.0.

- There was no observed gamma emission for ${ }^{3} \mathrm{He} . \quad{ }^{3} \mathrm{He}$ can emit one $\gamma$ in the process of neutron capture, but this process has such a low probability that we did not observe it in longer simulations. The corresponding photon emission data is present in ENDL99 as well as ENDL2008.2.

- New evaluations were submitted for ${ }^{35} \mathrm{Cl}$, ${ }^{37} \mathrm{Cl},{ }^{36} \mathrm{Ar},{ }^{46-50} \mathrm{Ti},{ }^{55} \mathrm{Mn},{ }^{57-61} \mathrm{Co},{ }^{73-75} \mathrm{As}$, ${ }^{76-78} \mathrm{Kr}, \quad{ }^{89} \mathrm{Y}, \quad{ }^{90} \mathrm{Zr}, \quad{ }^{99} \mathrm{Tc}, \quad{ }^{123-124} \mathrm{Xe}$, ${ }^{181-182} \mathrm{Ta},{ }^{182-186} \mathrm{~W}$ and ${ }^{197} \mathrm{Au}$. Gamma production should be checked to ascertain whether these changes make sense.

\section{b. Criticality Benchmarks}

Test: Run Mercury simulations of 40 fast criticality benchmark assemblies and 1 solution assembly.

Status: PASS for the 30 critical assemblies available when ENDL2008.1 was tested.

Notes: Comparison to benchmark $k_{\text {eff }}$ data

- PASS for 74/88 assemblies

- FAILED for 14/88 assemblies with low $Z$ reflectors made of $\mathrm{C}$ (graphite), solution, and $\mathrm{H}_{2} \mathrm{O}$ as well as $\mathrm{Pb}, \mathrm{Co}, \mathrm{Cu}$, duraluminium, and ${ }^{238} \mathrm{U}$.

\section{c. Reaction Ratios}

Test: Simulations of reaction rates for the $(n, f),(n, \gamma)$, and $(n, 2 n)$ reactions on a large selection of isotopes. The experiments consisted in foils placed inside well characterized benchmark critical assemblies such as Big Ten, Godiva, Jezebel and Flattop25 .

Status: Results were very similar to the ones obtained with the ndf library. Except for ${ }^{197} \mathrm{Au}(\mathrm{n}, \mathrm{g})$, the main differences between the two libraries were observed for the $(n, 2 n)$ cross-sections in Big Ten, which has a softer spectrum than the other assemblies. Longer Monte Carlo runs are probably warranted to improve the statistical errors in the 
high-energy part of the spectrum since it tends to fall off sharply.

\section{Notes:}

- ${ }^{238} \mathrm{U}(n, f)$ : Mercury reaction ratios are larger by $5 \%$ higher .

- Mercury reaction ratios for $(n, 2 n)$ on ${ }^{89} \mathrm{Y}$, ${ }^{169} \mathrm{Tm},{ }^{197} \mathrm{Au}$, and ${ }^{238} \mathrm{U}$ were $-13 \%,+9 \%$, $7 \%$ and $+9 \%$ respectively.

- ${ }^{197} \mathrm{Au}(n, \gamma)$ : the Mercury reaction ratios were $7 \%$ lower in Big Ten and 12\% lower in Godiva and Jezebel.

\section{d. LLNL Pulsed Spheres}

Test: Run Mercury simulations of 16 pulsed sphere experiments and produce time-of-flight spectra to compare with data.

Status: PASS. The TOF spectra were identical to those simulated with ENDL2008.1 for 11 spheres: Al; C; $\mathrm{Cu} ; \mathrm{Fe} ; \mathrm{H}_{2} \mathrm{O} ; \mathrm{Si}$; teflon; and Ti.

\section{Notes:}

- Mercury could not simulate $\mathrm{N}_{2}, \mathrm{~Pb},{ }^{232} \mathrm{Th}$, ${ }^{235} \mathrm{U},{ }^{238} \mathrm{U}$, and ${ }^{239} \mathrm{Pu}$ due to memory management issues.

- The simulated spectra for W and Ta were improved by the new evaluations (see figures 9 and 18).

- The new Au simulated spectrum seems shifted to lower energy. It is surprising since the newly evaluated cross sections agree well with the data. There may be a problem with the $(n, 2 n)$ energy distribution.

- Plots of the simulated results with newlyadded isotopes are included in the main text. The results for isotopes in common with ENDL2008.2 are unchanged.

\section{e. Oktavian Spheres}

Test: Run 1D Mercury simulations of 3 Oktavian sphere experiments compiled in the SINBAD suite and produce TOF spectra for comparison to data.

Status: PASS for $\mathrm{Ni}, \mathrm{Si}$, and $\mathrm{W}$. The results are equivalent to the MCNP5 simulations run using the ENDF.B-VII.0 library. Models can be found in the SINBAD report [OEC09].

Note: Plots of these simulations are included in the main text.

$$
\text { f. } \quad d(n, 2 n)
$$

Test: Run two broomstick problems for 5 and $14 \mathrm{MeV}$ pencil beams of neutrons incident on a small cylinder of deuterium. The radius of the cylinder is small enough for particles to escape after a collision. The number of $(n, 2 n)$ reactions is tallied.

Status: PASS. Values are equal to those obtained with ENDL2008.2 and ENDF/B-VII.0.

$$
\text { g. }(n, \gamma) \text { production }
$$

Test: Run Mercury simulations of 15 spheres and compare to previous simulations.

Status: Ten of fifteen spheres give the same value than ENDL2008.2. The average leaked gamma energy increased by approximately a factor of two for $\mathrm{Au}$ (factor of 1.6) and $\mathrm{Pb}$ (factor of 2.2). The leakage energy decreased significantly for Ta (factor of 0.085), Ti (factor of 0.007) and $\mathrm{W}$ (factor of 0.4). 


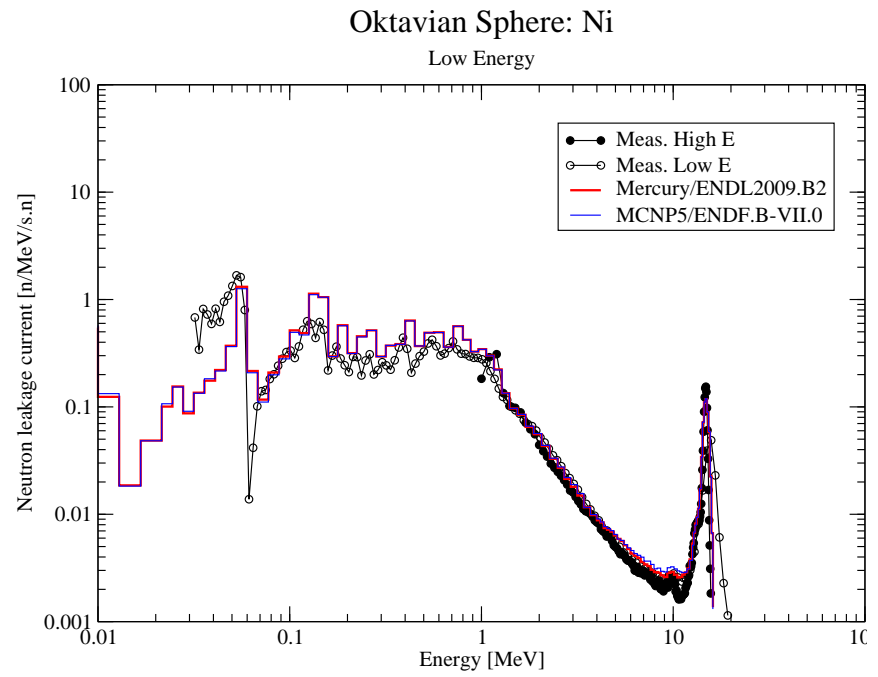

Wed Oct 7 15:27:58 2009

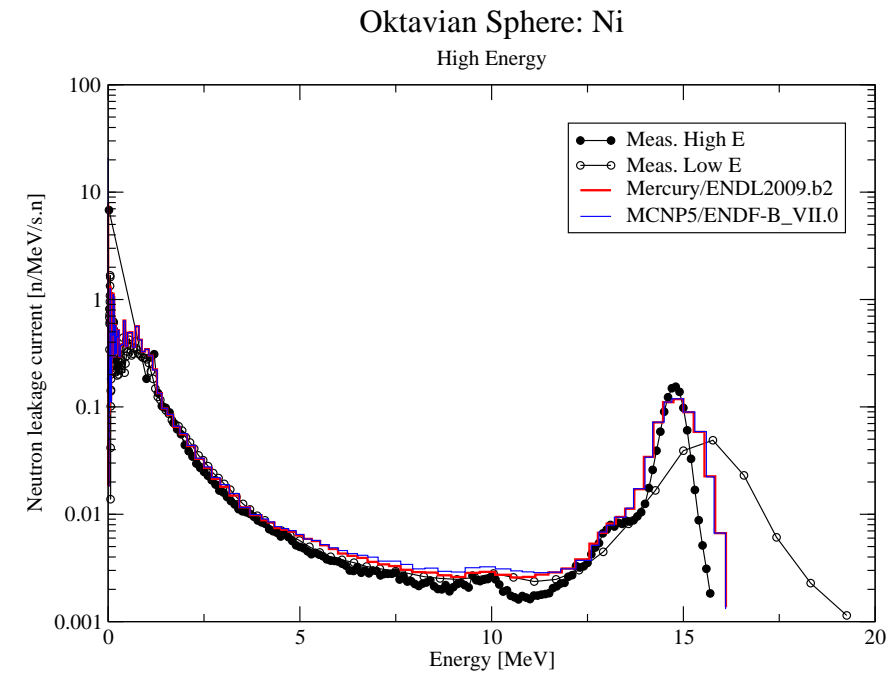

Wed Oct 7 15:28:51 2009

FIG. 49: Oktavian sphere nickel comparison.

Oktavian Sphere: Si

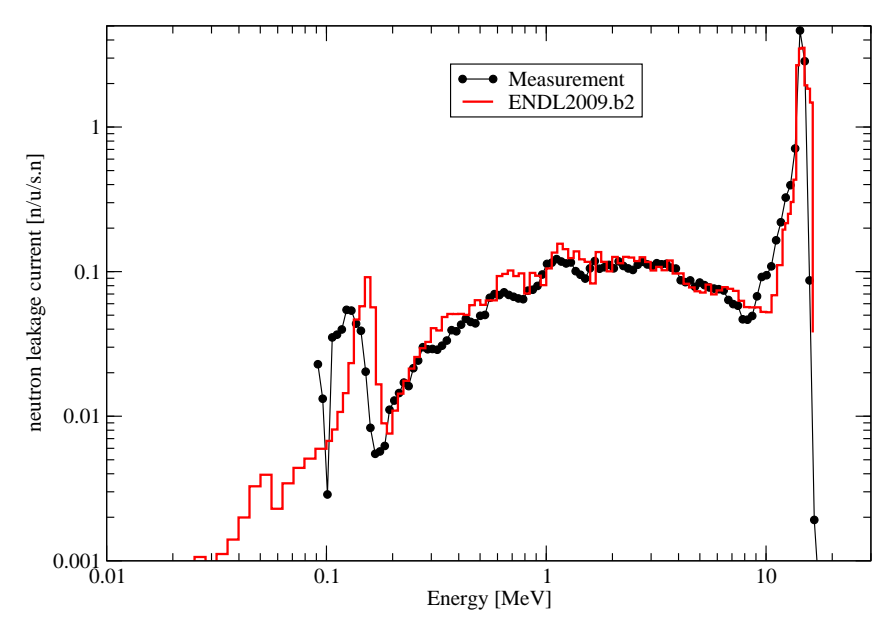

Tue Sep 29 22:33:39 2009

FIG. 50: Oktavian sphere silicon comparison.
Appendix C: Release Checklist

Here we reproduce the release checklist that accompanies this release.

Appendix D: The README file

Here we reproduce the README file that accompanies the release.

2009 Release of the Evaluated Nuclear Data Library (ENDL2009)

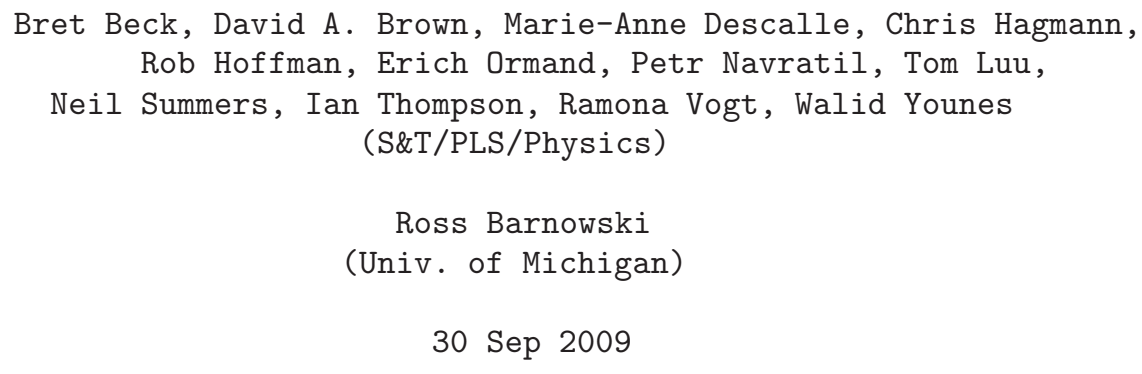


ENDL2009.0 Data Release Checklist

Basic Tests
\begin{tabular}{|l|c|l|l|}
\hline Check/Test & Success & Failure & Comments \\
\hline $\begin{array}{l}\text { python checker on } \\
\text { ascii data }\end{array}$ & $\checkmark$ & & \\
\hline $\begin{array}{l}\text { Check the } \\
\text { processing errors/ } \\
\text { warning messages }\end{array}$ & $\checkmark$ & & \\
\hline ndf checker & $\checkmark$ & & \\
\hline mcapm checker & $\checkmark$ & & \\
\hline
\end{tabular}

Amtran Tests
\begin{tabular}{|l|c|c|l|}
\hline Check/Test & Success & Failure & Comments \\
\hline Za-loop & $\checkmark$ & & $\begin{array}{l}\text { We need equivalent test for charged- } \\
\text { particle \& photonuclear data. }\end{array}$ \\
\hline keff & $\checkmark$ & & \\
\hline $\begin{array}{l}\text { Replacement } \\
\text { coefficients }\end{array}$ & & $\checkmark$ & Test still in development. \\
\hline Activation foils & $\checkmark$ & $\checkmark$ & $\begin{array}{l}\text { Some materials behave poorly, esp. }{ }^{59} \mathrm{Co}, \\
{ }^{241} \mathrm{Am},{ }^{58} \mathrm{Fe},{ }^{193} \mathrm{Ir},{ }^{209} \mathrm{Bi} .\end{array}$ \\
\hline
\end{tabular}

Mercury Tests

Mercury Tests
\begin{tabular}{|l|c|l|l|}
\hline Check/Test & Success & Failure & Comments \\
\hline za-loop & $\checkmark$ & & $\begin{array}{l}\text { Weneed equivalent test for charged- } \\
\text { particle \& photonuclear data. }\end{array}$ \\
\hline keff & $\checkmark$ & & \\
\hline $\begin{array}{l}\text { LLNL pulsed } \\
\text { spheres }\end{array}$ & $\checkmark$ & & $\begin{array}{l}\text { Some materials still have problems, but } \\
\text { perform better than other evaluations } \\
\text { on market, esp. Pb, Ta, W. }\end{array}$ \\
\hline Oktavian spheres & $\checkmark$ & & \\
\hline
\end{tabular}

Other Release Tasks

\begin{tabular}{|l|c|l|}
\hline Add correct bdfls file & $\begin{array}{c}\text { Complete } \\
\text { OCF: } \checkmark \\
\text { SCF: } \checkmark\end{array}$ & Comments \\
\hline Add/Edit README.txt & $\checkmark$ & \\
\hline Check directory layout & $\begin{array}{l}\text { OCF: } \checkmark \\
\text { SCF: } \checkmark\end{array}$ & \\
\hline Check file permissions & $\begin{array}{l}\text { OCF: } \checkmark \\
\text { SCF: } \checkmark\end{array}$ & \\
\hline Post on NADS & & $\begin{array}{l}\text { Pending CNP approval of endl2009.0, } \\
\text { expected 12/2009. }\end{array}$ \\
\hline Tag release in Svn repo & $\checkmark$ & Retagged on 11/19/2009. \\
\hline Release documentation & & In progress, expected by 1/2010. \\
\hline
\end{tabular}

Release Features

\begin{tabular}{|c|c|c|}
\hline & Present? & Comments \\
\hline Momentum deposition & $\checkmark$ & \\
\hline Energy deposition & $\sqrt{2}$ & \\
\hline $\begin{array}{l}\text { Energy-dependent Q-values } \\
\text { for }(\mathrm{n}, \mathrm{f})\end{array}$ & $\checkmark$ & $\begin{array}{l}\text { Missing for several recently updated } \\
\text { nuclei: }{ }^{225} \mathrm{Ra},{ }^{236} \mathrm{U},{ }^{240} \mathrm{Pu},{ }^{241} \mathrm{Am},{ }^{242} \mathrm{Am} .\end{array}$ \\
\hline Multi-temperature data & $\checkmark$ & $\begin{array}{l}\text { ndf: } 22 \text { temp. groups; mcf: } 12 \text { temp. } \\
\text { grid; both from } 10 \mathrm{meV}-0.1 \mathrm{MeV} .\end{array}$ \\
\hline $\begin{array}{l}\text { Large-Angle Coulomb } \\
\text { Scattering (LACS) data }\end{array}$ & $\checkmark$ & Not present in ndf files. \\
\hline $\begin{array}{l}\text { Thermal scattering }\left(\mathrm{S}_{\alpha \beta}\right) \\
\text { data }\end{array}$ & & $\begin{array}{l}\text { Partial support in Mercury, but uses } \\
\text { older translation of ENDF/B-VI data } \\
\text { generated for R. Cullen. }\end{array}$ \\
\hline $\begin{array}{l}\text { Unresolved Resonance } \\
\text { (URR) data }\end{array}$ & $\begin{array}{l}\checkmark(\mathrm{w} / \\
\text { caveats })\end{array}$ & $\begin{array}{l}\text { The ASCII formatted ENDL \& ENDF data } \\
\text { have URR data, but the processed } \\
\text { version hasn't fully been tested. So, } \\
\text { URR data is not included in the mcf } \\
\text { files. }\end{array}$ \\
\hline $\begin{array}{l}\text { Uncertainty/Covariance } \\
\text { data }\end{array}$ & $\begin{array}{l}(w / \\
\text { caveats) }\end{array}$ & $\begin{array}{l}\text { No client code exists for this data } \\
\text { currently. }\end{array}$ \\
\hline Isomers & $\begin{array}{l}\checkmark(\mathrm{w} / \\
\text { caveats })\end{array}$ & $\begin{array}{l}\text { The ASCII formatted ENDL \& ENDF data } \\
\text { have isomers, but processed data files } \\
\text { don't as client codes can't handle them. }\end{array}$ \\
\hline
\end{tabular}

ENDL2009.0 Data Release Checklist

\begin{tabular}{|c|c|c|c|}
\hline \multicolumn{4}{|l|}{ Basic Tests } \\
\hline Check/Test & Success & Failure & Comments \\
\hline $\begin{array}{l}\text { python checker on } \\
\text { ascii data }\end{array}$ & $\checkmark$ & & \\
\hline $\begin{array}{l}\text { Check the } \\
\text { processing errors/ } \\
\text { warning messages }\end{array}$ & $\checkmark$ & & \\
\hline ndf checker & 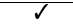 & & \\
\hline mcapm checker & $\checkmark$ & & \\
\hline \multicolumn{4}{|l|}{ Amtran Tests } \\
\hline Check/Test & Success & Failure & Comments \\
\hline za-loop & $\checkmark$ & & $\begin{array}{l}\text { We need equivalent test for charged- } \\
\text { particle \& photonuclear data. }\end{array}$ \\
\hline Keff & $\checkmark$ & & \\
\hline $\begin{array}{l}\text { Replacement } \\
\text { coefficients }\end{array}$ & & $\sqrt{2}$ & Test still in development. \\
\hline Activation foils & $\checkmark$ & $\checkmark$ & $\begin{array}{l}\text { Some materials behave poorly, esp. }{ }^{59} \mathrm{Co} \text {, } \\
{ }^{241} \mathrm{Am},{ }^{58} \mathrm{Fe},{ }^{193} \mathrm{Ir},{ }^{209} \mathrm{Bi} \text {. }\end{array}$ \\
\hline \multicolumn{4}{|l|}{ Mercury Tests } \\
\hline Check/Test & Success & Failure & Comments \\
\hline za-loop & $\checkmark$ & & $\begin{array}{l}\text { We need equivalent test for charged- } \\
\text { particle \& photonuclear data. }\end{array}$ \\
\hline $\mathrm{k}_{\mathrm{eff}}$ & $\sqrt{2}$ & & \\
\hline $\begin{array}{l}\text { LLNL pulsed } \\
\text { spheres }\end{array}$ & $\checkmark$ & & $\begin{array}{l}\text { Some materials still have problems, but } \\
\text { perform better than other evaluations } \\
\text { on market, esp. } \mathrm{Pb}, \mathrm{Ta}, \mathrm{W} \text {. }\end{array}$ \\
\hline Oktavian spheres & $\checkmark$ & & \\
\hline
\end{tabular}

FIG. 51: The release checklist for ENDL2009.0.

database, ENDL2009. ENDL2009 is the second in a series of major ENDL library releases designed to support LLNL's current and future nuclear data needs. This library includes 587 distinct transport-ready evaluations in the neutron sub-library and many physics improvements for calculating weapon performance, output effects, attribution signatures, key radiochemical diagnostics and performance of conventional and hybrid fission/fusion reactors. In building this library, we adopted the best of the world's nuclear data 
efforts: $46 \%$ of the library is from the ENDF/B-VII.0 library, $10 \%$ is from the JENDL libraries and $8 \%$ from other libraries. The remaining $36 \%$ of the neutron sub-library and all of the charged-particle sub-libraries consist of new evaluations developed at LLNL for the ENDL2009 library. In addition, ENDL2009 supports new features such as energy-dependent $Q$ values from fission, support for unresolved resonances and average momentum deposition. Furthermore, this is the first ENDL library release to be released in the eXtensible Evaluated Nuclear Data Language (XENDL). Finally, this release is our most highly tested release as we have strengthened our already rigorous testing regime by adding tests against LANL Activation Ratio Measurements and more than 1200 new critical assemblies. Our testing is now being incorporated into our development process and is serving to guide database improvements.

The new libraries can be found on LC in:

/usr/gapps/data/nuclear/endl_official/endl2009.0/ascii for the ENDL ASCII formatted data, /usr/gapps/data/nuclear/endl_official/endl2009.0/ndf for deterministic data and /usr/gapps/data/nuclear/endl_official/endl2009.0/mcf for Monte-Carlo data.

/usr/gapps/data/nuclear/endl_official/endl2009.0/tdf for thermonuclear data.

In addition, the data may be viewed in the Nuclear and Atomic Data System data viewer at http://nuclear.llnl.gov/NADS.

Release Notes

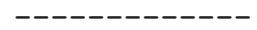

10/10/2008 Release ENDL2008.0:

The new files are posted on the in /usr/gapps/data/nuclear/endl_official/endl2008/. The ascii, mcf and ndf files are present in subdirectories, using the new directory layout.

\section{2/17/2009 Release ENDL2008.1:}

The new files are posted on the in /usr/gapps/data/nuclear/endl_official/endl2008.1/. The ascii, mcf and ndf files are present in subdirectories, using the new directory layout.

Resolved Issues:

1. The extra files in the $d(n, 2 n)$ evaluation which produced a factor of 2 change in the cross-section have been removed.

2. The 232Th nubar has been set to the correct value.

3. The $233 \mathrm{~Pa}$ nubar has been set to the correct value.

4. The missing energy dependent Q-values for fission was forgotten in the previous release and is now added back into the evaluations for all actinides.

5. A mistake in the 48Ti(n,g) outgoing gamma spectrum (taken from the ENDF/B-VII.O evaluation) produced several *hundred* MeV worth of outgoing gammas. We replaced this unphysical spectrum with one from Hauser-Feshbach model calculations. 
5/15/2009 Release ENDL2008.2:

The new files have been posted in /usr/gapps/data/nuclear/endl_official/endl2008.2. The ascii, mcf and ndf files are present in subdirectories, using the new directory layout.

New Features:

1. Expected value momentum deposition added

2. Large angle Coulomb scattering for $y i=2-6$ added

Resolved Issues:

1. Addition of the resonance region for $240 \mathrm{Am}$ and $73 \mathrm{As}$

2. Fixed unphysical gamma multiplicities in $41 \mathrm{Sc}, 103 \mathrm{Rh}, 125 \mathrm{Sn}$ amd $240 \mathrm{Am}$

3. Fixed angular grid miss-match issue in 103Rh and $27 \mathrm{Al}$

4. $I=3$ data added to natV, natOs, natTl

5. Added missing triton distributions for $70 \mathrm{Zn}, 71 \mathrm{Zn}, 63 \mathrm{Ni}, 72 \mathrm{Ga}, 66 \mathrm{Cu}, 61 \mathrm{Co}$

6. Removed extra $I=4$ files from $9 \mathrm{Be}, 11 \mathrm{Be}$

7. Other minor issues in $t, 7 \mathrm{Be}$

9/30/2009 Release ENDL2009.0:

The new files have been posted in /usr/gapps/data/nuclear/endl_official/endl2009.0. The ascii, mcf, ndf and tdf files are present in subdirectories, using the new directory layout.

New Features:

1. Unresolved resonance probability tables added to ascii data tables

2. TDF data now produced directly from ascii endl files

3. New structural material evaluations for $\mathrm{Al}, \mathrm{Ta}, \mathrm{W}, \mathrm{Re}, \mathrm{Pt}, \mathrm{Pb}$

4. New radiochemical diagnostic evaluations for $\mathrm{Ar}, \mathrm{Kr}, \mathrm{Xe}, \mathrm{Au}$

5. New evaluations for $\mathrm{Cl}, \mathrm{K}, \mathrm{Mn}, \mathrm{Y}, \mathrm{Mo}, \mathrm{Bi}$, Po

6. New actinide evaluations for $240 \mathrm{Am}, 240 \mathrm{Pu}, 239 \mathrm{U}$

7. Most evaluations also available in ENDF/B format in endf subdirectory

8. Add uncertainty \& covariance data to many evaluations 
9. Large-angle Coulomb scattering data added for all targets in charged-particle sublibraries

Resolved Issues:

1. Added resonances to Co evaluations

2. Charged particle data available in forward and inverse kinematics for particles $p$, d, t, 3He, a

3. 6Li files renamed to get correct two-body kinematics using mcapm

\section{Appendix E: Cross section uncertainty formats in ENDL2009}

The uncertainty and covariance data coexist with the raw ENDL-formatted ASCII data files in the ENDL2009 release directory. As an example, consider the ${ }^{75}$ As evaluation in the ENDL2009.0 subdirectory ascii/yi01/za033075/:

$\begin{array}{ll}\text { documentation.txt } & \text { yo00c46i000s000 } \\ \text { yo07c11i004s001 } & \text { yo00c01i000s000 } \\ \text { yo00c46i000s000_cov.xml } & \text { yo07c11i009s000 } \\ \text { yo00c10i000s000 } & \text { yo00c46i000s000_unc.xml } \\ \text { yo07c11i009s001 } & \ldots\end{array}$

One immediately notices that the neutron capture crosssection (yo=0, C=46, I=0) has covariance (_cov. $\mathrm{xml}$ extension) and uncertainty (_unc.xml extension) data.

The structure of a typical uncertainty file is as follows:

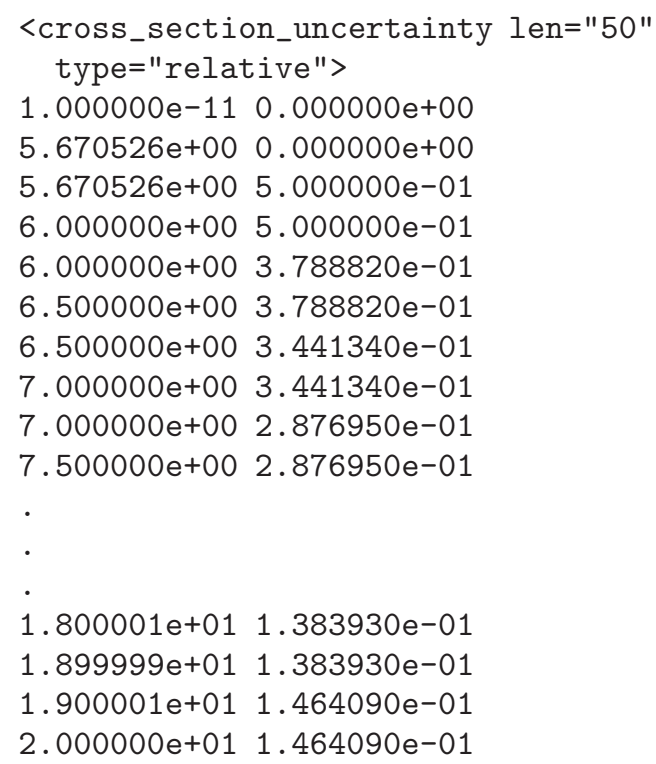

$7.500000 e+002.876950 e-01$

$2.000000 e+011.464090 e-01$

</cross_section_uncertainty $>$

The XML tag "cross_section_uncertainty" is selfexplanatory. The data is a list of energy-uncertainty pairs spanning the default ENDF energy range, $\left(10^{-11}<\right.$ $E<20 \mathrm{MeV}$. The data is grouped, with duplicate energies indicating a group boundary. The attribute "len" gives the number of energy-uncertainty pairs in the file. $\mathrm{n}+75 \mathrm{As}$

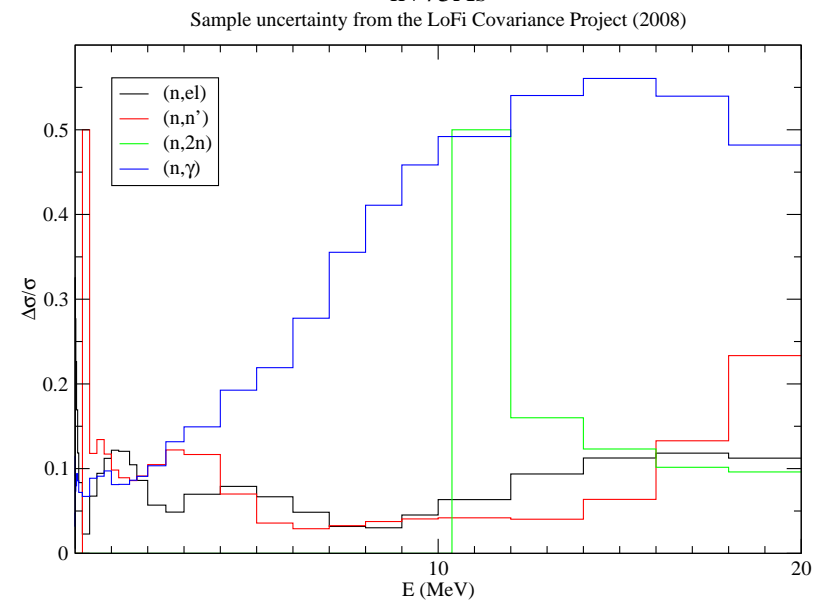

FIG. 52: The relative uncertainties in $n+{ }^{75} \mathrm{As}$, extracted from the LoFi covariance project. Note that while the uncertainties are "grouped," the cross section uncertainties can be correlated over many groups. This correlation length information is encoded in the full covariance.

The attribute "type" is equal to "relative", "absolute", or "derived". If the type is "absolute", the uncertainty is $\Delta \sigma(E)$. If the type is "relative" the uncertainty is really the relative uncertainty $\Delta \sigma(E) / \sigma(E)$, where the $\sigma(E)$ file must be taken from the corresponding ENDL-formatted cross-section file. Figure $\mathrm{E}$ is a sample plot of relative uncertainties from the ${ }^{75}$ As evaluation.

Appendix F: Known Issues

[ABC $\left.{ }^{+} 94\right] \mathrm{N}$ Arena, I Ya Barit, S Cavallaro, A d'Arrigo, G Fazio, G Giardina, V V Ostashko, M Sacchi, V N
Urin, and S V Zuyev. Investigation of the high excitation 
TABLE XVII: List of known issues in ENDL2009.0.

\begin{tabular}{|c|c|c|c|c|}
\hline Artifact ID & Title & Description & Priority & Submitted By \\
\hline $\operatorname{artf1105}$ & $n+{ }^{12} \mathrm{C}$ has old gamma data & ${ }^{12} \mathrm{C}$ has old gamma data and needs to be updated & 3 & D.A. Brown \\
\hline \multirow[t]{2}{*}{$\operatorname{artf10901}$} & $\begin{array}{l}n+{ }^{1} \mathrm{H}: \text { total cross section } \\
\text { not equal to the sum of the }\end{array}$ & The artifact title says it all! & 2 & E. Lent \\
\hline & partial cross sections & & & \\
\hline $\operatorname{artf10910}$ & $n+n:$ cross section not heated & The elastic cross section was not heated. & 4 & G. Zimmerman \\
\hline $\operatorname{artf10916}$ & $\begin{array}{l}\text { Too much energy deposition for } \\
{ }^{254} \mathrm{Cf}(n, \gamma)\end{array}$ & $\begin{array}{l}\text { The energy deposition for gammas in the capture reaction on } 98254 \\
\left(\text { i.e., } n+{ }^{254} \mathrm{Cf} \rightarrow \gamma+{ }^{255} \mathrm{Cf} \text { ) produces too much energy. For example, at }\right. \\
E=10^{-11} \text {, the total gamma energy should be } 4.6 \mathrm{MeV} \text {, while it is } \\
23.61 \mathrm{MeV}=5.129 \times 4.6 \mathrm{MeV} \text { since the gamma multiplicity is } 5.129 \text {. }\end{array}$ & 4 & B. Beck \\
\hline $\operatorname{artf10918}$ & $\begin{array}{l}\text { Too much energy deposition for } \\
{ }^{250} \mathrm{Cm}(n, \gamma)\end{array}$ & $\begin{array}{l}\text { This is similar to the za098254 gamma energy problem (maybe the } \\
\text { multiplicity is too high), but there also seems to be a problem with the } \gamma \mathrm{I}=4 \\
\text { distribution. For example, the }\left(E, E^{\prime}\right) \text { data calculated from } \\
\text { the } \mathrm{I}=4 \text { ( } i . e ., \text { multiplicity }=1 \text { ), shows a jump up and then back down } \\
\text { in } E^{\prime} \text { as } E \text { increases between } 0.001 \text { and } 0.002 \mathrm{MeV}\end{array}$ & 4 & B. Beck \\
\hline $\operatorname{artf11035}$ & $\begin{array}{l}{ }^{232} \mathrm{Th}(n, f) \text { cross sections } \\
\text { and } Q(E) \text { are inconsistent }\end{array}$ & $\begin{array}{l}\text { The cross section becomes non-zero at } 0.004 \mathrm{MeV} \text { while } Q(E) \\
\text { is non-zero all the way down to } 10^{-11} \mathrm{MeV} \text {. Affects group collapse } \\
\text { in MCAPM. }\end{array}$ & 4 & D.A. Brown \\
\hline $\operatorname{artf11115}$ & bdfls missing half lives & $\begin{array}{l}\text { The bdfls file is missing half lives for za024047 }\left({ }^{47} \mathrm{Cr}\right) \text {, za028067 }\left({ }^{67} \mathrm{Ni}\right) \\
\text { and za030073 }\left({ }^{73} \mathrm{Zn}\right) \text {. }\end{array}$ & 5 & D.A. Brown \\
\hline $\operatorname{artf12001}$ & Bad energy depositions again! & $\begin{array}{l}\text { There are more } \mathrm{C}=55 \text { gammas than can } \\
\text { be produced given the available energy in all reactions. }\end{array}$ & 2 & D.A. Brown \\
\hline $\operatorname{artf12275}$ & $n+{ }^{7} \mathrm{Be}$ evaluation stops at $8.1 \mathrm{MeV}$ & $\begin{array}{l}\text { This is the evaluation from P. Page (LANL), based on an } R \text {-matrix } \\
\text { analysis. The experimental data stopped at } 8.1 \mathrm{MeV} \text { and Page } \\
\text { did not extrapolate to higher energies. }\end{array}$ & 3 & D.A. Brown \\
\hline $\operatorname{artf12274}$ & $n+{ }^{7} \mathrm{Li}$ evaluation is old (ENDL99) & $\begin{array}{l}\text { But... The latest Hale evaluation uses the breakup data (mis-)format } \\
\text { so that in the }(n, n t) \text { reaction, the outgoing neutrons require } \\
\text { substantial interpretation while the outgoing tritons are missing. }\end{array}$ & 3 & D.A. Brown \\
\hline $\operatorname{artf12278}$ & $n+{ }^{240} \mathrm{Am}$ resonances are from ${ }^{242} \mathrm{Am}$ & $\begin{array}{l}\text { JENDL/AC-2008 has more reasonable resonances based } \\
\text { on systematics. Can we use these instead? }\end{array}$ & 4 & D.A. Brown \\
\hline $\operatorname{artf12273}$ & $n+{ }^{6} \mathrm{Li}$ evaluation is old (ENDL99) & $\begin{array}{l}\text { But... The latest Hale evaluation uses the breakup data (mis-)format } \\
\text { so that in the }(n, n d) \text { reaction outgoing neutrons require } \\
\text { substantial interpretation while the outgoing deuterons are missing. }\end{array}$ & 3 & D.A. Brown \\
\hline $\operatorname{artf12276}$ & $n+{ }^{67} \mathrm{Ni}$ stops at $12.8 \mathrm{MeV}$ & $\begin{array}{l}\text { This must be a bug. The problem was found in the } \\
(n, \mathrm{el}) \text { channel but it may be present in other channels. }\end{array}$ & 4 & B. Beck \\
\hline $\operatorname{artf12277}$ & $\begin{array}{l}\text { No documentation in several } n+\mathrm{Ni} \\
\text { evaluations. }\end{array}$ & $\begin{array}{l}\text { Impacts } \mathrm{Ni} \text { isotopes with } A=56,57,63,65-67 \text {, made for ENDL2008. } \\
\text { There are doc files, but they must have gotten lost in the shuffle... }\end{array}$ & 4 & D.A. Brown \\
\hline $\operatorname{artf12279}$ & $n+{ }^{59}$ Co resonances are $2 \times$ too high & $\begin{array}{l}\text { Looks like bad background subtraction when merging ENDF/B-VII.0 } \\
\text { resonances with our new evaluation. Impact activation ratios }(2 \times \\
\text { too high }(n, \gamma) \text { rate }) \text { and critical assemblies. }\end{array}$ & 3 & M.-A. Descalle \\
\hline $\operatorname{artf12358}$ & $\mathrm{t}(\mathrm{d}, n) \alpha$ has a spike & $\begin{array}{l}\text { In file yi03/za001003/yo01c11i001s000 at } E=8.9 \mathrm{MeV}, \mu=0.96111, \\
\text { there is a spike. It is in all ENDL releases from endl94 - present. }\end{array}$ & 3 & $\begin{array}{l}\text { M.S. McKinley, } \\
\text { T. Luu }\end{array}$ \\
\hline $\operatorname{artf12639}$ & Bad momentum depositions & $\begin{array}{l}\text { At the upper } E^{\prime} \text { points, there are denormalized numbers } \\
\text { (e.g. } 1 / 0) \text { in }\left\langle p_{z}\right\rangle \text { files. These come from denormalized } \\
\text { numbers in the } \ell=1 \text { term of the outgoing Legendre data }\left(P_{\ell=1}\left(E \mid E^{\prime}\right) \text { ). }\right. \\
\text { Several isotopes are impacted: the yo01c15i004s000 (\& derived) files in } \\
{ }^{232} \mathrm{Th},{ }^{231} \mathrm{~Pa} \text { and }{ }^{233} \mathrm{~Pa} \text {; and the yo02c40i004s000 (\& derived) files in }{ }^{153} \mathrm{Gd} \text {, } \\
{ }^{160} \mathrm{~Tb},{ }^{113} \mathrm{Sn},{ }^{133} \mathrm{Ba},{ }^{142} \mathrm{Pr},{ }^{74} \mathrm{As} \text { and }{ }^{86} \mathrm{Rb} \text {. }\end{array}$ & 2 & D.A. Brown \\
\hline $\operatorname{artf12640}$ & Uncertainties too high & $\begin{array}{l}\text { fete did not combine uncertainties in quadrature. Instead it } \\
\text { added them. Thus, when encountering a multiple-region covariance, } \\
\text { the uncertainties are too high. See attachment for an example. Impacts } \\
\text { any isotope that used multiple regions to represent covariance data } \\
\text { (nearly all }(n, \gamma),(n, \text { tot) and }(n, f)) \text {. }\end{array}$ & 4 & D.A. Brown \\
\hline $\operatorname{artf12736}$ & Errors for bremsstralung reactions & $\begin{array}{l}\text { The evaluation documentation lists many severe errors in endep } \\
\text { when processing bremsstrahlung (and other atomic) reactions. }\end{array}$ & 3 & M.S. McKinley \\
\hline $\operatorname{artf13270}$ & The ndf2-ndf 6 files are 87 group & $\begin{array}{l}\text { The ndf2-ndf } 6 \text { files for ENDL2009.0 were not reprocessed after ENDL2008.2 } \\
\text { so that they do not have } 230 \text { group structure. They may also be missing isotopes. }\end{array}$ & 2 & B. Beck \\
\hline
\end{tabular}


${ }^{8}$ Be region. Journal of Physics G: Nuclear and Particle Physics, 20(12):1973-1979, 1994.

[AGZZ84] S. N. Abramovich, B. Ja. Guzhovskij, V. A. Zherebcov, and A. G. Zvenigorodskij. Estimated values of total and differential cross sections of proton interactions with nuclei ${ }^{6} \mathrm{Li}$ and ${ }^{7} \mathrm{Li}$. Vop. At.Nauki i Tekhn., Ser. Yadernye Konstanty, 4:17, 1984.

$\left[\mathrm{BBD}^{+}\right.$07] B. Beck, D. A. Brown, F. Daffin, G. W. Hedstrom, and R. Vogt. Implementation of energy-dependent $\mathrm{Q}$ values for fission. Technical Report UCRL-TR-234617, LLNL, 2007.

$\left[\mathrm{BDH}^{+}\right.$09] D.A. Brown, M.-A. Descalle, R. Hoffman, K Kelley, P. Navratil, J. Pruet, N. Summers, I. Thompson, and R. Vogt. Release of the 2008 Evaluated Nuclear Data Library (ENDL2008). Technical Report LLNL-TR-413190, LLNL, 2009.

$\left[\mathrm{BHH}^{+}\right.$06a] B. Beck, G. W. Hedstrom, T. S. Hill, A. A. Marchetti, and D. P. McNabb. ASCII format specifications for the Evaluated Nuclear Data Libraries (ENDL). Technical Report UCRL-TM-218475, LLNL, 2006.

[BHH06b] D.A. Brown, G. Hedstrom, and T. Hill. User's guide to fete: From ENDF To ENDL. Technical Report UCRL-CODE-218718, LLNL, 2006. UCRL-SM-218496.

[BLL74] C. A. Burke, M. T. Lunnon, and H. W. Lefevre. ${ }^{7} \mathrm{Li}(p, n)^{7} \mathrm{Be}$ angular distributions to $E_{p}=3.8 \mathrm{MeV}$. Phys. Rev. C, 10(4):1299-1308, Oct 1974.

[BO09] J. T. Burke and Others. (unknown). Submitted to Phys. Rev. C, 2009.

[BPL10] D. A. Brown, J. Pruet, and T. Luu. kiwi: A tool for Monte-Carlo propagation of nuclear data uncertainties. code in development, 2010.

[Bri06] B. Briggs. International handbook of evaluated criticality safety benchmark experiments. Technical Report NEA/NSC/DOC(95), Nuclear Energy Agency, 2006.

[Bro08] D. A. Brown. endl2endf. code in development, 2008.

$\left[\mathrm{C}^{+} 83\right]$ J. R. Calarco et al. Absolute cross section for the reaction ${ }^{3} \mathrm{H}\left(p, \gamma_{0}\right)^{4} \mathrm{He}$ and a review of ${ }^{4} \mathrm{He}\left(\gamma, p_{0}\right)^{3} \mathrm{H}$ measurements. Phys. Rev. C, 28:483-488, 1983.

$\left[\mathrm{C}^{+} 02\right] \mathrm{R}$. S. Canon et al. ${ }^{3} \mathrm{H}(p$ polarized, $\gamma){ }^{4} \mathrm{He}$ reaction below $E_{p}=80 \mathrm{keV}$. Phys. Rev. C, 65:044008, 2002.

$\left[\mathrm{CJM}^{+} 62\right]$ Y. Cassagnou, J. M. F. Jeronymo, G. S. Mani, A. Sadeghi, and P. D. Forsyth. The ${ }^{7} \operatorname{Li}(p, \alpha) \alpha$ reaction. Nuclear Physics, 33:449 - 457, 1962.

$\left[\mathrm{COH}^{+}\right.$06] M.B. Chadwick, P. Oblozinský, M. Herman, N.M. Greene, R.D. McKnight, D.L. Smith, P.G. Young, R.E. MacFarlane, G.M. Hale, S.C. Frankle, A.C. Kahler, T. Kawano, R.C. Little, D.G. Madland, P. Moller, R.D. Mosteller, P.R. Page, P. Talou, H. Trellue, M.C. White, W.B. Wilson, R. Arcilla, C.L. Dunford, S.F. Mughabghab, B. Pritychenko, D. Rochman, A.A. Sonzogni, C.R. Lubitz, T.H. Trumbull, J.P. Weinman, D.A. Brown, D.E. Cullen, D.P. Heinrichs, D.P. McNabb, H. Derrien, M.E. Dunn, N.M. Larson, L.C. Leal, A.D. Carlson, R.C. Block, J.B. Briggs, E.T. Cheng, H.C. Huria, M.L. Zerkle, K.S. Kozier, A. Courcelle, V. Pronyaev, and S.C. van der Marck. ENDF/B-VII.0: Next generation evaluated nuclear data library for nuclear science and technology. Nuclear Data Sheets, 107(12):2931 - 3060, 2006. Evaluated Nuclear Data File ENDF/B-VII.0.

[CSQC07] R. Capote, E. Soukhovitskii, J.M. Quesada, and S. Chiba. Lane consistency of the dispersive coupled-channel optical model potential. In O.Bersillon, F.Gunsing, E.Bauge, R.Jacqmin, and S.Leray, editors,
Proceedings of the International Conference on Nuclear Data for Science and Technology, page 047. Commissariat à l'Énergie Atomique, EDP Sciences, 2007.

$\left[\mathrm{CTK}^{+} 07\right]$ R. Capote, A. Trkov, I. Kodeli, E. Soukhovitskii, L. C. Leal, M. Herman, and D. W. Muir. Evaluation of tungsten isotopes in the fast neutron range including cross section covariance estimation. International Conference on Nuclear Data for Science and Technology, pages 689-692, 2007.

[CW84] F. E. Cecil and F. J. Wilkinson. Measurement of the ground-state gamma-ray branching ratio of the $d t$ reaction at low energies. Phys. Rev. Lett., 53(8):767-770, Aug 1984.

$\left[\mathrm{DAA}^{+} 04\right]$ Pierre Descouvemont, Abderrahim Adahchour, Carmen Angulo, Alain Coc, and Elisabeth VangioniFlam. Compilation and R-matrix analysis of Big Bang nuclear reaction rates. Atomic Data and Nuclear Data Tables, 88(1):203 - 236, 2004.

[Das07] D. Dashdorj. Phys. Rev. C, (75):054612, 2007.

[DCP09] M.-A. Descalle, C. Clouse, and J. Pruet. Monte Carlo and deterministic simulations of activation ratio experiments for ${ }^{238} \mathrm{U}(n, f),{ }^{238} \mathrm{U}(n, \gamma)$ and ${ }^{238} \mathrm{U}(n, 2 n)$ in the Big Ten benchmark critical assembly. Technical Report LLNL-TR-415151, LLNL, 2009.

[DP08] M.-A. Descalle and J. Pruet. Nuclear data verification based on monte carlo simulations of the LLNL pulsed-sphere benchmark experiments (1979 \& 1986) using the Mercury code. Technical Report LLNL-TR404630, LLNL, 2008.

[DS71] J. J. Devaney and M. L. Stein. Plasma energy deposition from nuclear elastic scattering. 46:323 - 333, 1971.

[FB99] S. Frankle and J. Briesmeister. Spectral measurements in critical assemblies: MCNP specifications and calculated results. Technical Report LA-13675, LANL, 1999.

$\left[\mathrm{GHK}^{+}\right.$90] E. Goldberg, L.F. Hansen, T.T. Komoto, B.A. Pohl, R.J. Howerton, R.E. Dye, E.F. Plechaty, and W. E. Warren. Neutron and gamma-ray spectra from a variety of materials bombarded with $14-\mathrm{MeV}$ neutrons. Nucl. Sci. Eng., 105:319, 1990.

$\left[\mathrm{GLS}^{+} 00\right]$ K. H. Guber, L. C. Leal, R. O. Sayer, R. R. Spencer, P. E. Koehler, R. Q. Wright, J. A. Harvey, and N. W. Hill. "neutron capture and neutron total cross sections measurements for ${ }^{27} \mathrm{Al}$ at the Oak Ridge Electron Linear Accelerator". volume 529, pages 737-739. AIP, 2000.

[HBK95] K. I. Hahn, C. R. Brune, and R. W. Kavanagh. ${ }^{3} \mathrm{H}(p, \gamma){ }^{4} \mathrm{He}$ cross section. Phys. Rev. C, 51:1624-1632, 1995.

$\left[\mathrm{HCC}^{+} 07\right]$ M. Herman, R. Capote, B.V. Carlson, P. Obložinský, M. Sin, A. Trkov, H. Wienke, and V. Zerkin. EMPIRE: Nuclear reaction model code system for data evaluation. Nucl. Data Sheets, 108:47, 2007.

[KD04] A.J. Koning and M.C. Duijvestijn. Nucl. Phys. A, 744:15, 2004.

[KHD07] A. J. Koning, S. Hilaire, and M. C. Duijvestijn. TALYS-1.0. In O. Bersillon, F. Gunsing, E. Bauge, R. Jacqmin, and S. Leray, editors, Proceedings of the International Conference on Nuclear Data for Science and Technology, Nice, France, 22-27 April 2007, page 211. EDP Sciences, April 2007.

$\left[\mathrm{KHS}^{+} 93\right]$ J. E. Kammeraad, J. Hall, K. E. Sale, C. A. Barnes, S. E. Kellogg, and T. R. Wang. Measurement 
of the cross-section ratio ${ }^{3} \mathrm{H}(d, \gamma){ }^{5} \mathrm{He} /{ }^{3} \mathrm{H}(d, \alpha) n$ at 100 keV. Phys. Rev. C, 47(1):29-35, Jan 1993.

[Kop] J. Kopecky. private communication to the talys authors.

[KR08] A. J. Koning and D. Rochman. TENDL-2008: Consistent TALYS-based Evaluated Nuclear Data Library including covariance data. Technical Report JEFF-DOC 1262, Nuclear Research and Consultancy Group (NRG), 2008.

[Kul67] L. A. Kull. $(p, d)$ reactions with ${ }^{6} \mathrm{Li},{ }^{7} \mathrm{Li}$, and ${ }^{9} \mathrm{Be}$. Phys. Rev., 163(4):1066-1073, Nov 1967.

[Lar98] N.M. Larson. Updated user guide for SAMMY: Multilevel R-matrix fits to neutron data using Bayes' equations. Technical Report ORNL/TM-9179/R4, ORNL, December 1998.

[LKH ${ }^{+}$08] R.C. Little, T. Kawano, G.D. Hale, M.T. Pigni, M. Herman, P. Oblozinský, M.L. Williams, M.E. Dunn, G. Arbanas, D. Wiarda, R.D. McKnight, J.N. McKamy, and J.R. Felty. Low-fidelity covariance project. Nuclear Data Sheets, 109(12):2828 - 2833, 2008. Special Issue on Workshop on Neutron Cross Section Covariances June 24-28, 2008, Port Jefferson, New York, USA.

[MH98] A. Marchetti and G.W. Hedstrom. New Monte Carlo simulations of the LLNL pulsed sphere experiments. Technical Report UCRL-ID-131461, LLNL, 1998.

[MK72] F. Manero and V.A. Konshin. At. En. Rev., 10, 1972.

[Mug06] S. F. Mughabghab. Atlas of Neutron Resonances. Elsevier Science, April 2006.

[MWRT82] R. C. McBroom, H. R. Weller, N. R. Roberson, and D. R. Tilley. ${ }^{3} \mathrm{H}(p, \gamma){ }^{4} \mathrm{He}$ reaction below $E_{p}=30$ MeV. Phys. Rev. C, 25:1644-1648, 1982.

[Net08] Nuclear Reaction Data Centres Network. Exfor formats description for users (EXFOR basics). Technical Report IAEA-NDS-206, IAEA Nuclear Data Section, 2008.

[OEC09] OECD Nuclear Energy Agency Data Bank. SINBAD2009.2. Technical report, OECD Nuclear Energy Agency, 2009.

[Oh08] S.Y. Oh, 2008.

$\left[\mathrm{PAD}^{+} 76\right]$ C. H. Poppe, J. D. Anderson, J. C. Davis, S. M. Grimes, and C. Wong. Cross sections for the ${ }^{7} \mathrm{Li}(p, n)^{7} \mathrm{Be}$ reaction between 4.2 and $26 \mathrm{MeV}$. Phys. Rev. C, 14(2):438-445, Aug 1976.

[Pag04] P.R. Page. ${ }^{8}$ Be nuclear data evaluation. Technical Report T-16:NW-18/6-04, 2004. Memo.

[PB72] G. Presser and R. Bass. Reactions ${ }^{7} \mathrm{Li}+n,{ }^{7} \mathrm{Li}+p$ and excited states of the $\mathrm{A}=8$ system. Nuclear Physics A, 182(2):321 - 341, 1972.

[PC81a] S. T. Perkins and D. E. Cullen. Elastic nuclear plus interference cross sections for light-charge particles. 77:20 $-39,1981$.

[PC81b] S.T. Perkins and D.E. Cullen. Elastic nuclear plus interference cross sections for light-charge particles. Nucl. Sci. Eng., 77:20-39, 1981.

[PHB63] C. H. Poppe, C. H. Holbrow, and R. R. Borchers. Neutrons from d + t and d + h. Phys. Rev., 129(2):733739, Jan 1963.

[PJBJ55] J.E. Perry Jr and S.J. Bame Jr. $t(p, \gamma)^{4}$ He Reaction. Phys. Rev., 99:1368-1375, 1955.

$\left[\mathrm{RGD}^{+} 77\right]$ R. Risler, W. Grüebler, A. A. Debenham, V. König, P. A. Schmelzbach, and D. O. Boerma. In- vestigation of the ${ }^{6} \mathrm{Li}(d, \alpha){ }^{4} \mathrm{He}$ reaction between 1.5 and 11.5 MeV. Nuclear Physics A, 286(1):115 - 130, 1977.

[SCOW72] R. L. Schulte, M. Cosack, A. W. Obst, and J. L. Weil. ${ }^{2} \mathrm{H}+$ reactions from 1.96 to $6.20 \mathrm{MeV}$. Nuclear Physics A, 192(3):609 - 624, 1972.

[SLKG76] K. K. Sekharan, H. Laumer, B. D. Kern, and F. Gabbard. A neutron detector for measurement of total neutron production cross sections. Nuclear Instruments and Methods, 133(2):253 - 257, 1976.

[SNJN92] G. De Saussure, N.M.Larson, J.A.Harvey, and N.W.Hill. Ann. Nucl. Energy, 19:393, 1992.

[Sum08] N. C. Summers. geft: Get ENDL From TALYS. code in development, 2008.

[tag63] Erratum. Nuclear Physics, 41:176 - 176, 1963.

[TCKL08] A. Trkov, R. Capote, I. Kodeli, and L. Leal. Evaluation of tungsten nuclear reaction data with covariances. Nuclear Data Sheets, 109(12):2905 - 2909, 2008. Special Issue on Workshop on Neutron Cross Section Covariances June 24-28, 2008, Port Jefferson, New York, USA.

[Vog08] R. Vogt. Energy-dependent fission $q$ values generalized for all actinides. LLNL-TR-407620, LLNL-TR4076202008.

$\left[\mathrm{WAB}^{+} 72\right]$ C. Wong, J.D. Anderson, P. Brown, L.F. Hansen, J.L. Kammerdiener, C. Logan, and B.A. Pohl. Livermore pulsed sphere program: Program summary through July 1971. Technical Report UCRL-51144, Rev. 1, LLNL, 1972.

[War01] S. Warshaw. The TDF system of thermonuclear plasma reaction rates, mean energies, and two-body final state particles spectra. UCRL-ID-144510, UCRLID-144510 2001.

[WIB $\left.{ }^{+} 07\right]$ C. Wilkerson, M. Mac Innes, D. Barr, H. Trellue, R. MacFarlane, and M. Chadwick. A comparison of reaction rate calculations using ENDF/B-VII with critical assembly measurements. In Int. Conf. Nucl. Data for Science and Technology, number DOI:10,1051/ndata:07332, 2007.

[WRW91] R.M. White, D.A. Resler, and S.I. Warshaw. Evaluation of charged-particle reactions for fusion applications. Proc. from Nuclear Data for Sci. and Tech., pages 834-839, 1991. Juelich, Fed. Rep. Germany, 13-17 May, Springer-Verlag.

[YB05] W. Younes and H. C. Britt. Estimates of the ${ }^{237,239} \mathrm{U}(n, f)$ cross sections for $0.1<E_{n}(\mathrm{MeV})<=20$. Technical Report UCRL-TR-212600, LLNL, May 2005.

[YBB04] W. Younes, H. C. Britt, and J. A. Becker. Estimated $(n, f)$ cross-sections for ${ }^{236,236 m, 237,238} \mathrm{~Np},{ }^{237,237 m} \mathrm{Pu}$, and $240,241,242,242 m, 243,244,244 m$ Am. Technical Report UCRL-TR-201913, LLNL, January 2004.

[YCM ${ }^{+}$07] P.G. Young, M.B. Chadwick, R.E. MacFarlane, P. Talou, T. Kawano, D.G. Madland, W.B. Wilson, and C.W. Wilkerson. Evaluation of neutron reactions for ENDF/B-VII: ${ }^{232-241} \mathrm{U}$ and ${ }^{239} \mathrm{Pu}$. Nuclear Data Sheets, 108(12):2589 - 2654, 2007. Special Issue on Evaluations of Neutron Cross Sections.

[66] In reality, only four reactions were completely calculated. The final state distributions for the reaction $\mathrm{t}(\mathrm{t}, 2 n) \alpha$ were not calculated.

[67] This feature is still under development. 